\title{
Underground Natural Gas Storage Reservoir Management Phase II
}

\author{
Final Report \\ June 1, 1995 - March 30, 1996 \\ RECEIVED \\ OCT $\bigcirc 6998$ \\ OSTI
}

\author{
By: \\ I. Ortiz \\ R. V. Anthony
}

Work Performed Under Contract No.: DE-AC21-94MC31113

For

U.S. Department of Energy

Office of Fossil Energy

Federal Energy Technology Center

P.O. Box 880

Morgantown, West Virginia 26507-0880

By

United Energy Development Consultants

2301 Duss Avenue

Suite 12

Ambridge, Pennsylvania 15003

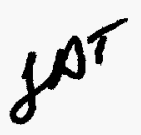




\section{Disclaimer}

This report was prepared as an account of work sponsored by an agency of the United States Government. Neither the United States Government nor any agency thereof, nor any of their employees, makes any warranty, express or implied, or assumes any legal liability or responsibility for the accuracy, completeness, or usefulness of any information, apparatus, product, or process disclosed, or represents that its use would not infringe privately owned rights. Reference herein to any specific commercial product, process, or service by trade name, trademark, manufacturer, or otherwise does not necessarily constitute or imply its endorsement, recommendation, or favoring by the United States Government or any agency thereof. The views and opinions of authors expressed herein do not necessarily state or reflect those of the United States Government or any agency thereof. 


\section{DISCLAIMER}

Portions of this document may be illegible in electronic image products. Images are produced from the best available original document. 


\section{ABSTRACT}

Gas storage operators are facing increased and more complex responsibilities for managing storage operations under Order 636 which requires unbundling of storage from other pipeline services. Low cost methods that improve the accuracy of inventory verification are needed to optimally manage this stored natural gas. Migration of injected gas out of the storage reservoir has not been well documented by industry.

The first portion of this study addressed the scope of unaccounted for gas which may have been due to migration. The volume range was estimated from available databases and reported on an aggregate basis. Information on working gas, base gas, operating capacity, injection and withdrawal volumes, current and non-current revenues, gas losses, storage field demographics and reservoir types is contained among the FERC Form 2, EIA Form 191, AGA and FERC Jurisdictional databases.

Gas migration, or unaccounted for gas, studied in Phase I included a review of Form-2, (190 - 1993) and EIA-191 data. Based on the Form-2 data submitted by major interstate transporters, most of the unaccounted for gas was reported as transportation losses, as shown below. Total unaccounted for gas amounts to less than $0.5 \%$ of total sales. Whether gas losses are accurately reported, will be reflected by revisions (write-downs) of base gas as a result of Order 636 in following years.

FERC Form 2 -- Gas Account - Natural Gas pages 520-521

\begin{tabular}{|c|c|c|c|c|c|c|c|}
\hline & Line no. 18 & 58 & 59 & 60 & 61 & 62 & 63 \\
\hline & SCF & & & SCF & & SCF & \\
\hline & GAS WTHDRAWN & & & DISTRI- & & TOTAL & $\overline{S C F}$ \\
\hline & FROM & SCF & SCF & BUTION & SCF & UNACCOUNTED & TOT SALES, \\
\hline & UNDERGROUND & STORAGE & TRANSMISSION & SYSTEM & OTHER & FOR & OTHER DEL \& \\
\hline YR. & STORAGE & LOSSES & SYSTEM LOSSES & LOSSES & LOSSES & NATURAL GAS & UNACC FOR \\
\hline 1990 & $639,047,065$ & $2,643,043$ & $51,261,481$ & $5,358,600$ & $20,099,519$ & $79,362,643$ & $40,997,189,070$ \\
\hline 1991 & $923,023,648$ & $(5,394,904)$ & $125,327,191$ & $5,774,167$ & $23.619,529$ & $149,325,983$ & $39,239,995,470$ \\
\hline 1992 & $1,029,439,323$ & 995,525 & $108,856,539$ & $2,403,167$ & $16,025,252$ & $128,669,886$ & $36,749,827,856$ \\
\hline 1993 & $1,032,115,337$ & 125,298 & $120,317,124$ & $(2,111)$ & $31,730,977$ & $152,171,268$ & $37,147,687,684$ \\
\hline
\end{tabular}

The average cost of gas reported by operators on Form-2 is shown below. Current gas price reflects the current gas price while the non-current price reflects to cost of base gas. As shown, the total average gas cost of storage has decreased from $\$ 1.18$ to $\$ 0.83$ per MCF from 1990 to 1993.

FERC Form 2 - Gas Stored (page 220, column a-f, lines 1-7)

\begin{tabular}{|c|c|c|c|c|c|c|}
\hline \multicolumn{2}{|r|}{ GAS } & \multicolumn{5}{|c|}{ BALANCE } \\
\hline & STORED & GAS DELIVERED & GAS WTHDRAWN & AT END OF & GAS VOLUME & AMOUNT PER \\
\hline YR. & CODE & TO STORAGE & FROM STORAGE & YEAR & SCF & MCF \\
\hline \multirow[t]{3}{*}{1990} & Curr 16401 & $\$ 1,671,414,923$ & $\$ 1,155,222,735$ & $\$ 1,603,723,121$ & $861,868,236$ & $\$ 1.86$ \\
\hline & Noncurr & $\$ 651,735,673$ & $(\$ 16,597,001)$ & $\$ 1,195,275,209$ & $1,553,681,461$ & $\$ 0.77$ \\
\hline & Total & $\$ 2,347,842,430$ & $\$ 1,067,725,409$ & $\$ 2,839,523,538$ & $2,408,686,839$ & $\$ 1.18$ \\
\hline \multirow[t]{3}{*}{1991} & Curr16401 & $\$ 1,282,191.676$ & $\$ 1,455,660,200$ & $\$ 1,403,937,734$ & $739,449,873$ & $\$ 1.90$ \\
\hline & Noncurr & $\$ 178,152,452$ & $\$ 219,775,354$ & $\$ 1,311,389,103$ & $1,607,482,990$ & $\$ 0.82$ \\
\hline & Total & $\$ 1,383,357,750$ & $\$ 1,596,068,365$ & $\$ 2,720,659,673$ & $2,353,288,428$ & $\$ 1.16$ \\
\hline \multirow[t]{3}{*}{1992} & Curr16401 & $\$ 1,065,975,303$ & $\$ 1,125,384,782$ & $\$ 950,551,892$ & $587,422,222$ & $\$ 1.62$ \\
\hline & Noncurr & $\$ 464,346,468$ & $\$ 303,654,173$ & $\$ 1,250,821,230$ & $1,718,166,474$ & $\$ 0.90$ \\
\hline & Total & $\$ 1,619,388,984$ & $\$ 1,500,210,746$ & $\$ 2,419,751,246$ & $2,390,250,340$ & $\$ 1.14$ \\
\hline 1993 & Curr16401 & $\$ 608,574,624$ & $\$ 819,703,481$ & $\$ 187,428,689$ & $120,981,017$ & $\$ 1.55$ \\
\hline
\end{tabular}


Noncurr

$\$ 457,929,885$

$\$ 644,799,134$

$\$ 1,469,922,895$

$2,033,706,583$

$\$ 0.72$

Total

$\$ 1,224$

$\$ 1,685$

$\$ 1,900$

2,295

$\$ 0.83$

A summary of total unaccounted for gas is shown below. An average of less than $0.33 \%$ of gas as reported on Form-2 is unaccounted.

\begin{tabular}{cccc} 
& $\begin{array}{c}\text { STORAGE } \\
\text { LOSSES }\end{array}$ & $\begin{array}{c}\text { TRANSMISSION } \\
\text { SYSTEM LOSSES }\end{array}$ & $\begin{array}{c}\text { TOTAL } \\
\text { UNACCOUNTED }\end{array}$ \\
\hline 1990 & $0.41 \%$ & $0.13 \%$ & $0.19 \%$ \\
1991 & $-0.58 \%$ & $0.32 \%$ & $0.38 \%$ \\
1992 & $0.10 \%$ & $0.30 \%$ & $0.35 \%$ \\
1993 & $\underline{0.01 \%}$ & $\underline{0.33 \%}$ & $\underline{0.41 \%}$ \\
avg. & $-0.016 \%$ & $0.27 \%$ & $0.33 \%$ \\
\hline
\end{tabular}

Analysis of ElA-191 data indicated inconsistencies when comparing reported values to those calculated. The following table shows the results of those presented in the Phase I report. As shown, over the period 1992-1994 over 143 BCF of gas is unaccounted based on material balance calculations and reported data. The largest difference is in the stratagraphic (STRAT) category. This category represents over $86 \%$ of the gas migration calculated.

\begin{tabular}{lrrrrr}
\hline & \multicolumn{1}{c}{ BCF } & \% Total & 1992 & 1993 & 1994 \\
\hline AQUIFER & $(10.3)$ & $7.20 \%$ & $(6.7)$ & $(2.6)$ & $(1.0)$ \\
CAVERN & $(9.7)$ & $6.75 \%$ & $(1.9)$ & $(7.4)$ & $(0.3)$ \\
STRAT & $(123.4)$ & $86.05 \%$ & $(66.0)$ & $(37.6)$ & $(19.8)$ \\
& $(143.4)$ & $100.00 \%$ & $(74.7)$ & $(47.6)$ & $(21.1)$ \\
\hline
\end{tabular}

This value of gas that is unaccounted ranges from $\$ 222.16 \$ 103.65$ million dollars over this three year period or $\$ 50$ million dollars per year, mainly from stratagraphic reservoirs. The average gas cost used was from Form-2 current and non-current prices for 1993 of $\$ 1.55$ and \$o.72 per MCF.

Mechanical communication with adjacent formations through faulty wellbores, or migration of gas out of the storage reservoir due to unknown faults, poor reservoir traps or abandoned production wells can lead to unaccounted for volumes of natural gas. Common gas migration mechanisms are associated with storage reservoir types, regional location, vintage, depth, pressure and trap characteristics.

Over $80 \%$ of underground gas storage is in depleted stratigraphic or structural reservoirs. The second portion of this study focused on these reservoir types. A three dimensional reservoir simulator was used to evaluate gas migration mechanisms during operation of storage fields. A model was constructed which contained about 55 BCF of gas and had 5 injection and withdrawal wells. Original reservoir pressure was 1200 psia. The field was operated on 180 day cycles over a ten year period.

This base model was modified by the inclusion of a very low permeability boundary $(0.001 \mathrm{md})$, which would simulate a stratigraphic trap juxtaposed to a very low permeability formation. Again the model was run and compared to the base case. The results were identical.

A thief zone was included by the use of a well completed in the very low permeability zone. Gas migration effects were studied. Typical $P / Z$ calculations indicated that small volumes were lost even in formations with 0.001 md permeability.

Mitigation strategies were then developed to reduce gas migration from thief zones. By drilling horizontal wellbores, gas migration was eliminated or reduced. Sensitivity to horizontal 
wellbore length was studied. In this example, wellbores over $1000^{\prime}$ in length eliminated gas migration effects.

Horizontal wellbores have been utilized for deliverability enhancement by some operators, but their use to reduce delta pressures and gas migrations also have an important role in the reduction of gas migration. Industry has been aware of over-pressuring storage reservoirs to increase storage capacity and deliverability, but caution should be exercised in the implementation. Gas migration could be increased.

Storage operators commonly limit the amount of time to recharge (reinject) gas into storage during the summer months. Operators may limit reinjection time due to operational consideration (equipment repair), optimize gas costs, or to reduce gas migration losses. Based on the results of this study, increased gas migration effects could result.

The key elements of this study show that gas migration can result if reservoir limits have not been properly identified, gas migration can occur in formation with extremely low permeability (0.001 md), horizontal wellbores can reduce gas migration losses and over-pressuring (unintentionally) storage reservoirs by reinjecting working gas over a shorter time period may increase gas migration effects. 


\section{PREFACE}

Mechanical communication with adjacent formations or migration of gas out of the storage reservoir due to unknown faults, poor reservoir traps or abandoned production wells can lead to unaccounted for volumes of natural gas. The first portion of this study addressed the scope of unaccounted for gas which may have been due to migration. The volume range was estimated from available databases and reported on an aggregate basis.

Inconsistencies were noted in total gas volumes reported in EIA-191 and accumulated total gas balances for some operators. The depleted structural and stratigraphic reservoir type had the highest percentage of fields exhibiting an apparent small, ongoing gas migration. This small amount of yearly migration is not readily apparent on hysteresis curves, which is part of the standard industry inventory verification procedure. Thus, small, ongoing gas migration may escape standard detection. However, the cumulative volumes due to this migration can be significant over time. Four storage fields were shut in during the period evaluated (1991-1994). Apparent reasons were that these fields had gas migration problems.

Over $80 \%$ of underground gas storage is in depleted stratigraphic or structural reservoirs. The second portion of the study focused on these reservoir types. A three dimensional reservoir simulator was used to study gas migration mechanisms during operation of storage fields. A model was constructed (3stor.dat) which contained about 55 BCF of gas and had five injection and withdrawal wells. Original reservoir pressure was $1200 \mathrm{psia}$. The field was operated on 180 day cycles over a ten year period. The resulting performance is discussed in the text.

This base model was modified (3storlow.dat) by the inclusion of a very low permeability boundary $(0.001 \mathrm{md})$, which would simulate a stratigraphic trap juxtaposed to a very low permeability formation. Again the model was run and compared to the base case. The results were identical.

A thief zone was included by the use of a well completed in the very low permeability zone. Gas migration effects were studied. Typical P/Z calculations indicated that small volumes were lost even in formations with 0.001 md permeability.

Mitigation strategies were then developed to reduce gas migration from thief zones. By drilling horizontal wellbores, gas migration was eliminated or reduced. Sensitivity to horizontal wellbore length was studied. In this example, wellbores over $1000^{\prime}$ in length eliminated gas migration effects.

Horizontal wellbores have been utilized for deliverability enhancement by some operators, but their use to reduce delta pressures and gas migration also have an important role in the reduction of gas migration. Industry has been aware of over-pressuring storage reservoirs to increase storage capacity and deliverability, but caution should be exercised it's implementation. Gas migration could be increased.

Storage operators commonly limit the amount of time to recharge (reinject) gas into storage during the summer months. Operators may limit reinjection time due to operational consideration (equipment repair), optimize gas costs, or to reduce gas migration losses. Based on the results of this study, increased gas migration effects could result.

The key elements of this study show that gas migration can result if reservoir limits have not been properly identified, gas migration can occur in formation with extremely low permeability ( $0.001 \mathrm{md})$, horizontal wellbores can reduce gas migration losses and over-pressuring (unintentionally) storage reservoirs by reinjecting working gas over a shorter time period may increase gas migration effects. 


\section{ACKNOWLEDGMENTS}

UEDC would like to thank the people at the following organizations for their contribution to this effort:

EIA (Energy Information Administration)

\begin{tabular}{ll} 
Kendrick Brown \\
Linda Oliver \\
Rosemary Jamison \\
\hline FERC (Federal Energy Regulatory Commission) \\
\hline \\
Office of Pipeline Regulation & Office of Chief \\
$\begin{array}{l}\text { Kevin P. Madden } \\
\text { Thomas J. Brownfield } \\
\text { Randolph E. Mathura } \\
\text { Webster Grey } \\
\text { Thomas V. Bahumian }\end{array}$ & $\begin{array}{l}\text { Accountant } \\
\text { Joseph A. Frangipane }\end{array}$ \\
\hline
\end{tabular}




\section{EXECUTIVE SUMMARY}

\subsection{TECHNICAL PERSPECTIVE}

The three basic requirements in designing and operating storage reservoirs are verification of inventory as related to capacity, gas containment or retention against migration and the assurance of deliverability to meet market demand. Mechanical communication with adjacent formations or migration of gas out of the storage reservoir due to unknown faults, poor reservoir traps or abandoned production wells can lead to unaccounted for volumes of natural gas.

An important aspect of underground storage facilities is the migration of natural gas beyond the designated storage volume, primarily during the injection cycle. The migrated gas is often difficult to recover, thereby reducing the volume of recoverable working gas. Several years of data indicate a declining trend in the overall working gas volume with a corresponding increase in base gas. Gas migration with respect to underground natural gas storage has not been well documented. An effective, economical means of controlling migration in underground gas storage facilities is needed.

\subsection{TECHNICAL APPROACH}

The amount of natural gas unaccounted for annually from underground storage fields was estimated from both public and restricted access databases. Data examined include:

1. the American Gas Association's (AGA) Survey of Underground Natural Gas Storage Facilities in the United States and Canada (1992 database, published report 1993)

2. the Federal Energy Regulatory Commission's (FERC) Form 2 (1990-1993)

3. the FERC's Semi-Annual Report on Jurisdictional Underground Natural Gas Storage Fields in the US (January 1983 through September 1994)

4. the Energy Information Agency (EIA) form EIA-191 (1991-1994).

The AGA database was used to determine the number and types of storage reservoirs, geographic area, and reservoir drive and trapping mechanisms. The FERC Form 2 database was used to initially highlight the potential magnitude of gas migration, by examining company financial data. Proprietary data from the EIA (Energy Information Administration), which indicates monthly gas volumes on a per field basis, was used estimate the volume of gas migration for each major reservoir type.

A literature search was performed in order to gather information on gas migration mechanisms as they relate to reservoir type and assess current mitigation strategies and inventory verification methods.

A three dimensional reservoir simulator was used to study gas migration mechanisms during operation of storage fields. This base model was modified by the inclusion of a very low permeability boundary $(0.001 \mathrm{md})$, which would simulate a stratigraphic trap juxtaposed to a very low permeability formation. A thief zone was included by the use of a well completed in the very low permeability zone. Gas migration effects were studied. Mitigation strategies were then developed to reduce gas migration.

\footnotetext{
'Shikari, YA, "Gas Research Institute Underground Gas Storage Program: An Overview", SPE Paper No. 17739 presented at the SPE Gas Technology Symposium, Dallas, TX, June, 1988
} 


\subsection{RESULTS}

The FERC Form-2 reports very little gas loss associated with underground storage. The majority of losses are reported as transmission losses. Losses indicated by utilizing EIA-191 data are larger. These numbers were developed by performing material balance calculations on reported data. Seldom were reported base gas levels reduced. Most often they were increased and the resulting working gas volumes were reduced accordingly. Overall, industry has reduced base gas volumes by $500 \mathrm{BCF}$ in the four year period evaluated. This is an indication of reduced deliverability, changing markets or gas losses.

The values of the gas losses were derived from the Weighted Average Cost of Gas (WACOG) as reported by operators. The value of the gas in underground storage reservoirs is reported as current and non-current cost. Current is the value of the gas undercurrent gas pricing market conditions and non-current is the cost of gas purchased for base gas.

Gas migration, or unaccounted for gas, studied in Phase I included a review of Form-2, (190 - 1993) and EIA-191 data. Based on the Form-2 data submitted by major interstate transporters, most of the unaccounted for gas was reported as transportation losses, as shown below. Total unaccounted for gas amounts to less than $0.5 \%$ of total sales. Whether gas losses are accurately reported, will be reflected by revisions (write-downs) of base gas as a result of Order 636 in following years.

FERC Form 2 -- Gas Account - Natural Gas pages 520-521

\begin{tabular}{|c|c|c|c|c|c|c|c|}
\hline \multirow{2}{*}{\multicolumn{2}{|c|}{$\begin{array}{c}\text { Line no. } 18 \\
\text { SCF }\end{array}$}} & \multirow[t]{2}{*}{58} & \multirow[t]{2}{*}{59} & 60 & \multirow[t]{2}{*}{61} & 62 & \multirow[t]{2}{*}{63} \\
\hline & & & & SCF & & SCF & \\
\hline & GAS WTHDRAWN & & & DISTRI- & & TOTAL & SCF \\
\hline & FROM & SCF & SCF & BUTION & MCF & UNACCOUNTED & TOT SALES, \\
\hline & UNDERGROUND & STORAGE & TRANSMISSION & SYSTEM & OTHER & FOR & OTHER DEL \& \\
\hline YR. & STORAGE & LOSSES & SYSTEM LOSSES & LOSSES & LOSSES & NATURAL GAS & UNACC FOR \\
\hline 1990 & $639,047,065$ & $2,643,043$ & $51,261,481$ & $5,358,600$ & $20,099,519$ & $79,362,643$ & $40,997,189,070$ \\
\hline 1991 & $923,023,648$ & $(5,394,904)$ & $125,327,191$ & $5,774,167$ & $23,619,529$ & $149,325,983$ & $39,239,995,470$ \\
\hline 1992 & $1,029,439,323$ & 995,525 & $108,856,539$ & $2,403,167$ & $16,025,252$ & $128,669,886$ & $36,749,827,856$ \\
\hline 1993 & $1,032,115,337$ & 125,298 & $120,317,124$ & $(2,111)$ & $31,730,977$ & $152,171,288$ & $37,147,687,684$ \\
\hline
\end{tabular}

The average cost of gas reported by operators on Form- 2 is shown below. Current gas price reflects the current gas price while the non-current price reflects to cost of base gas. As shown, the total average gas cost of storage has decreased from $\$ 1.18$ to $\$ 0.83$ per MCF from 1990 to 1993

\begin{tabular}{|c|c|c|c|c|c|c|}
\hline \multicolumn{7}{|c|}{$\begin{array}{l}\text { ERC Form } 2 \text { - Gas Stored (page 220, column a-f, lines 1-7) } \\
\text { GAS }\end{array}$} \\
\hline \multirow[b]{2}{*}{ YR. } & STORED & GAS DELIVERED & GAS WTHDRAWN & AT END OF & GAS VOLUME & AMOUNT PER \\
\hline & CODE & TO STORAGE & FROM STORAGE & YEAR & SCF & MCF \\
\hline \multirow[t]{3}{*}{1990} & Curr 16401 & $\$ 1,671,414,923$ & $\$ 1,155,222,735$ & $\$ 1,603,723,121$ & $861,868,236$ & $\$ 1.86$ \\
\hline & Noncurr & $\$ 651,735,673$ & $(\$ 16,597,001)$ & $\$ 1,195,275,209$ & $1,553,681,461$ & $\$ 0.77$ \\
\hline & Total & $\$ 2,347,842,430$ & $\$ 1,067,725,409$ & $\$ 2,839,523,538$ & $2,408,686,839$ & $\$ 1.18$ \\
\hline \multirow[t]{3}{*}{1991} & Curr16401 & $\$ 1,282,191,676$ & $\$ 1,455,660,200$ & $\$ 1,403,937,734$ & $739,449,873$ & $\$ 1.90$ \\
\hline & Noncurr & $\$ 178,152,452$ & $\$ 219,775,354$ & $\$ 1,311,389,103$ & $1,607,482,990$ & $\$ 0.82$ \\
\hline & Total & $\$ 1,383,357,750$ & $\$ 1,596,068,365$ & $\$ 2,720,659,673$ & $2,353,288,428$ & $\$ 1.16$ \\
\hline \multirow[t]{3}{*}{1992} & Curr16401 & $\$ 1,065,975,303$ & $\$ 1,125,384,782$ & $\$ 950,551,892$ & $587,422,222$ & $\$ 1.62$ \\
\hline & Noncurr & $\$ 464,346,468$ & $\$ 303,654,173$ & $\$ 1,250,821,230$ & $1,718,166,474$ & $\$ 0.90$ \\
\hline & Total & $\$ 1,619,388,984$ & $\$ 1,500,210,746$ & $\$ 2,419,751,246$ & $2,390,250,340$ & $\$ 1.14$ \\
\hline \multirow[t]{2}{*}{1993} & Curr16401 & $\$ 608,574,624$ & $\$ 819,703,481$ & $\$ 187,428,689$ & $120,981,017$ & $\$ 1.55$ \\
\hline & Noncurr & $\$ 457,929,885$ & $\$ 644,799,134$ & $\$ 1,469,922,895$ & $2,033,706,583$ & $\$ 0.72$ \\
\hline
\end{tabular}


A summary of total unaccounted for gas is shown below. An average of less than $0.33 \%$ of gas as reported on Form-2 is unaccounted.

\begin{tabular}{cccc}
$\begin{array}{c}\text { STORAGE } \\
\text { LOSSES }\end{array}$ & $\begin{array}{c}\text { TRANSMISSION } \\
\text { SYSTEM LOSSES }\end{array}$ & $\begin{array}{c}\text { TOTAL } \\
\text { UNACCOUNTED }\end{array}$ \\
\hline 1990 & $0.41 \%$ & $0.13 \%$ & $0.19 \%$ \\
1991 & $-0.58 \%$ & $0.32 \%$ & $0.38 \%$ \\
1992 & $0.10 \%$ & $0.30 \%$ & $0.35 \%$ \\
1993 & $\underline{0.01 \%}$ & $\underline{0.33 \%}$ & $\underline{0.41 \%}$ \\
avg. & $-0.016 \%$ & $0.27 \%$ & $0.33 \%$ \\
\hline
\end{tabular}

Analysis of EIA-191 data indicated inconsistencies when comparing reported values to those calculated. The following table shows the results of those presented in the Phase I report. As shown, over the period 1992-1994 over 143 BCF of gas is unaccounted base on material balance calculations and reported data. The largest difference is in the stratagraphic (STRAT) category.

\begin{tabular}{lrrrrr}
\hline & \multicolumn{1}{c}{ BCF } & & 1992 & 1993 & 1994 \\
\hline AQUIFER & $(10.3)$ & $7.20 \%$ & $(6.7)$ & $(2.6)$ & $(1.0)$ \\
CAVERN & $(9.7)$ & $6.75 \%$ & $(1.9)$ & $(7.4)$ & $(0.3)$ \\
STRAT & $\frac{(123.4)}{(143.4)}$ & $\frac{86.05 \%}{100.00 \%}$ & $\frac{(66.0)}{(74.7)}$ & $\frac{(37.6)}{(47.6)}$ & $\frac{(19.8)}{(21.1)}$ \\
\hline
\end{tabular}

This value of gas that is unaccounted ranges from $\$ 222.16 \$ 103.65$ million dollars over this three year period or $\$ 50$ million dollars per year, mainly from stratagraphic reservoirs. The average gas cost used was from Form-2 current and non-current prices for 1993 of $\$ 1.55$ and \$0.72 per MCF.

Over $80 \%$ of underground gas storage is in depleted stratigraphic or structural reservoirs in the Northeast and Midwest. The second portion of the study focused on these reservoir types. A three dimensional reservoir simulator was used to study gas migration mechanisms during operation of storage fields. A model was constructed which contained about $55 \mathrm{BCF}$ of gas and had five injections and withdrawal wells. Original reservoir pressure was 1200 psia. The field was operated on 180 day cycles over a ten year period. The resulting performance is discussed in the text.

This base model was modified by the inclusion of a very low permeability boundary $(0.001 \mathrm{md})$, which would simulate a stratigraphic trap juxtaposed to a very low permeability formation. Again the model was run and compared to the base case. The results were identical.

A thief zone was included by the use of a well completed in the very low permeability zone. Gas migration effects were studied. Typical $P / z$ calculations indicated that small volumes were lost even in formations with 0.001 md permeability.

Mitigation strategies were then developed to reduce gas migration from thief zones. By drilling horizontal wellbores, gas migration was eliminated or reduced. Sensitivity to horizontal wellbore length was studied. In this example, wellbores over $1000^{\prime}$ in length eliminated gas migration effects.

Horizontal wellbores has been utilized for deliverability enhancement by some operators, but their use to reduce delta pressures and gas migration also have an important role in the 
reduction of gas migration. Industry has been aware of over-pressuring storage reservoirs to increase storage capacity and deliverability, but caution should be exercised it's implementation. Gas migration could be increased.

Storage operators commonly limit the amount of time to recharge (reinject) gas into storage during the summer months. Operators may limit reinjection time due to operational consideration (equipment repair), optimize gas costs, or to reduce gas migration losses. Based on the results of this study, increased gas migration effects could result.

\subsection{PROJECT IMPLICATIONS}

The key elements of this study show that gas migration can result if reservoir limits have not been properly identified, gas migration can occur in formation with extremely low permeability $(0.001 \mathrm{md})$, horizontal wellbores can reduce gas migration losses and over-pressuring (unintentionally) storage reservoirs by reinjecting working gas over a shorter time period may increase gas migration effects. A thief zone was included by the use of a well completed in the very low permeability zone. Gas migration effects were studied. 


\section{TABLE OF CONTENTS}

1. DISCLAIMER

...ii

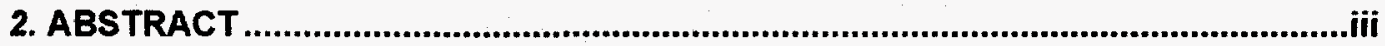

3. PREFACE

4. ACKNOWLEDGMENTS ......................................................................................vii

5. EXECUTIVE SUMMARY .......................................................................................

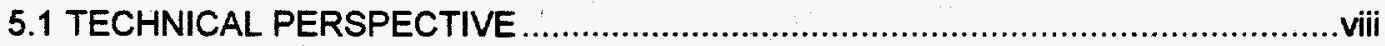

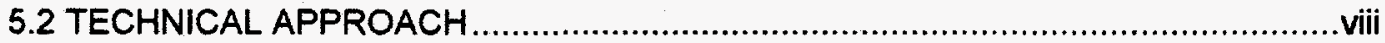

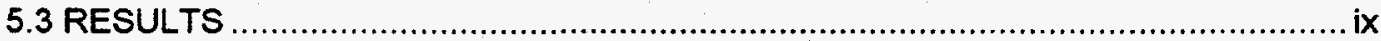

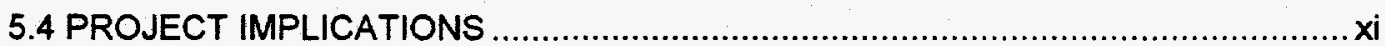

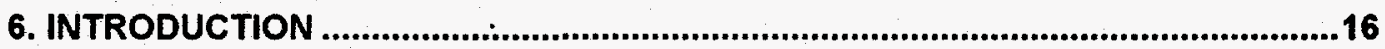

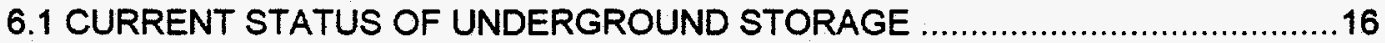

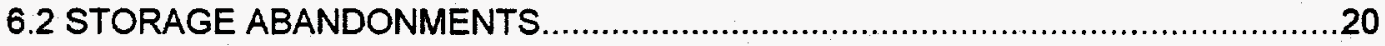

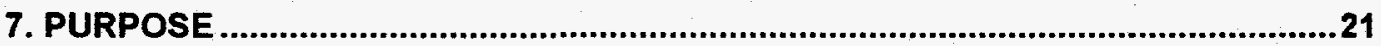

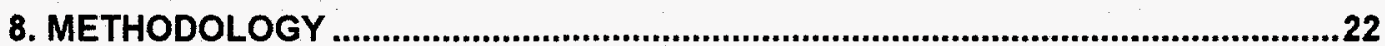

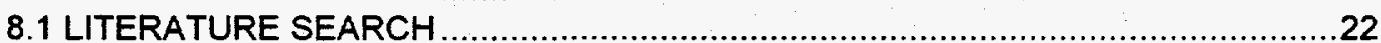

8.2 DATABASE SEARCH AND ANALYSIS

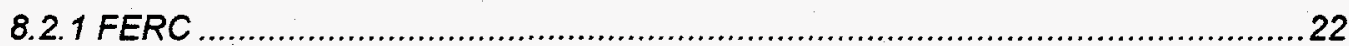

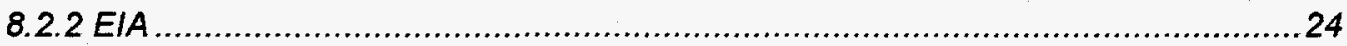

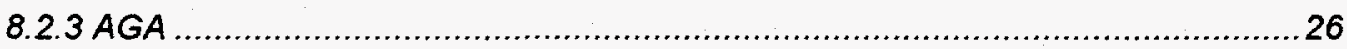

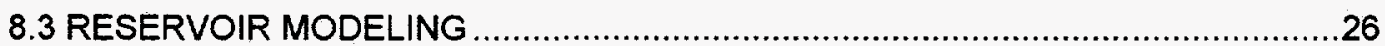

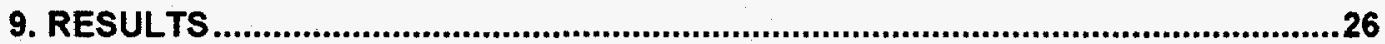

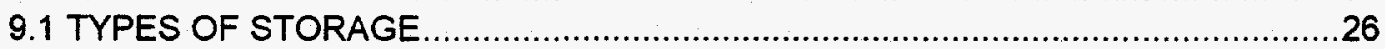

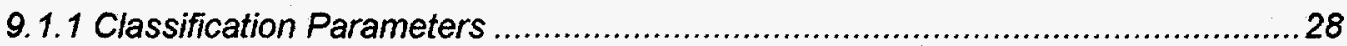

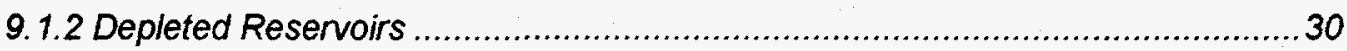

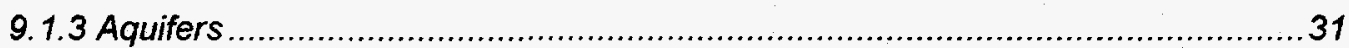

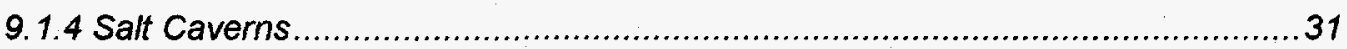

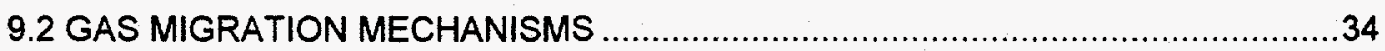

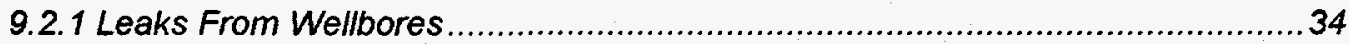

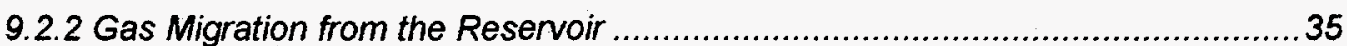

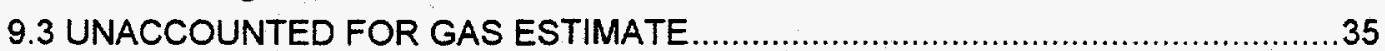

9.4 GAS MIGRATION MODEL AND HORIZONTAL WELL SIMULATION .................42

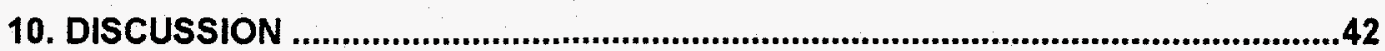

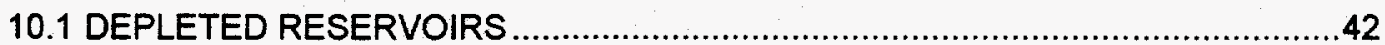

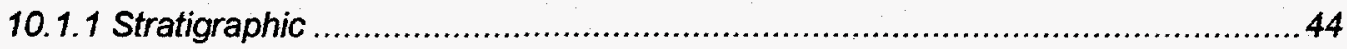

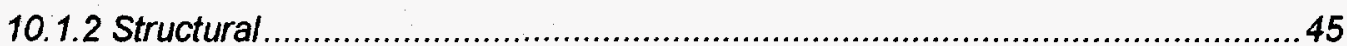

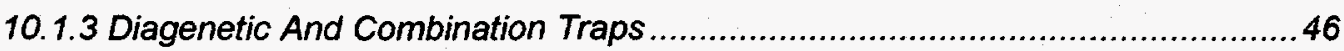

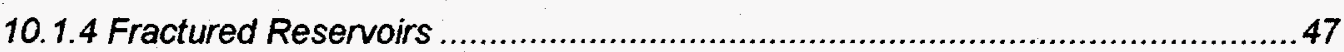

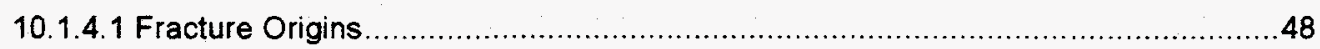

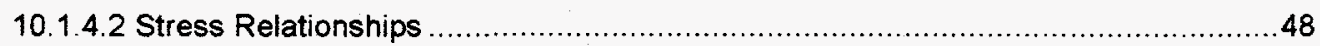

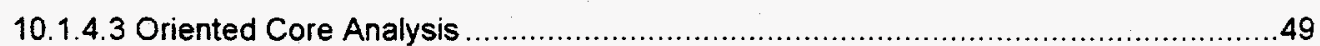

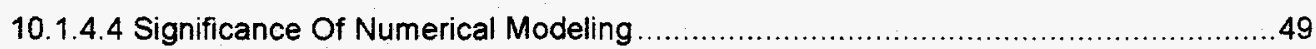

10.1 .5 Inventory Verification .....................................................................50

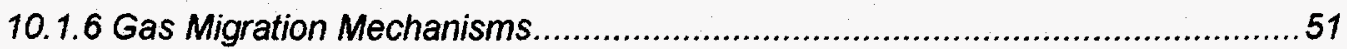

10.1.6.1 Homogenous (Base) Reservoir Case ...........................................................51 


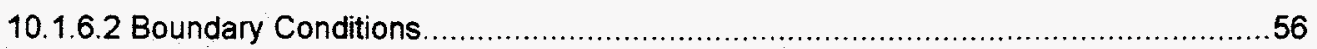

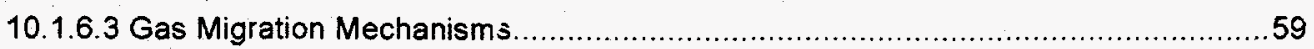

10.1.7 Mitigation Strategies .................................................................61 61

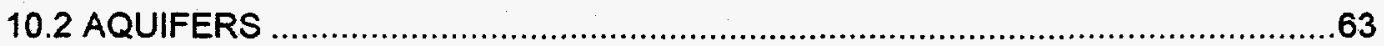

10.2.1 Gas Migration ............................................................................64

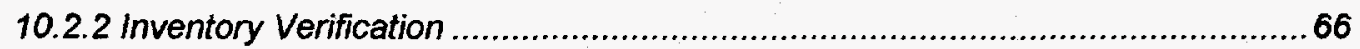

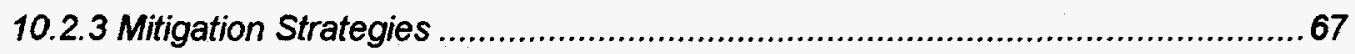

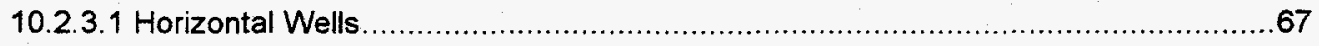

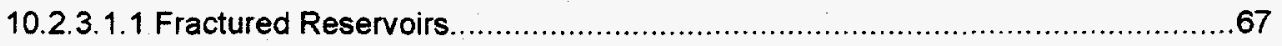

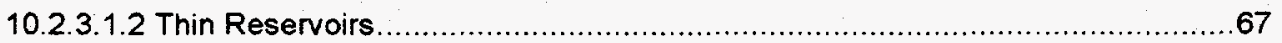

10.2.3.1.3 Reservoirs With Gas And Water Coning Problems ...................................68

10.2.3.2 Use Of Foam To Reduce Gas Migration..................................................69

10.2.3.3 Completion Planning For Elimination Of Sand Production In Thinly-Bedded Aquifer Gas Storage Wells 70

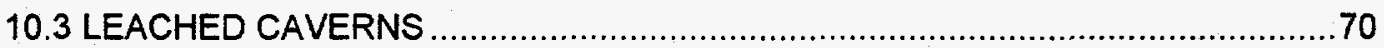

10.3.1 Gas Migration ........................................................................... 72

10.3.2 Mitigation Strategies .................................................................... 72

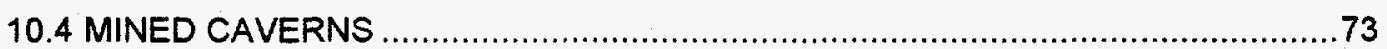

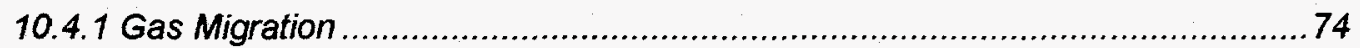

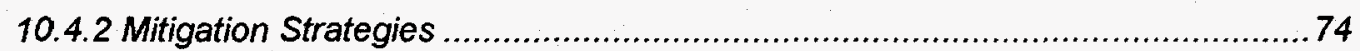

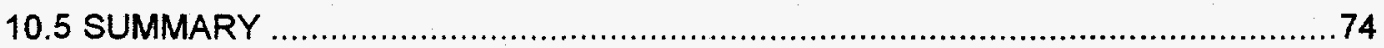

10.5.1 Gas Migration Mechanisms..................................................... 74

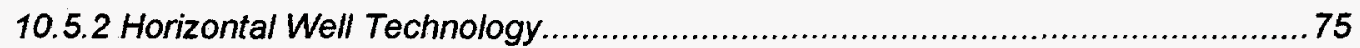

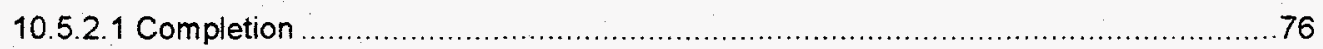

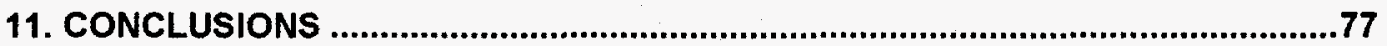

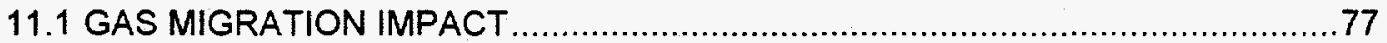

11.2 RESERVOIR MODELING IMPLICATIONS ............................................... 77

12. REFERENCES ............................................................................................79

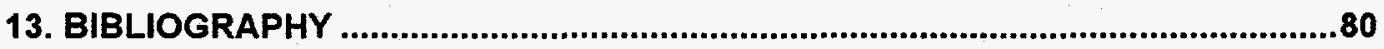

14. CODE OF FEDERAL REGULATIONS ON GAS STORAGE ..............................85

15. GLOSSARY...................................................................................................89

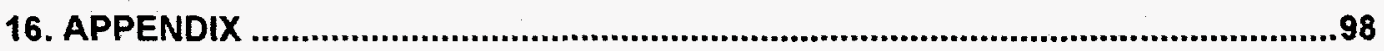




\section{FIGURES}

FigURE 6---6-16-2: STOR. AGE CAPACITY IN THE US vs. NUMBER OF OPERATORS ................................18

FigURE 6-3: UNDERGROUND NATURAL GAS STORAGE CAPACITY BY STATE.......................................18

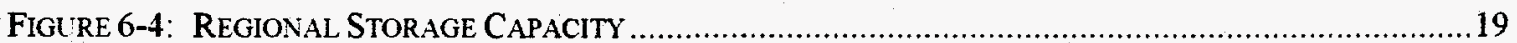

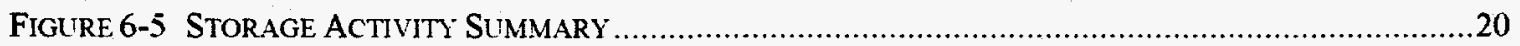

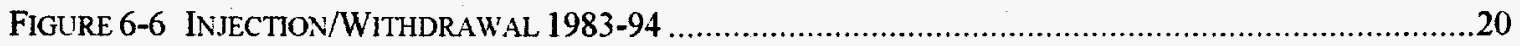

FIGUIRE 8-1: GRAPH FROM JURISDICTIONAL REPORT SHOWING TOTAL JURISDICTIONAL OPERATING

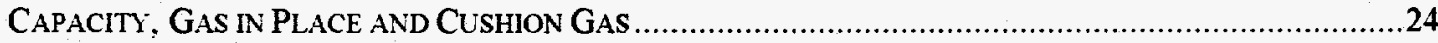

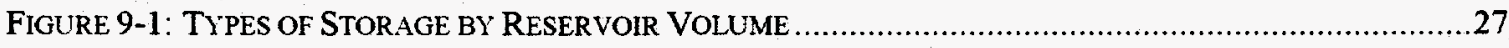

FIGURE 9-2: TYPES OF UNDERGROUND STORAGE BY NUMBER OF RESERVOIRS ..................................28

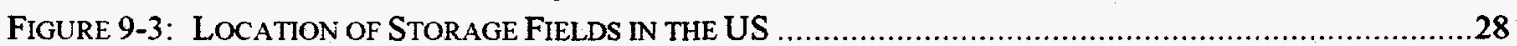

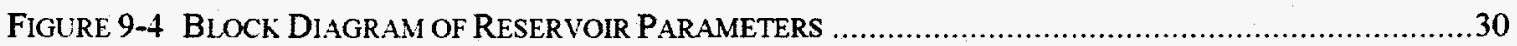

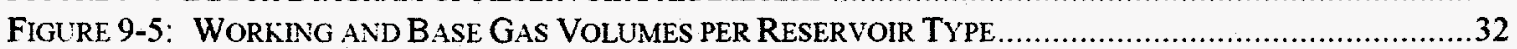

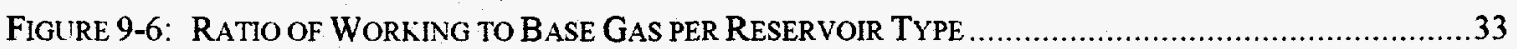

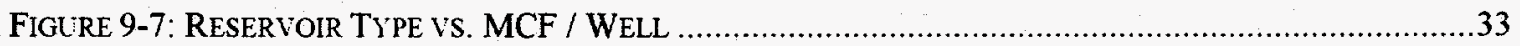

FiguRE 9-8: PERCENT DifFERENCE VS. REPORTED TOTAL GAS ............................................................

FIGURE 10-1: LOCATION OF DEPLETED RESERVOIR STORAGE IN THE US …........................................43

FIGURE 10-2: STRATIGRAPHIC STORAGE RESERVOIR CHARACTERISTICS .............................................45

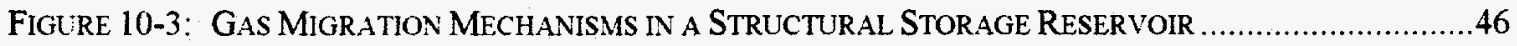

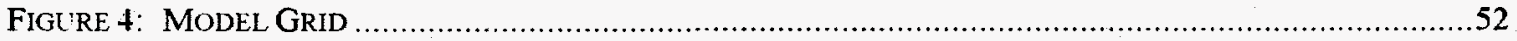

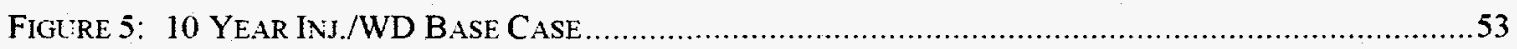

FIGLRE 6: AVERAGE STORAGE RESERVOIR PRESSURE PERFORMANCE .................................................53

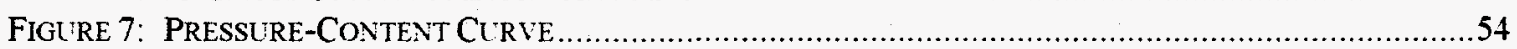

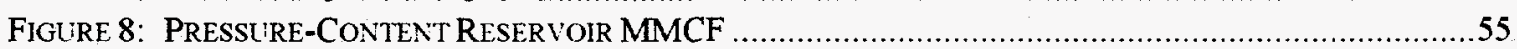

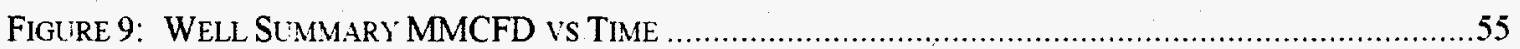

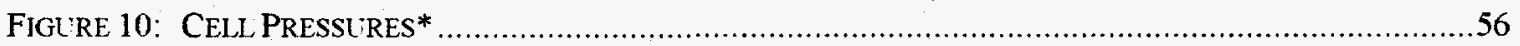

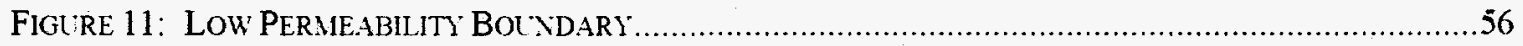

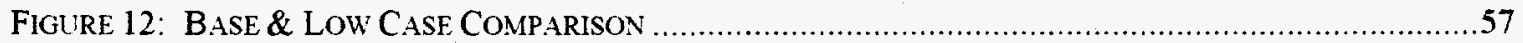

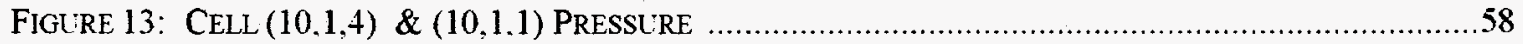

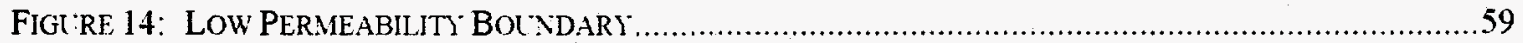

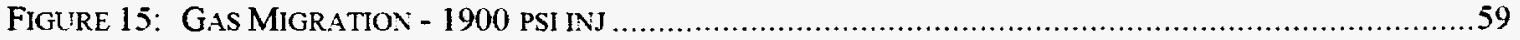

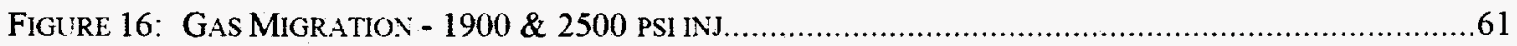

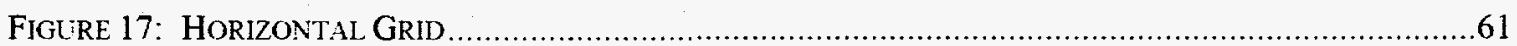

FIGURE 18: HoRIZONTAL AND VERTICAL INJECTION COMPARISON ON MIGRATION .....................................62

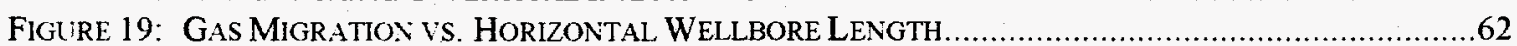

FIGL'RE 10-20: LOCATTON OF AQU IFER STORAGE RESERVOIRS IN THE US ...........................................63

FigUiRE 10-21: LEAKING vS. NoN-LEAKING AQUIFER PRESSURE CURVES ............................................66

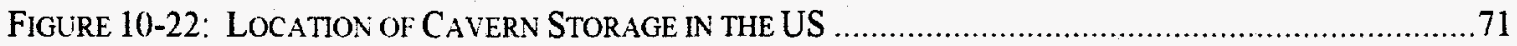

TABLES

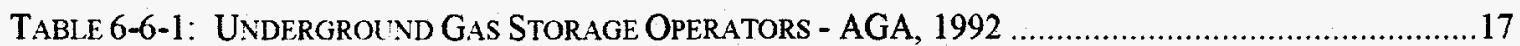

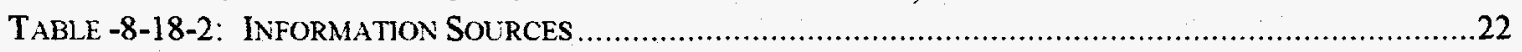

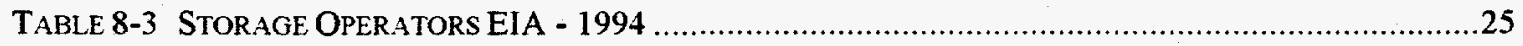

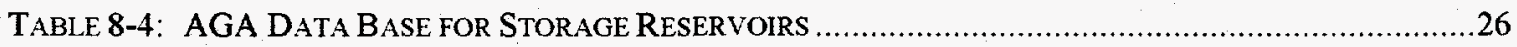

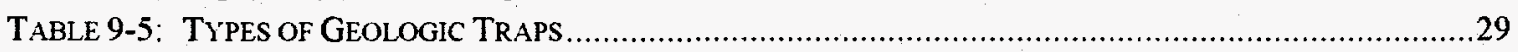

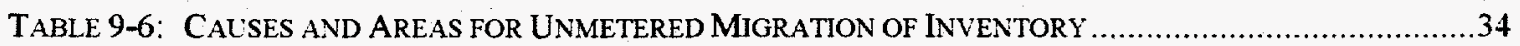

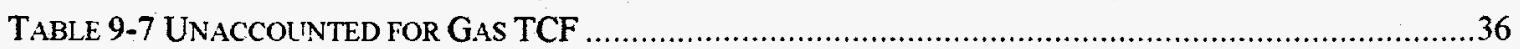

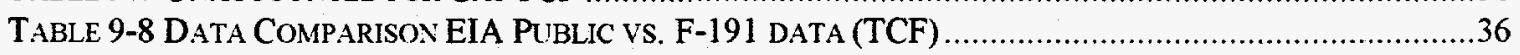

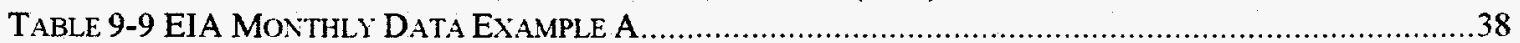

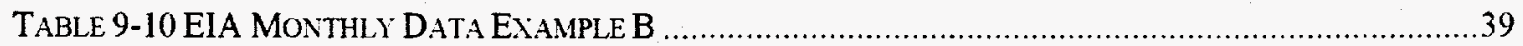

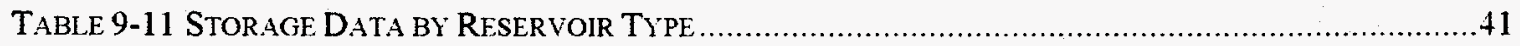

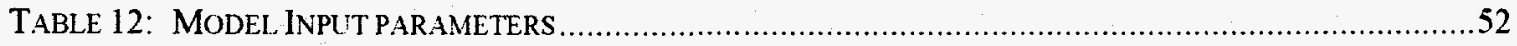

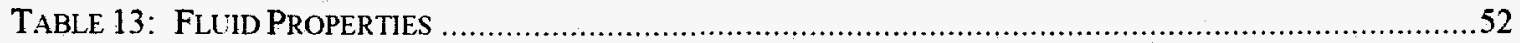


TABLE 16-14: ADDITIONS TO AND WITHDRAWALS FROM Gas STORAGE BY STATE, .98

TABLE 16-15: UNDERGROL ND NATURAL GAS STORAGE CAPACITY BY STATE,

TABLE 16-16: STATUS OF UNDERGROUND GAS STORAGE AT THE END OF THE 1991-92 WITHDRAWAL SEASON100

TABLE 16-17: STATUS OF L'NDERGROUND GAS STORAGE AT THE END OF THE 1991-92 WITHDRAWAL SEASON

BY GEOGRAPHICAL AREA.

100

TABLE 16-18: TYPES OF STORAGE FIELDS IN THE GEOGRAPHICAL REGIONS OF THE US ........................... 100

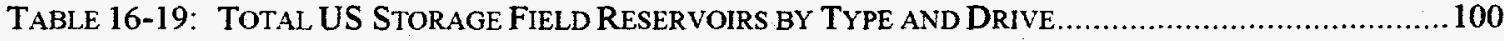

TABLE 16-20: AVERAGE PROPERTIES FOR VARIOUS STORAGE RESERVOIR TYPES ...............................101

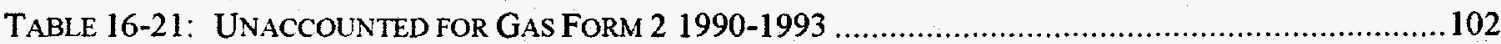

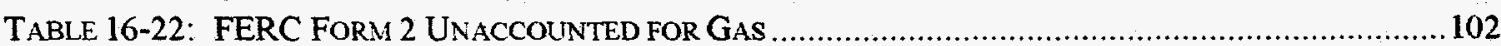

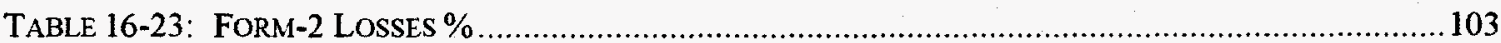

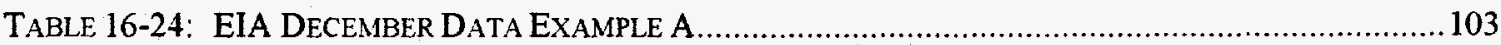

TABLE 16-25: DIFFERENCE IN CALCULATED vs REPORTED TOTAL GAS ................................................ 104 


\section{INTRODUCTION}

\subsection{CURRENT STATUS OF UNDERGROUND STORAGE}

The principal owners and operators of underground storage facilities are

1. interstate pipeline companies

2. local distribution companies (LDC's)

3. intrastate pipeline companies

4. independent storage service providers.

Several natural gas producers and large industrial users also own a limited amount of storage. ${ }^{2}$

Interstate pipelines operate about $62 \%$ of all working gas capacity in the United States. Historically, these FERC-jurisdictional companies have owned and distributed most of the natural gas from US underground storage sites. Underground storage has traditionally been important to interstate pipeline companies because they depend heavily on storage inventories to facilitate load balancing and system supply management on their long-haul transmission lines. ${ }^{3}$

LDC's and intrastate pipeline companies account for about $34 \%$ of working gas capacity. LDC's generally use gas from storage sites to serve customer needs directly, whereas intrastate pipeline companies use underground storage for operational balancing and system supplies as well as the energy needs of end-use customers. While most LDC and intrastate pipeline storage operations are subject only to state regulatory agencies, $14 \%$ ( 8 of 58 ) are subject to FERC jurisdiction because they also provide significant service to the interstate market.

Independent operators own or operate about $4 \%$ of current working gas capacity. Many of the salt formation and high-deliverability sites currently being developed have been initiated by independent storage service operators. If the independent operators principally serve the interstate market they are subject to FERC regulations; otherwise, they are state regulated. Several independent storage operations are joint ventures that include major interstate pipeline companies and LDC's as partners, or they are subsidiaries of interstate pipeline companies operating as independent entities. ${ }^{5}$

\footnotetext{
2 Energy Information Administration, "The Value of Underground Storage in Today's Natural Gas Industry", p. 45.

${ }^{3}$ ibid. p. 45-46.

${ }^{4}$ Ibid.

${ }^{5}$ ibid.
} 


\section{Table 6-6-1: Underground Gas Storage Operators - AGA, 1992}

\author{
COMPANY NAME \\ ANR Pipeline Company \\ ANR Storage Company \\ Alcan Ingot \& Recycling \\ 4. ARKLA Energy Resources \\ Arkansas Oklahoma Gas Corp. \\ Arkansas Western Gas Company \\ Battle Creek Gas Company \\ Bear Creek Storage Company \\ CNG Transmission Corporation
}

10. Cabot Oil \& Gas Corporation

11. Cabot Storage Corp.

12. Central Illinois Light Company

13. Central Illinois Public Service Co.

14. Citizens Gas \& Coke Utility Co.

15. Colorado Interstate Gas Company

16. Columbia Gas Transmission Corp.

17. Consolidated Gas Supply Corp.

18. Consumers Power Company

19. Delta Natural Gas Company, Inc.

20. ENRON Gas Pipeline Operating

21. El Paso Natural Gas Company

22. Elizabethtown Natural Gas Dept

23. Equitrans Inc.

24. Gas Company of New Mexico

25. Hampshire Gas Company

26. Honeoye Storage Corporation

27. Hoosier Gas Corp.

28. Illinois Power Company

\section{COMPANY NAME}

1. Indiana Gas Company, Inc.

2. KN Energy, Inc.

3. Lawrenceburg Gas Company

4. Llano, Inc.

5. Lone Star Gas Company

6. Louisville Gas \& Elec. Co.

7. Michigan Consolidated Gas Co

8. Michigan Gas Storage Co.

9. Michigan Gas Utilities Co.

10. Minnegasco, Inc.

11. Mississippi River Trans. Corp.

12. Mississippi Valley Gas Co.

13. Montana Power Company

14. Mountain Fuel Supply Co.

15. National Fuel Gas Supply Corp.

16. National Gas \& Oil Corp.

17. Natural Gas $P / L$ Co. of America

18. North Penn Gas Company

19. Northern Gas Company

20. Northern lilinois Gas Co

21. Northern Ind. Pub. Service Co.

22. Northern Natural Gas Company

23. Oklahoma Natural Gas Co.

24. Pacific Gas \& Electric Co.

25. Panhandle Eastern $P / L C$ Co.

26. Penn-York Energy Corporation

27. Phillips Petroleum Company

28. Public Service $\mathrm{Co}$. of Colorado
1. Gasco, Inc.

COMPANY NAME

2. Southeastern Michigan Gas Co

3. Southern California Gas Company

4. Southern Indiana Gas \& Elec. Co.

5. Southern Natural Gas

6. Southwestern Gas Pipeline, Inc.

7. Southwest Gas Storage Company

8. T.W. Phillips Gas \& Oil Co

9. Texas Eastern Transmission Corp

10. Texas Gas Transmission Corp.

11. Texas Utilities Fuel Company

12. The East Ohio Gas Company

13. The Peoples Gas Light \& Coke Co.

14. The Peoples Natural Gas Co.

15. Transcontinental Gas P/L Corp.

16. Transok inc.

17. Trunkline Gas Company

18. United Gas Pipe Line Company

19. Valero Energy Corporation

20. United Cities Gas Storage Co

21. Washington Natural Gas Co.

22. Western Kentucky Gas Co.

23. Williams Natural Gas Co.

24. Williston Basin Interstate P/L Co.

25. Winnie Pipeline Company

26. ZCA Gas Gathering Co. Inc.

Source: AGA "Survey of Underground Gas Storage Facilities in the United States and Canada", 1993

The AGA database, above, lists a total of 83 operators in the United States who maintain active storage fields with a total capacity of around 7 trillion cubic feet (TCF) of gas. Approximately $45 \%$ of gas stored underground is working gas, while the remaining $55 \%$ is base gas. Roughly $75 \%$ of this gas had been under the jurisdiction of the Federal Energy Regulatory Commission (FERC). However, the percentage of total working gas in interstate storage owned by storage operators at the start of the heating season fell from $73 \%$ in 1986 to $46 \%$ in $1993 .{ }^{6}$

From the AGA database, the number of storage operators that represent a large percentage of the total storage capacity is relatively small. One quarter of storage field operators maintains three quarters of the US underground storage capacity. Half of the storage capacity is operated by $10 \%$ of the active storage operators. Nearly one-quarter of the storage capacity in the US is operated by only two companies. The following figure illustrates the relative number of operators versus the total US storage capacity.

\footnotetext{
${ }^{6}$ Ibid., p 25.
} 
Figure 6---6-16-2: Storage Capacity in the US vs. Number of Operators

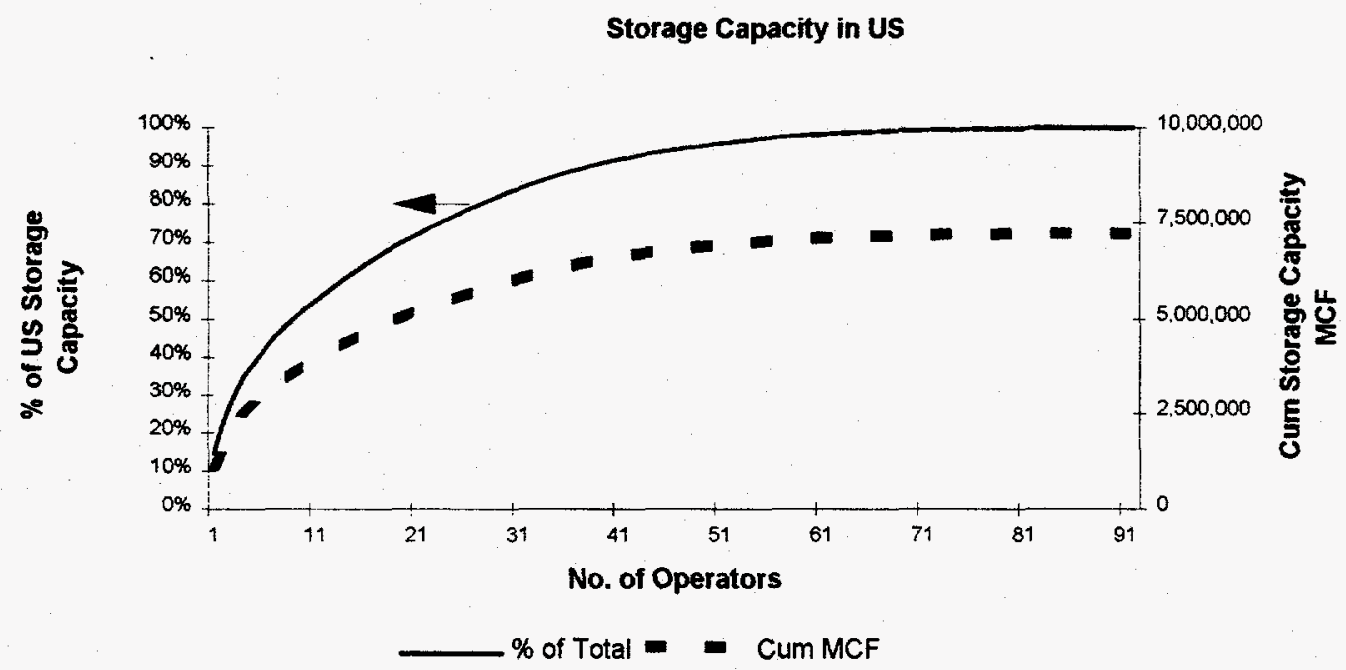

Underground natural gas storage facilities in United States are located in only 26 of the lower 48 states. Even there, almost half the total storage capacity is concentrated in only three of these states as illustrated by the map on the following page. Figure No. 6-2 summarizes the natural gas storage capacity by state.

Figure 6-3: Underground Natural Gas Storage Capacity by State

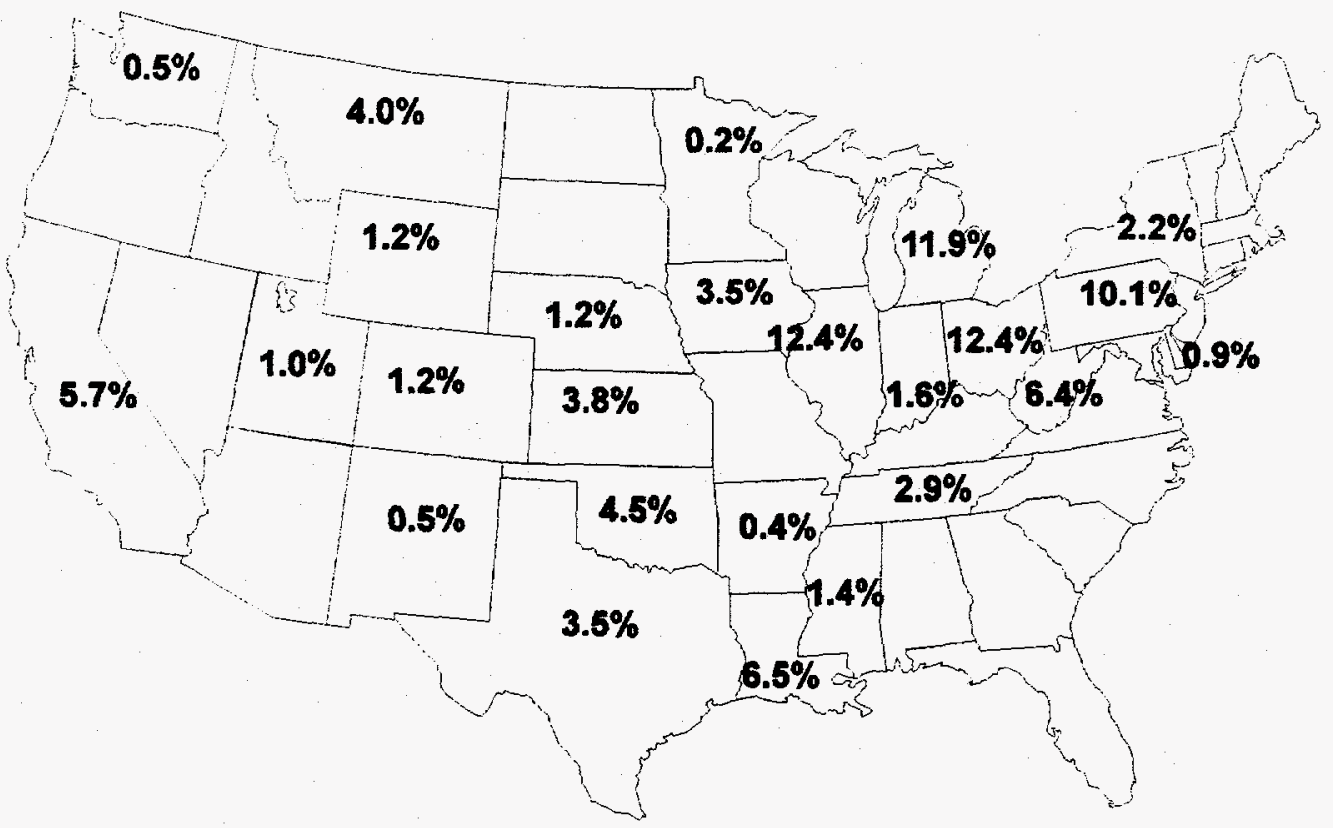

Source: Energy information Administration (EIA), Form EIA-191, "Underground Gas Storage Report." 
To service the heavy heating load in the Northeast and Midwest, more than half of the country's working gas capacity is located east of the Mississippi River, ${ }^{\text {? }}$ as shown in the chart on the following page. Figure No. 6-4 summarizes the regional underground storage in the US:

Figure 6-4: Regional Storage Capacity

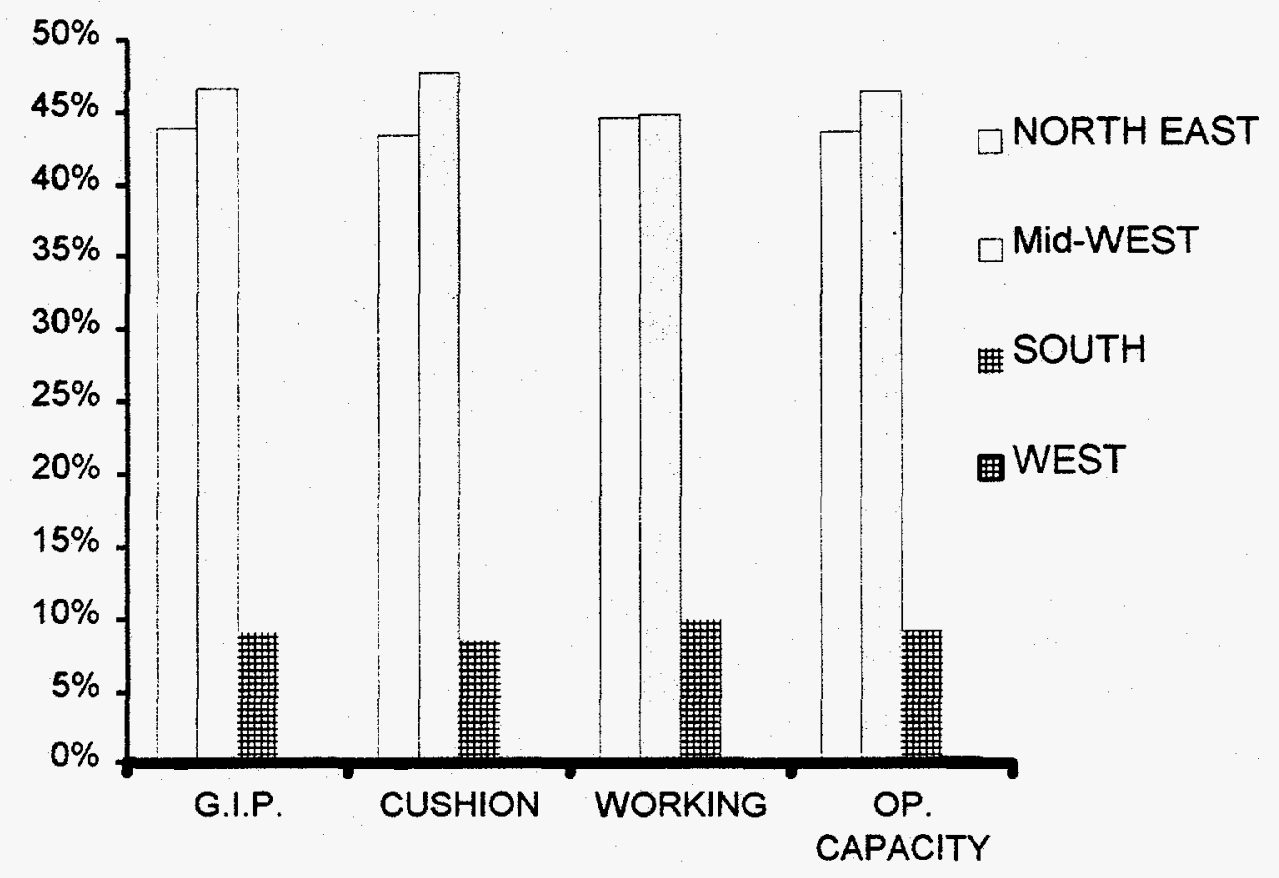

Source: AGA 1992 Database

Working gas inventory levels at the beginning of the heating season (Nov. 1) drifted progressively lower from 1990 to 1993 (3.5 TCF in 1990 to 3.0 TCF in 1993). Working gas inventories at the end of the heating season also dropped significantly in 1992, 93 and 94, both in volume and as a percentage of working gas capacity. Between 1985 and 1991, end-of-season inventories ranged from $32 \%$ to $43 \%$ of capacity. In 1992 , inventories were $32 \%$ of capacity but dropped to $25 \%$ after the severe weather in 1993 and $1994 .{ }^{\circ}$

The decrease in working gas was accompanied by a concurrent increase in the base gas inventory levels. While industry attributes this increase in base gas as a strategy to optimize deliverability, an increase in the base gas inventory can also signify unrecoverable gas due to migration. The following figures illustrate this trend. Overall storage activity from 1988 is shown on the following Figure No. 6-5 and the cyclic injection and withdrawal since 1983 are shown on the following Figure No. 6-6.

\footnotetext{
${ }^{7}$ Energy Information Administration, The Value of Underground Storage in Today's Natural Gas Industry, p. vii ${ }^{8}$ Ibid.
} 
Figure 6-5 Storage Activity Summary

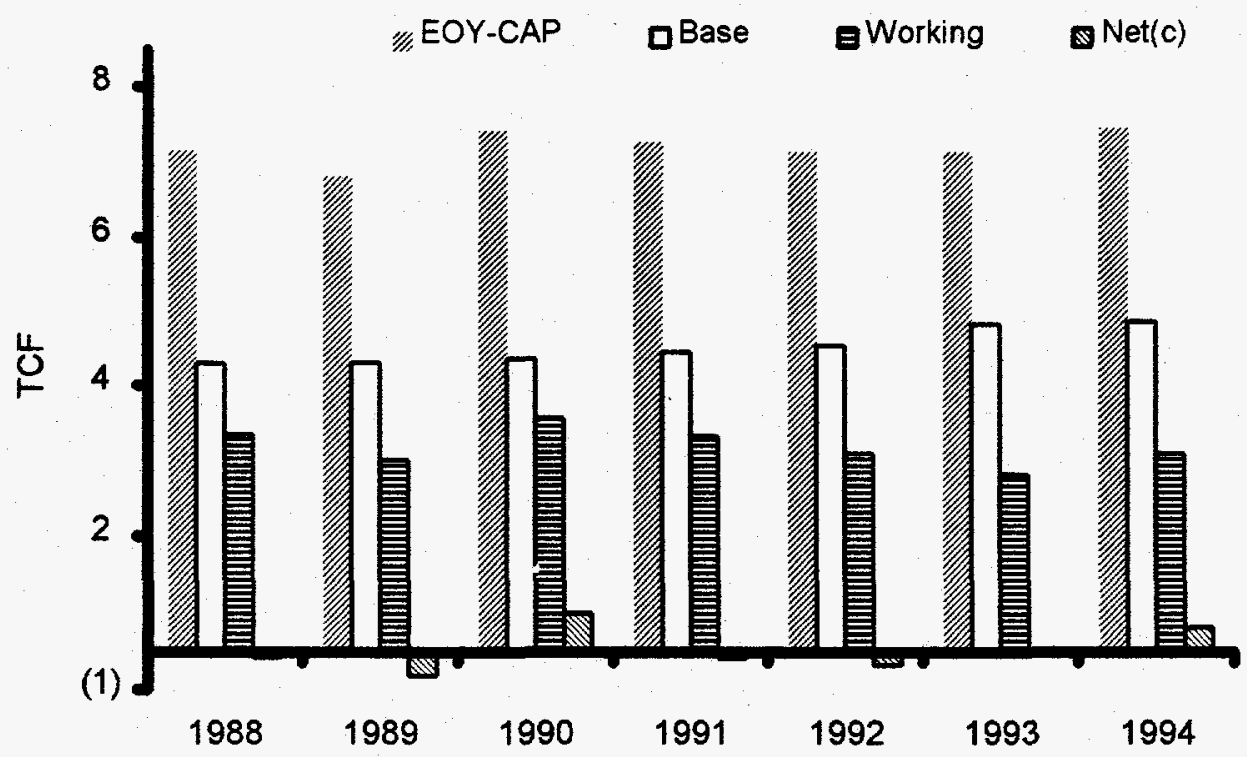

Source: Energy Information Administration, Natural Gas Monthly, Table 13

Figure 6-6 Injection/Withdrawal 1983-94

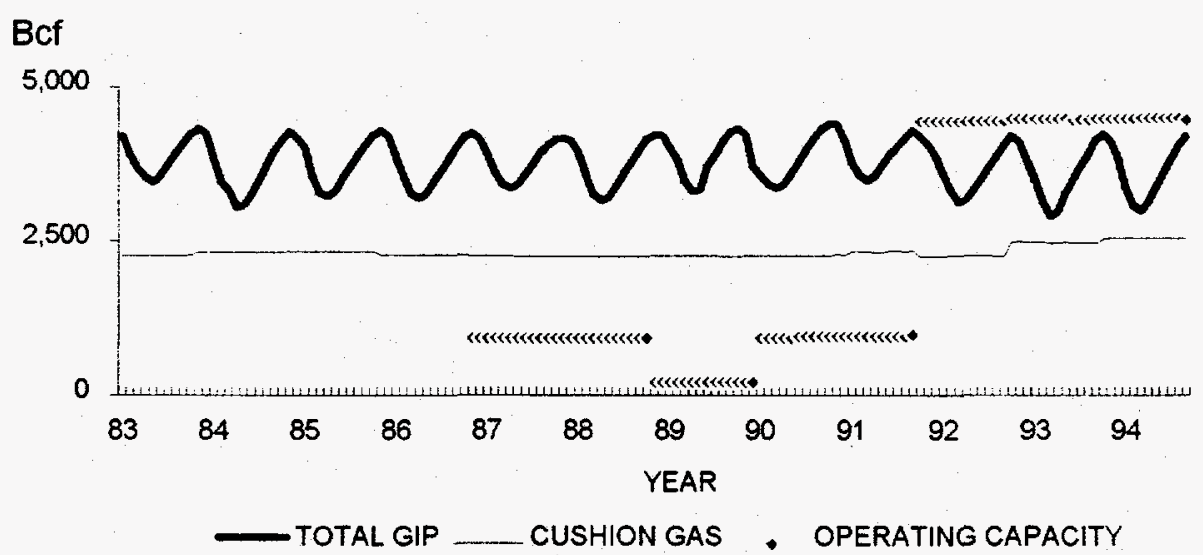

Source: Webster Gray, FERC Jurisdictional Underground Storage Fields Database

\subsection{STORAGE ABANDONMENTS}

Of the 29 storage sites taken out of service from 1990 through 1993 , at least 13 , and, perhaps, as many as 21 have been or are being depleted and will be abandoned or left inactive. Most of the 21 are considered by their owners to be uneconomical to operated in today's 
marketplace without incurring a major workover expense; a few are inactive because continued operation would raise safety concerns. The remaining 8 of the 29 sites are classified as standby by their operators; that is, they contain no working gas, and other than withdrawing remaining recoverable gas or operations to maintain standby status, minimal activity has been reported. All but 2 of the 29 deactivated sites are depleted gas or oil reservoirs, with the others aquifer sites. For the most part, they are small fields. ${ }^{9}$ Nine are located in the Northeast, 11 in the Midwest and Central regions and 9 in the South and West.

A close examination of the types of storage fields that have been taken out of service tends to show how, with the growth of open access storage and increased need by operators to market storage services, marginal and poorly located storage may be falling victim to economics and a changing market environment. Reasons given for inactivating or abandoning storage sites are:

- Too small a field to support itself

4 sites

- Need major workovers; leaking casings, seepage, etc. 4 sites

- Substantial migration losses

3 sites

- Safety

3 sites

- Located at nonstrategic place on system / loss of client 3 sites

In total, since the early 1970's, as many as 82 storage facilities in the US have been officially abandoned, classified as standby, or are simply no longer being used. However, their daily deliverability is only $1.8 \%$ of total storage deliverability in 1994 . In contrast, the new sites brought into service from 1990 thorough 1993 increased daily deliverability by $9.2 \%(5,694$ MCF). ${ }^{10}$ Since 1990 , a number existing storage sites have been placed into inactive or standby mode while several more have abandonment application pending before FERC or state public utility commissions. ${ }^{11}$ New storage capacity has not displaced existing capacity; rather, the competitive marketplace has culled marginal operations from the nation's storage inventory. Also, it is worth noting that standby sites, as well as a number of the inactive sites, have not been totally abandoned and could be reactivated in the future. ${ }^{12}$

\section{PURPOSE}

Recognizing and controlling gas migration from the reservoir can improve storage operations. Current underground gas storage operation and maintenance costs are said to average $5 \%$ of the total cost-of-service for pipeline and distribution companies, ${ }^{13}$ with an actual range from zero to over $20 \%{ }^{14}$ Unaccounted for gas is estimated to equal roughly $7 \%$ of the operations and maintenance costs associated with underground storage. One source of unaccounted for gas from underground storage facilities is the migration of natural gas beyond the designated storage volume, primarily during the injection cycle. The migrated gas is often difficult to recover, thereby reducing the volume of recoverable working gas. An effective, economical means of controlling migration in underground gas storage facilities is therefore needed. ${ }^{15}$ Prior to Order 636 , which unbundles the cost of storage from other pipeline operations, there was not a strong impetus to fully investigate the occurrence, causes and sources of this gas migration.

\footnotetext{
9 Ibid., p. 33

${ }^{10}$ Ibid.

11 lbid, p. 30

12 Ibid. p. 33.

${ }^{13}$ from AGA communication

${ }^{14}$ from analysis of FERC Form 2

${ }^{15}$ Shikari, YA, "Gas Research Institute Underground Gas Storage Program: An Ovenview".
} 


\section{METHODOLOGY}

Sources of information used in this report include textbooks, joumal articles, American Gas Association (AGA) and Gas Research Institute (GRI) reports, and Federal Energy Regulatory Commission (FERC) and Energy Information Administration (EIA) databases. Underground storage fields, operators and geologic formations were identified and categorized and the available databases were analyzed. A summary of the sources of information is tabled below:

Table -8-18-2: Information Sources

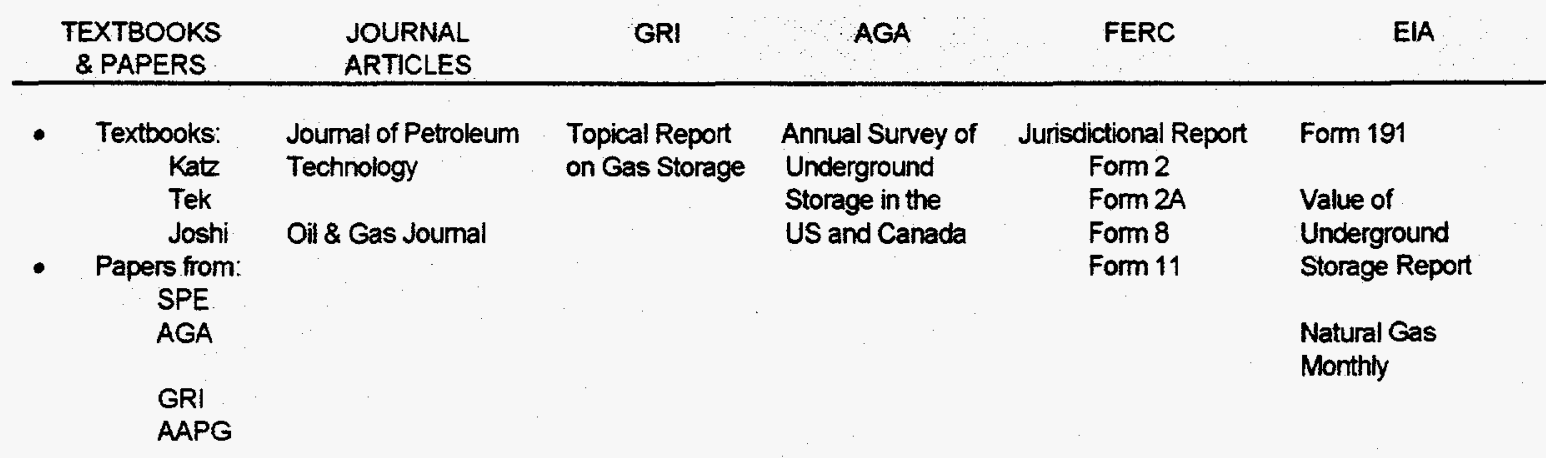

\subsection{LITERATURE SEARCH}

A literature search was conducted among available textbooks, journal articles and topical reports which yielded:

- Geological, geographical, historical and reservoir information on underground storage fields.

- Gas migration mechanisms, both mechanical and reservoir associated, for the three main types of underground storage fields.

- Information on new technologies, including horizontal drilling, which can be used to mitigate gas migration from storage reservoirs.

\subsection{DATABASE SEARCH AND ANALYSIS}

Databases and reports are available from a number of public sources, including both private and government institutions. Non-government sources include the Gas Research Institute (GRI) and the American Gas Association (AGA). Energy Information Administration (EIA) and Federal Regulatory Commission (FERC) public databases were also accessed. Consistent with the regulations regarding the use of this information, certain restricted data was also provided by the EIA. All of these databases (summarized below) were imported to Microsoft Excel spreadsheet format for database manipulation and sorted by category, such as company, geographical area, and storage type.

\subsubsection{FERC}

Public reports on underground gas storage are available through the Federal Energy Regulatory Commission (FERC). Data from 1988 onward has been submitted to the FERC by companies under the FERC's jurisdiction via electronic media and has been incorporated into computer databases. The following FERC reports were initially examined:

- Form 2: Annual Report of Major Natural Gas Companies, filed by about 45 interstate and natural gas pipeline companies with combined gas sold for resale and gas transported or stored for a fee 
exceeding 50 billion cubic feet. The 132-page report (on each company) contains general corporate information, financial statements and supporting schedules, and engineering statistics.

- Form 2-A: Annual Report of Non-major Natural Gas Companies, filed by about 86 interstate natural gas pipeline companies with annual sales or volume transactions of more than 200 million cubic feet but less than 50 billion cubic feet. The 19-page report contains corporate information, financial statements and supporting schedules, and engineering statistics.

- Form 8: Underground Gas Storage Report, five-page report filed monthly by about 40 natural gas companies that operate natural gas storage fields in the United States.

- Form 11: Natural Gas Pipeline Company Monthly Statement, filed by about 35 natural gas pipeline companies that sold and/or transported, for a fee, more than 50 billion cubic feet of gas during the previous calendar year. The 7-page report contains data on revenues, income, operating and maintenance expenses, and gas supplies. ${ }^{16}$

Between one-half and three-quarters of the volume of gas stored underground are in fields operated by companies reporting in FERC Form 2 . Therefore, a detailed analysis was conducted on FERC Form 2 data. A sample page from this form is contained in the Appendix. The FERC Form 2 database includes information such as company financial data, total monthly injections and withdrawals per company and total unaccounted for natural gas by company. Transmission, distribution, other, storage, and production gas loss categories are reported as a total by the operator. Current and non-current revenue categories give an indication of the working gas (current) vs. the base gas (non-current). An abrupt increase in the non-current category may indicate an increase in the base gas in an attempt to compensate for gas migration.

An in-house FERC report, "The Semi-Annual Report on Jurisdictional Underground Natural Gas Storage Fields in the United States" was also obtained, along with the supporting electronic database and graphs covering a ten-year period. Monthly injection and withdrawal cycles of gas from underground storage are reported by each pipeline company subject to the jurisdiction of the FERC. Graphs of this data covering a ten year period were obtained for each jurisdictional company as well as aggregate regional graphs. The graph of the overall total operating capacity, gas in place and cushion (base) gas is illustrated as Figure No. 8-1, on the following page. The gas volumes represent around $70 \%$ of the volume of gas stored underground in the United States.

The FERC Jurisdictional report is based on the compilation of present and past information, technical interpretation and analysis by the Supply Analysis Branch staff (currently reorganized under the FERC's Office of Pipeline Regulation). Reported as an aggregate of all active storage fields operated per company, the FERC Jurisdictional database does not discern individual storage field volumes. However, the total and regional database graphs were used to spot overall trends in operating capacity, gas in place and cushion, or base, gas.

This data, graphed by company, was used to

1. track changes in operating capacity, which would indicate a possible addition or abandonment/shut-in of a storage field.

2. observe changes in injection and withdrawal cycles.

3. note an increasing trend in cushion or "base" gas., which may be indicative of gas migration.

\footnotetext{
${ }^{16}$ FERC, "A Guide to the Public Information at the Federal Energy Regulatory Commission", Washington, DC, February, 1994.
} 


\subsubsection{EIA}

Figure 8-1: Graph from Jurisdictional Report showing Total Jurisdictional Operating Capacity, Gas in Place and Cushion Gas

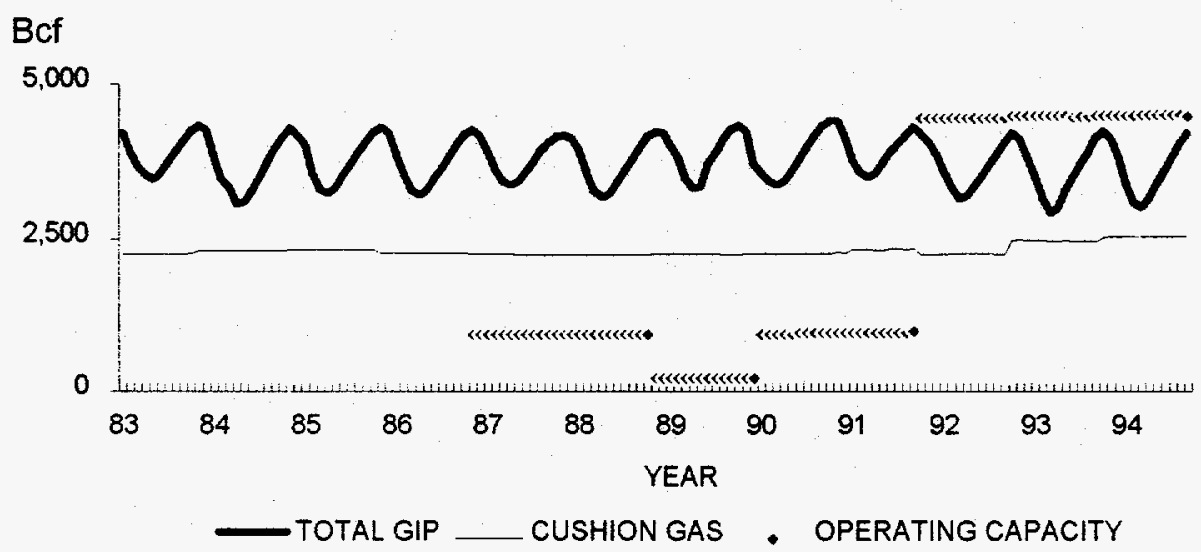

Source: Webster Gray, FERC Jurisdictional Underground Storage Fields Database

The Energy Information Administration (EIA) collects monthly individual storage field data on working and base gas volumes, total gas in storage and injections and withdrawals which they report on Form 191.

Reported monthly to the EIA, Form 191 contains confidential information on injection, withdrawal and peak day withdrawal volumes, base, working and total gas volumes on all active underground storage facilities in the United States. All companies that operate underground natural gas storage fields in the US must provide this information on a per field basis, which forms a comprehensive database for underground storage analysis.

The following companies have submitted data on this form: 
Table 8-3 Storage Operators EIA - 1994

COMPANY NAME

1 ALCAN ALUMINUM CORPORATION

2 AMERICAN GAS STORAGE CORP.

3 AMOCO GAS COMPANY

4 ANR PIPELINE CO.

5 ANR STORAGE

6 ARKANSAS WESTERN GAS COMPANY

7 BATTLE CREEK GAS COMPANY

8 BLUE LAKE GAS STORAGE COMPANY

9 BRIDGELINE GAS DIST. COMPANY

10 CENTANA.INTRASTATE PIPELINE CO

11 CENTRAL ILLINOIS LIGHT COMPANY

12 CENTRAL ILLINOIS PUBLIC SVC. C

13 CITIZENS GAS \& COKE UTILITY

14 CITY OF BRADY

15 CNG TRANSMISSION CORP.

16 COLORADO INTERSTATE GAS COMPAN

17 COLUMBIA GAS OF PA.

18 COLUMBIA GAS TRANSMISSION

19 CONSUMERS POWER COMPANY

20 CRANBERRY PIPELINE CORP

21 DELHI GAS PIPELINE CORP.

22 DELTA NATURAL GAS COMPANY

23 DOW CHEMICAL COMPANY

24 DOW PIPELINE COMPANY

25 EAST OHIO GAS COMPANY

26 EATON RAPIDS GAS STORAGE SYS.

27 EGYPTIAN GAS STORAGE CORP

28 EL PASO NATURAL GAS COMPANY

29 ELIZABETHTOWN NATURAL GAS

30 ENRON STORAGE COMPANY

31 EQUITRANS

32 EXXON COMPANY

33 GAS COMPANY OF NEW MEXICO

34 GASCO INC.

35 HAMPSHIRE GAS COMPANY

36 HATTIESBURG GAS STORAGE CO

37 HONEOYE STORAGE CORPORATION

38 HOUSTON PIPE LINE COMPANY

39 HUNTINGBURG MUNICIPAL GAS UTIL

40 ILLINOIS POWER COMPANY

41 INDIANA GAS COMPANY

$42 \mathrm{KN}$ INTERSTATE GAS TRANS

43 KOCH GATEWAY PIPELINE CO.

44 LACLEDE GAS COMPANY

45 LAWRENCEBURG GAS CO.

46 LLANO

47 LONE STAR GAS COMPANY

48 LOUISVILLE GAS \& ELECTRIC CO.

49 MERIDIAN OIL STORAGE INC.

50 MICHIGAN CONSOLIDATED GAS CO.

51 MICHIGAN GAS STORAGE COMPANY

52 MICHIGAN GAS UTILITIES

53 MIDWEST GAS STORAGE

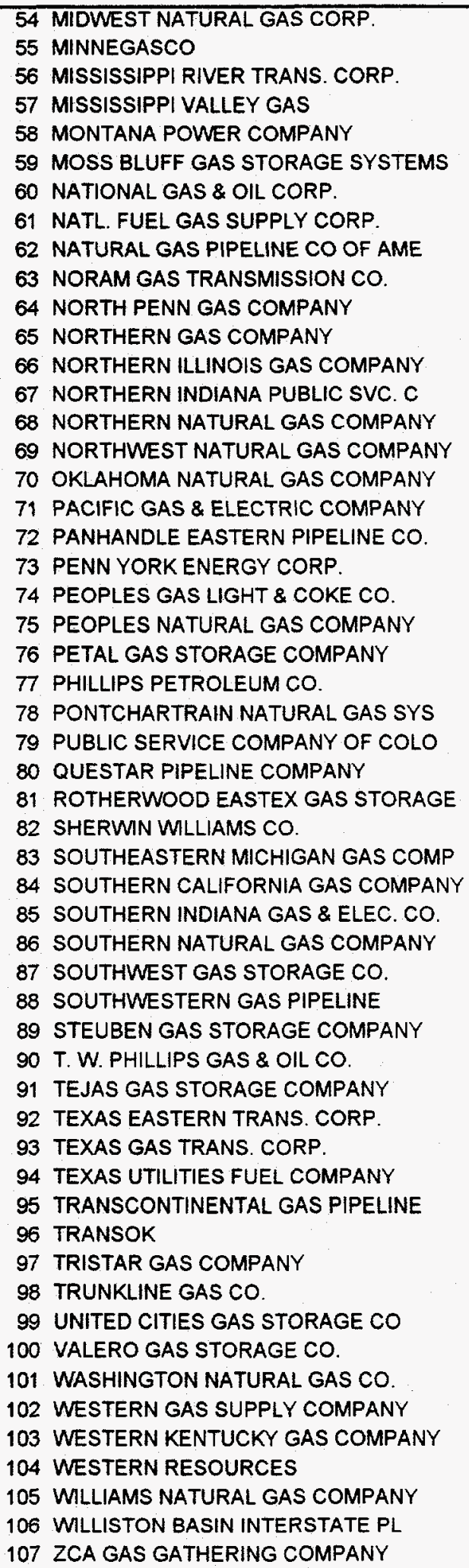

from EIA Form 191 


\subsubsection{AGA}

The AGA Operating Section Report-Survey of Underground Gas Storage Facilities in the United States and Canada contains individual storage field summaries, including the company, reservoir name, formation, type of trap, reservoir characteristics, base and working gas, and field specifications as indicated by the example below. Monthly volumes per field are not available. Cumulative and averages for a total of 425 reservoirs listed in the AGA report are summarized below:

Table 8-4: AGA Data Base for Storage Reservoirs

\begin{tabular}{|c|c|c|c|c|c|c|c|c|}
\hline & DESCRIPTION & AVG. & & DESCRIPTION & $\begin{array}{l}\text { TOTAL } \\
\text { AVG. }\end{array}$ & & DESCRIPTION & TOTAL \\
\hline 1 & COMP. NO. & & 16 & PRESS PSIA & 1,063 & 30 & NATIVE WORK & 33,977 \\
\hline 2 & RES.NO. & & 17 & ACRE LIMITS & $1,212,717$ & 31 & INJCTD WORK & $2,643,400$ \\
\hline 3 & RESERVOIR NAME & & 18 & ACRE TOTAL & $3,494,572$ & 32 & TOTAL WORK & $2,670,593$ \\
\hline 4 & ACTIVE & & 19 & INPUT WELLS & 15,218 & 33 & GRAND TOTAL & $7,238,213$ \\
\hline 5 & COUNTY & & 20 & PROB WELLS & 3,479 & 34 & UFVOL & $1,394,219$ \\
\hline 6 & DATE DISC. & & 21 & TOTAL WELLS & 18,485 & 35 & MAX VOL. & $17,115,668$ \\
\hline 7 & DATE ACTIVE. & & 22 & CPSTATIONS NO & & 36 & MAX DATE & \\
\hline 8 & RTYPE & & 23 & HORSEPOWER & $2,549,062$ & 37 & FUTURE BASE & 100,927 \\
\hline 9 & NAME FORMATION & & 24 & PIPESIZMAX IN. & & 38 & FUTURE WORK & 524,858 \\
\hline 10 & AGE & & 25 & PIPESIZMIN IN. & & 39 & FUTURE TOTAL & 749,080 \\
\hline 11 & CONTENTS & & 26 & RES. MSCF & $5,324,819$ & 40 & CAP. MCF & $8,916,835$ \\
\hline 12. & SD H-ft. & 69.71 & 27 & NATIVE BASE-MCF & $1,278,094$ & 41 & MAX DELIVER & $58,064,039$ \\
\hline 13 & TYPE TRAP & & 28 & INJCTD BASE & $2,914,047$ & 42 & MAX PRESS & \\
\hline 14 & MAX DEPTH & 2,778 & 29 & TOTAL BASE & $4,567,620$ & 43 & STATE & \\
\hline 15 & MIN. DEPTH & 2,329 & & & & & & \\
\hline
\end{tabular}

Source: AGA "Survey of Underground Gas Storage Facilities in the United States and Canada", 1992 Database

The types of storage fields were determined from reservoir characteristics in order to perform a comparison assessment of gas migration mechanisms. AGA's database was used to determine gas storage demographics. The operators, geologic reservoir types, and basic field parameters such as certified capacity was identified for each of the reported storage fields in the United States.

\subsection{RESERVOIR MODELING}

A three dimensional reservoir simulator was used to study gas migration mechanisms during operation of storage fields. A model was constructed which contained about 55 BCF of gas and had 5 injections and withdrawal wells. Original reservoir pressure was 1200 psia. The field was operated on 180 day cycles over a ten year period. This base model was modified by the inclusion of a very low permeability boundary $(0.001 \mathrm{md})$, which would simulate a stratigraphic trap juxtaposed to a very low permeability formation. A thief zone was included by the use of a well completed in the very low permeability zone. Gas migration effects were studied. Mitigation strategies were then developed to reduce gas migration from thief zones. Drilling horizontal wellbores and sensitivity to horizontal wellbore length were modeled.

\section{RESULTS}

\subsection{TYPES OF STORAGE}

Storage reservoirs can be classified by several parameters. Common classification schemes include drive mechanism, type of geologic trap, lithology, permeability and initial fluid content. In working with available databases and reports, an attempt was made to determine the common parameters addressed in each of the databases. Three types of underground storage recognized by the FERC, EIA, GRI and AGA are:

1) depleted reservoir, 
2) aquifer, and

3) cavern or mine.

The figure below shows the total gas volume in US storage reservoirs in each of these classifications. The number of reservoirs in each classification is indicated in parentheses:

Figure 9-1: Types of Storage by Reservoir Volume

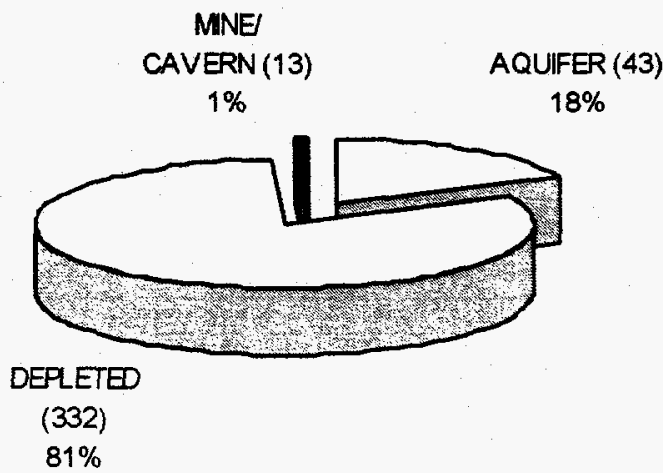

Source: AGA "Survey of Underground Gas Storage Facilities in the United States and Canada", 1992 Database

Depleted reservoirs are the only type of storage field found in the Northeast. Aquifers are most common in the Midwest, while most salt caverns are found along the Gulf Coast. Half of the salt caverns are located in Texas. The one storage reservoir in an abandoned coal mine is located in Colorado. Of the volume of gas in storage, $1 \%$ is located in salt caverns which encompass $3 \%$ of the reservoirs, $18 \%$ of the volume is located in aquifers which encompass $11 \%$ of the reservoirs and $81 \%$ of the gas volume is in depleted reservoirs which encompass $86 \%$ of the gas storage reservoirs. The following pie chart shows the percentages of each type of reservoir in the United States. 
Figure 9-2: Types of Underground Storage by Number of Reservoirs

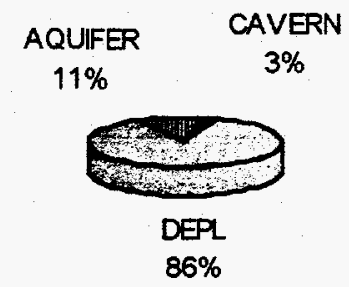

Source: AGA "Survey of Underground Gas Storage Facilities in the United States and Canada", 1992 Database

Figure 9-3: Location of Storage Fields in the US

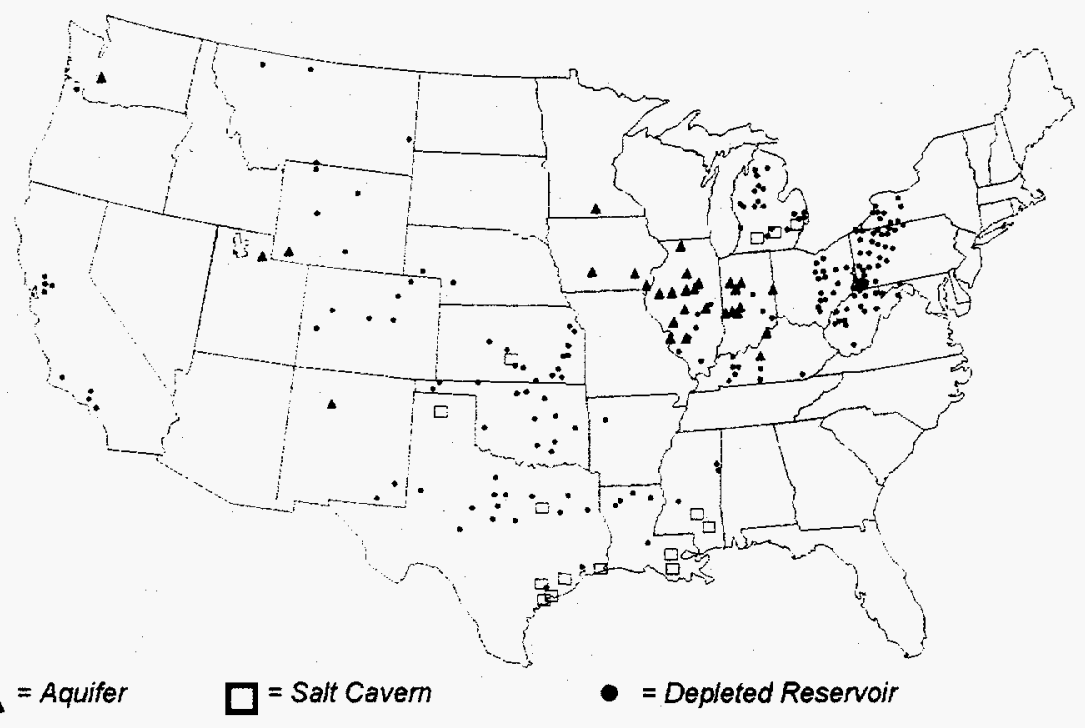

\subsubsection{Classification Parameters}

The 3 storage classifications above are defined, in part, by drive mechanism, type of geologic trap, lithology, and initial fluid content. (Permeability is another important parameter which strongly influences well deliverability, however, the value of field permeability is often uncertain or unknown). The initial fluid content is addressed in the main classifications of depleted reservoir and aquifer. The remaining secondary classification parameters are:

- Type of Geologic Trap

- Lithology

- Drive Mechanism

Geologic trap type defines the mechanism by which the gas is contained in the reservoir and kept from migrating or escaping from the storage zone. Several types of geologic traps are recognized in the table below. 
Table 9-5: Types of Geologic Traps

STRUCTURAL

faulted structural

faulted anticline

structural lens

anticline

dome

domal anticline

anticlinal dome

closed anticline

elongated anticline

plunging anticline

truncated anticline
STRATIGRAPHIC

sand lens

terrace lens

porosity lens

permeability trap

permeability pinch-out

stratigraphic draping

bioherm

reef

pinnacle reef
COMBINATION STRAT/STRUCT

faulted stratigraphic

reef-anticline

anticlinal pinch-out
SALT

salt intrusion

salt caverns

after GRI topical report, "State-of-Technology assessment and Evaluation of Gas Storage Well Productivity and Enhancement Techniques, December, 1993, p.9

Although a variety of geological terms are used by the operators, these terms fall into four basic trap types:

\section{1.stratigraphic \\ 2.structural \\ 3.combination of stratigraphic/structural \\ 4.salt cavern (man-made)}

Lithology is another important and easily determined categorization parameter. All known underground gas storage reservoirs consist of porous formations of sandstones, or carbonates, are salt dome associated. ${ }^{17}$

Drive mechanism can usually be described as one of two readily determinable states: water drive or pressure drive. Drive mechanism has an important effect on the productivity of a well. ${ }^{18}$ All of the caverns and most (around $85 \%$ ) of the depleted reservoirs are classified as pressure drive. Pressure drive has also been referred to as pressure depletion or volumetric expansion. Water drive constitutes the drive mechanism in the remaining $15 \%$ of depleted reservoirs. All aquifers have water drive mechanisms, since the term aquifer refers to a water-bearing zone. Thus, the initial fluid content of all aquifers is water. The following block diagram summarizes these relationships:

\footnotetext{
${ }^{17}$ Young, F.S., and Deskins, G., "State-of-Technology Assessment and Evaluation of Gas Storage Well
} Productivity Enhancement Techniques". Topical Report \#1, GRI-93/0001, Gas Research Institute, Chicago, IL, December, 1993, p. 9.

$$
{ }^{18} \text { Ibid. }
$$


Figure 9-4 Block Diagram of Reservoir Parameters

\section{OARBonate}

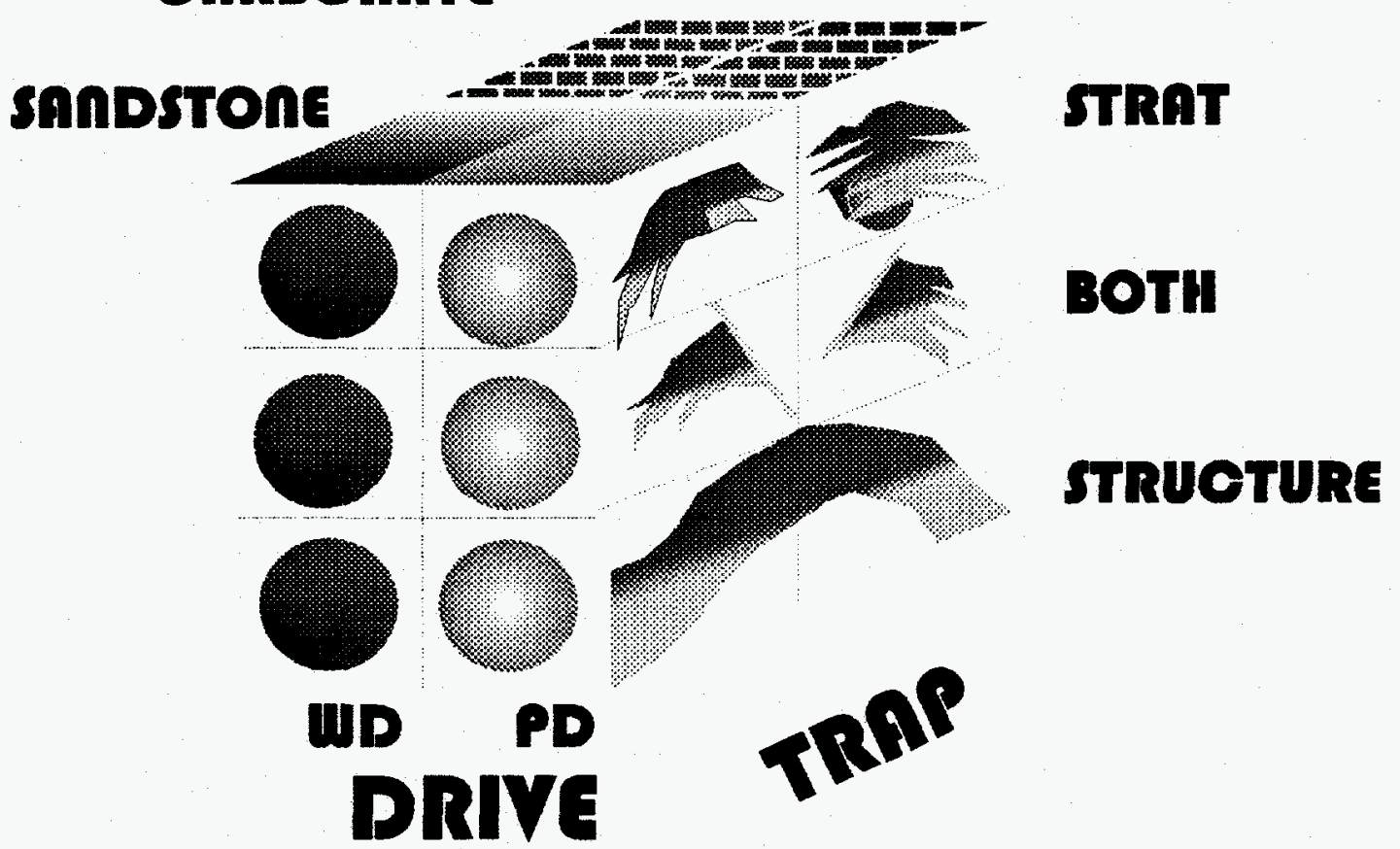

after GRI topical report, "State-of-Technology Assessment and Evaluation of Gas Storage Well Productivity Enhancement Techniques", December, 1993, p. 10

\subsubsection{Depleted Reservoirs}

The majority of existing gas storage in the United States is held in depleted natural gas or oil fields located close to consumption centers, most of which are located in the Northeast and Midwest. Conversion of a field from production to storage duty takes advantage of existing wells, gathering systems, and pipeline connections. The geology and producing characteristics of a depleted field is also well known. However, choices of storage field location and performance are limited by the inventory of depleted fields in any region. ${ }^{19}$

Depleted oil and gas fields are the most prevalent storage medium. Structural fields have created a hydrocarbon containment through mechanical deformation, whether by the folding or faulting of rock formations. Stratigraphic fields create containment by material changes in successive layers. Reef fields have been created within preserved coral reefs from ancient seas. The cushion gas requirement for a depleted field generally averages around $50 \%$. The cost for depleted reservoir storage is relatively low, with development costs ranging from $\$ 2.00$ to $\$ 3.50 / \mathrm{Mcf}$ and annual single cycle user costs ranging from $\$ 0.20$ to $\$ 1.50 / \mathrm{Mcf}$, depending on the facility's age. ${ }^{20}$

In the Northeastern US, a majority of these depleted reservoirs are channel, bar or blanket sands formed in fluvial-deltaic environments along shallow Paleozoic seas. Hydrocarbon traps

${ }^{19}$ Energy Information Administration, The Value of Underground Storage in Today's Natural Gas Industry, p. 46.

Beckman, K.L., Determeyer, P.L., Mowrey, E.H. (International Gas Consulting, Inc.), “Natural Gas Storage: Historical Development and Expected Evolution", GRI-95/0214, Gas Research Institute, Transmission \& Storage Group, June 1995, p.5. 
are stratigraphic or structural. Often reservoirs exhibit a combination of structural and stratigraphic factors in their formation, creating a complex fluid movement and cementation history (known as diagenesis) which affects the current properties of the reservoir.

Gas migration in depleted stratigraphic storage reservoirs could occur in the injection phase, where gas may be pushed out into the less permeable portions of the reservoir where it then becomes trapped.

Gas may also migrate through unknown faults or fracture systems. This migration occurs most frequently during injection in older fields (which may have been put into storage service before modern logging techniques to better delineate the field limits were available) and in structurally complex areas.

\subsubsection{Aquifers}

In some areas, most notably the Midwestern United States, natural aquifers have been converted to gas storage reservoirs. An aquifer is suitable for gas storage if the water-bearing sedimentary rock formation is overlaid with an impermeable cap rock. While the geology of aquifer is similar to depleted production fields, their use in gas storage usually requires more base (cushion) gas and greater monitoring of withdrawal and injection performance. Deliverability rates may be enhanced by the presence of an active water drive. ${ }^{21}$

Aquifers are porous and permeable water-bearing rock formation offering either structural or stratigraphic trapping mechanisms. Aquifer storage is the second most prevalent type of storage, with some very large fields located in the upper midwestern US. Their primary drawback for use as a natural gas storage facility is the cushion gas requirement, mentioned above, which can be as high as $80 \%$ of the total gas volume. In addition, long development times, typically about 5 years, are generally required in order to test and characterize the trap for suitability for storage. Aquifer storage is typically slightly more expensive than depleted reservoir storage to develop and use, due to the higher base gas and operating cost requirements. Development costs range from $\$ 2.00$ to $\$ 4.00 / \mathrm{Mcf}$, and user costs range from $\$ 0.60$ to $\$ 1.75 /$ year on a single cycle basis. ${ }^{22}$

Gas migration occurs when there is incomplete structural closure, or during overpressuring of the reservoir, both of which allow the gas to escape through a structurally lower "saddle" into another structurally high portion of the formation. Overpressuring may also cause gas to migrate through the seal, or caprock. This is a common migration mechanism in aquifers, where the gas has to be injected at a higher pressure than the formation pressure. These migration mechanisms are also factors to be considered in depleted reservoirs where structure is the trapping mechanism, as well.

\subsubsection{Salt Caverns}

Caverns are mined or leached hollow spaces underground, and include salt, either in bedded salt formations or in salt domes, or mechanically competent rock caverns, including one former coal mine. Caverns are excellent for cycling applications since they operate as pressure vessels. Cushion gas requirements are generally lowest for these facilities, averaging about $33 \%$ of the total gas volume. In addition, the physical development time for these facilities is typically one to two years. The primary disadvantage is the higher cost, both for development $(\$ 7.00$ to $\$ 14.00 / \mathrm{Mcf})$ and to use $(\$ 0.80$ to $\$ 4.50 / \mathrm{Mcf}$ on a single cycle basis). Higher user costs can be

\footnotetext{
${ }^{21}$ Ibid.

22 Beckman, K.L., Determeyer, P.L., Mowrey, E.H. (international Gas Consulting, Inc.), "Natural Gas Storage: Historical Development and Expected Evolution", GRI-95/0214, Gas Research Institute. Transmission \& Storage Group, June 1995, p.6.
} 
mitigated by using the cavern's flexibility for multiple cycles, resulting in cycle costs as low as $\$ 0.20 /$ Mcf. $^{23}$

Salt caverns, the third main type of storage, provide very high withdrawal and injection rates compared with their working gas capacity. Base gas requirements are relatively low. The large majority of salt cavern storage facilities have been developed in salt dome formation located in the Gulf Coast states. Salt caverns leached from bedded salt formation in Northeastern, Midwestern, and Western states are also being developed to take advantage of the high volume and flexible operations possible with a cavern facility. Cavern construction is more costly than depleted field conversions when measured on the basis of dollars per thousand cubic feet of working gas, but the ability to perform several withdrawals and injection cycles each year reduces the per-unit cost of each thousand cubic foot of gas injected and withdrawn. ${ }^{24}$

Storage facilities may be classified as seasonal supply reservoirs (depleted gas/oil fields and aquifers for the most part) and high-deliverability sites (mostly salt cavern reservoirs). Compared to seasonal storage, high-deliverability sites can be drawn down in $\mathbf{2 0}$ days or less and refilled in 40 days $^{\text {or less. }}{ }^{25}$

Figure 9-5: Working and Base Gas Volumes per Reservoir Type

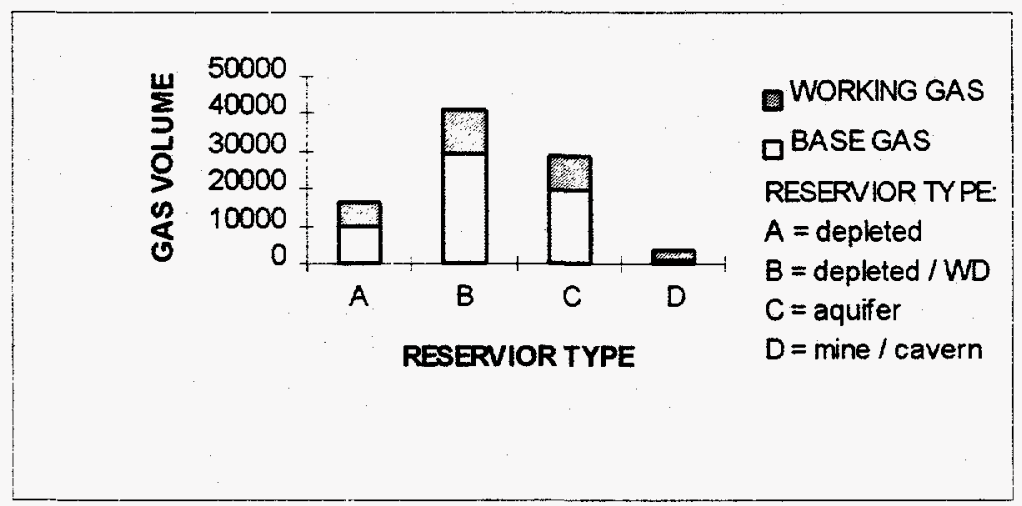

Source: AGA "Survey of Underground Gas Storage Facilities in the United States and Canada", 1992 Database

Although salt caverns account for the smallest number of reservoirs and lowest gas volume they have the highest percentage of working gas relative to the total gas-in-place.

${ }^{23}$ Beckman, K.L., Determeyer, P.L., Mowrey, E.H. (International Gas Consulting, Inc.), “Natural Gas Storage: Historical Development and Expected Evolution", GRI-95/0214, Gas Research Institute. Transmission \& Storage Group. June 1995, p.5.

$$
\begin{aligned}
& { }^{24} \text { Ibid. } \\
& { }^{25} \text { Ibid, p. 46-47 }
\end{aligned}
$$


Figure 9-6: Ratio of Working to Base Gas per Reservoir Type+++++++ ?+++++++++ ÿÿ:öp

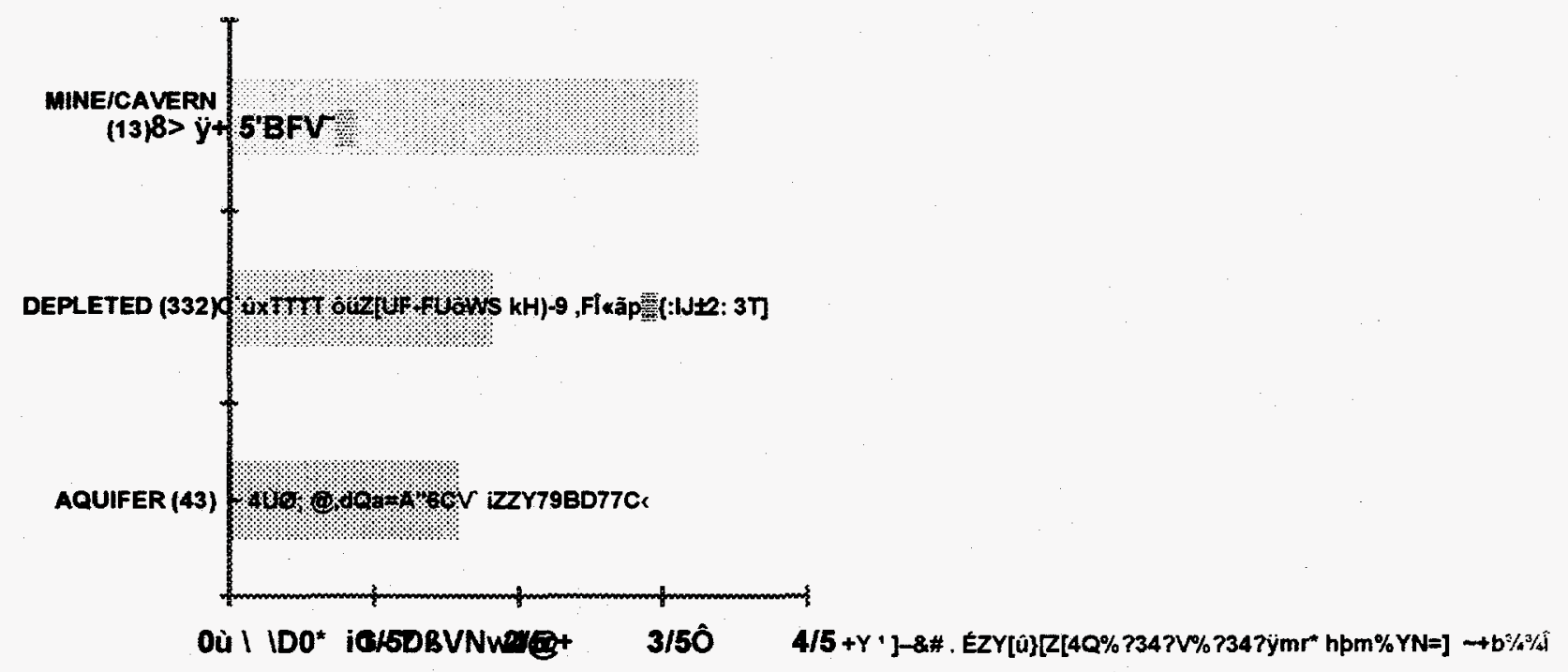

Source: AGA "Survey of Underground Gas Storage Facilities in the United States and Canada", 1992 Database

Salt caverns also have the highest volume per well, while the depleted reservoirs have the lowest. Consequently, storage in depleted fields requires more wells per reservoir, on average. 


\section{Rattionututing}

Figure 9-7: Reservoir Type vs. MCF / Well

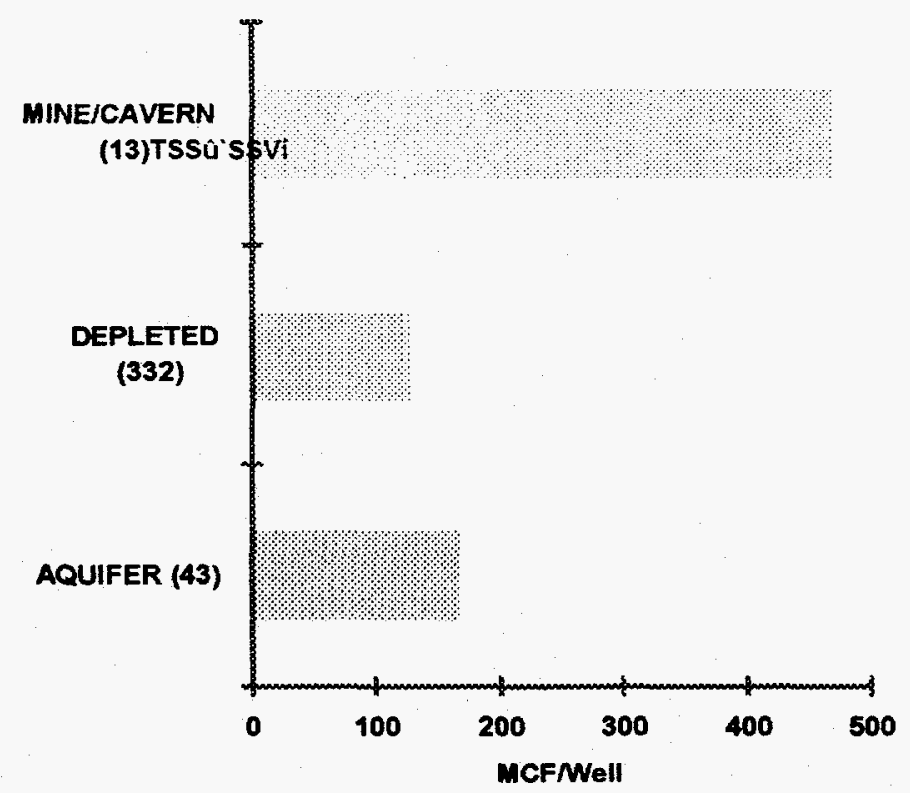

Source: AGA "Survey of Underground Gas Storage Facilities in the United States and Canada", 1992 Database 


\subsection{GAS MIGRATION MECHANISMS}

Gas in underground storage reservoirs can migrate from the storage horizon due to an incomplete geologic trap in the reservoir or caprock, or can be unaccounted for through mechanical imperfection, such as, an accidental blowout, pipeline leaks caused by corrosion, and corrosion leaks in the wells. Migration or seepage subject to direct detection in well heads, gathering systems, compressor plants and pipelines are usually minor and repairable or writtenoff. Unmetered migration of gas from underground storage occurs in two distinct areas:

-Around the wellbores

-In the reservoir away from the wellbores ${ }^{26}$

The following table summarizes three major causes for this unmetered migration of inventory:

Table 9-6: Causes and Areas for Unmetered Migration of Inventory

WELLHEADS

Christmas Tree

Gathering System

Surface Equipment

Compressor

Pipeline
WELLBORES

Casing Collars (mechanical)

Corrosion (internal and/or external)

Cement Bond

Leaks

Blowouts
RESERVOIRS

Fractures

Faults

Areas of Minimum Structural Closure

Caprock Thresholds

Down Structure

Gas Fingering (in aquifers)

Areas of Lower Permeability

(after Tek, M.R., Underground Storage of Natural Gas, Guff Publishing Co., Houston, TX, 1987, p. 203.)

Use of tracers can be helpful in determining the leak path, whether from the wellbores or across the caprock. Recently, isotope chemistry has been helpful in identifying storage gas which has migrated away. Computer oriented techniques related to history match studies can also be used to identify leaks from storage. ${ }^{27}$

\subsubsection{Leaks From Wellbores}

If the leak is occurring through one or more wellbores, one or more corrosion pinholes, or imperfect casing collar joints, the nature of fiow is from a void space (inside wellbore exposed to storage pressure) through an orifice-like passage to a low-pressure porous environment. The flow is compressible. The pressure upstream is nearly equal to the storage pressure. The pressure downstream depends upon the depth and the local subsurface brine gradient. In most circumstances of wellbore leak, the ratio of downstream pressure to upstream pressure is equal to or less than the critical pressure ratio for storage gas. Under these conditions, the rate of leak can be modeled and calculated from the critical flow equation, which leads to an inventorypressure relationship. ${ }^{28}$

It is easier to detect, control and repair leaks from wellbores. Several loggings and surveying techniques are available and are effectively used in correcting wellbore problems. These include temperature survey, noise logs, pressure testing of casing and tubing, cement bond surveys, corrosion logs, caliper surveys, and downhole photography. Remedial means involve cementing liners, recompletion, corrosion control, and general equipment overhaul. ${ }^{29}$

\footnotetext{
${ }^{26}$ Tek, M.R., Underground Storage of Natural Gas, Vol 3, Contributions in Petroleum Geology and Engineering Series, Gulf Publishing Co., Houston, TX, 1987. p. 203.

27 Ibid., p. 204.

${ }^{28}$ Ibid., p. 206-207.

${ }^{29}$ Ibid., p. 204
} 


\subsubsection{Gas Migration from the Reservoir}

Reservoir gas migration, on the other hand, is more difficult to detect and control. They may be due to wellbore-induced or incipient fractures, faults, saddles, caprock imperfections, diffusion, dissolution, and uncontrolled fingering. If the storage reservoir is leaking at a location away from the wellbore, the uncontrolled movement and escape of gas may be across the threshold of the caprock or laterally across the reservoir limits. In either case, the flow of gas is from porous media to porous media. $^{30}$

Remedial measures involve pressure control, locating collector zones, recycling and monitoring. There have been just a few cases where the only remedy left was abandonment of the project for reason of safety and economy. ${ }^{31}$

The operation of an underground gas storage reservoir is distinguished from that of a gas field by the alternating displacement of fluids with a much higher flow rate. Displacement efficiency during each gas injection or withdrawal phase is history dependent and linked to the fluid distribution at the end of the previous injection-withdrawal cycle. Using 2D glass micromodels, it can be observed experimentally that wetting films located in the corners of throat section conduct flow. Wetting film flow ger rerates gas loop structure which increases injection efficiency and also the amount of trapped gas during withdrawal. During the next injection, blob distribution and wetting film flow induce a quicker breakthrough. Using a network simulator which takes into account wetting film flow, the influence of flow-rate on cycling is highlighted. ${ }^{32}$

\subsection{UNACCOUNTED FOR GAS ESTIMATE}

\section{1.) ElA total data}

Initially public EIA was obtained via internet. These numbers are presented and described below. The EIA reports end of year (EOY) and beginning of year (BOY) GIP volumes (see Table No. 11-4 ). The amount of GIP can be calculated by the following:

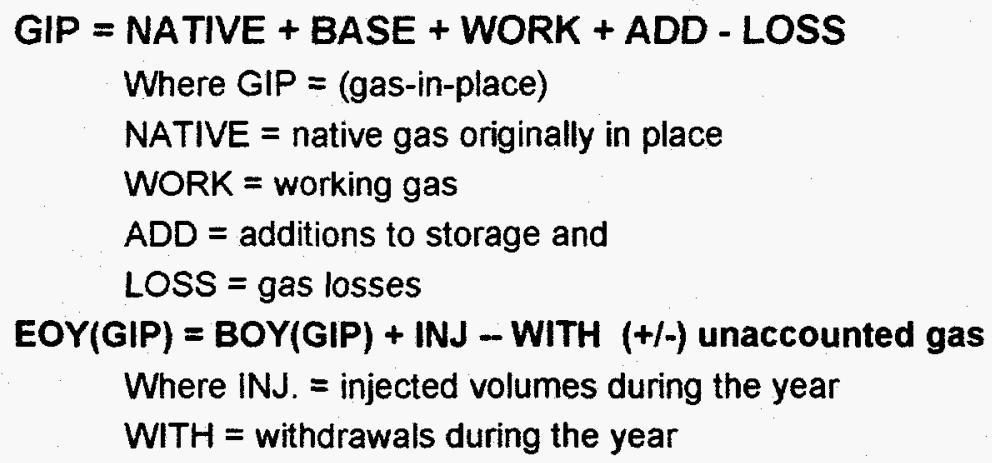

32 Billiotte, J., DeMoegen, H., and Oren, P.E., "Experimental Micro-modeling and Numerical Simulation of Gas/Water Injection/Withdrawal Cycles as Applied to Underground Gas Storage Reservoir", SPE Advanced Technology Series, Vol. 1. No. 1, Society of Petroleum Engineers, Richardson, TX, 1993, p. 133-139. 
Table 9-7 Unaccounted for Gas TCF

\begin{tabular}{ccccccc} 
(TCF) & $\begin{array}{c}\text { EOY GIP }= \\
\text { EOY GIP }-\end{array}$ & $\begin{array}{c}\text { BOY GIP }+ \\
\text { BOY GIP }-\end{array}$ & $\begin{array}{c}\text { INJ }- \\
\text { INJ }\end{array}$ & $\begin{array}{c}\text { WITH } \\
+ \text { WITH }\end{array}$ & $\begin{array}{c}\text { Unaccounted for Gas } \\
+ \text { ADD }\end{array}$ & $\begin{array}{c}- \text { LOSD } \\
\text { LOSS }\end{array}$ \\
\cline { 2 - 7 } 1988 & 6.7 & - & 2.17 & 2.24 & & $(0.01)$ \\
1989 & 6.3 & 6.7 & 2.49 & 2.80 & & 0.11 \\
1990 & 6.9 & 6.3 & 2.43 & 1.93 & & $(0.08)$ \\
1991 & 6.8 & 6.9 & 2.61 & 2.69 & & 0.03 \\
1992 & 6.6 & 6.8 & 2.56 & 2.72 & & $(0.03)$ \\
1993 & 6.6 & 6.6 & 2.76 & 2.72 & & 0.00 \\
1994 & 7.0 & 6.6 & 2.72 & 2.41 & & $0.02^{33}$
\end{tabular}

Source: Energy Information Administration, Natural Gas Monthly, Table 13.

Approximately $20 \mathrm{BCF}$ of gas are unaccounted for over the 1988 to 1994 time period based on Table No.9-2. However, during any one year storage fields are added, abandoned, base levels are revised to reflect operating conditions. Theoretically, this table should yield a total of zero, but due to data reporting inconsistencies a value of 0.020 TCF was obtained.

The data used in this study was transmitted by the EIA (F-191 data) was initially compared with other EIA published data. This is shown on the following Table No.6-3. There is about a $1 \%$ or less difference in the data received and previously EIA published data.

Table 9-8 Data Comparison EIA Public vs. F-191 data (TCF)

\begin{tabular}{cccc}
\hline EIA Public & EOY GIP & INJ & + WITH \\
\hline 1988 & 6.65 & 2.17 & 2.24 \\
1989 & 6.325 & 2.49 & 2.80 \\
1990 & 6.936 & 2.43 & 1.93 \\
1991 & 6.778 & 2.61 & 2.69 \\
1992 & 6.641 & 2.56 & 2.72 \\
1993 & 6.649 & 2.76 & 2.72 \\
1994 & 6.961 & 2.72 & 2.41 \\
\hline F-191 Data & & & \\
1991 & 6.69 & 2.56 & 2.64 \\
1992 & 6.56 & 2.50 & 2.67 \\
1993 & 6.56 & 2.70 & 2.65 \\
1994 & 6.87 & 2.68 & 2.37 \\
\hline
\end{tabular}

Table No.9-9, two pages ahead, is an example (A) of the monthly data reported for a depleted reservoir. Column 4 is the reported actual total gas, Column 7 is the calculated monthly total and Column 8 is another calculated total volume on a running total basis. Column 7 and 8 are the same for the first month, but Column 8 is simply the net of injection and withdrawal (Column 5 and 6 ) on an ongoing basis. In this example the monthly difference Column 10 (Column 5 and 7 ) is very small, while the running total (Column 8 ) percentage difference Column 9 is very different. Column 9 increases with time, however if one used the most current total gas (Dec., 1994) and calculated backwards, the difference would increase with time. The figure on the following page, illustrates this difference for all storage fields reporting on Form 191.

\footnotetext{
${ }^{33}$ Note: These are revised from Baton Rouge, LA contractors meeting, April 46, 1995
} 
Figure 9-8: Percent Difference vs. Reported Total Gas

Percent Difference Calculated vs Reported Total Gas

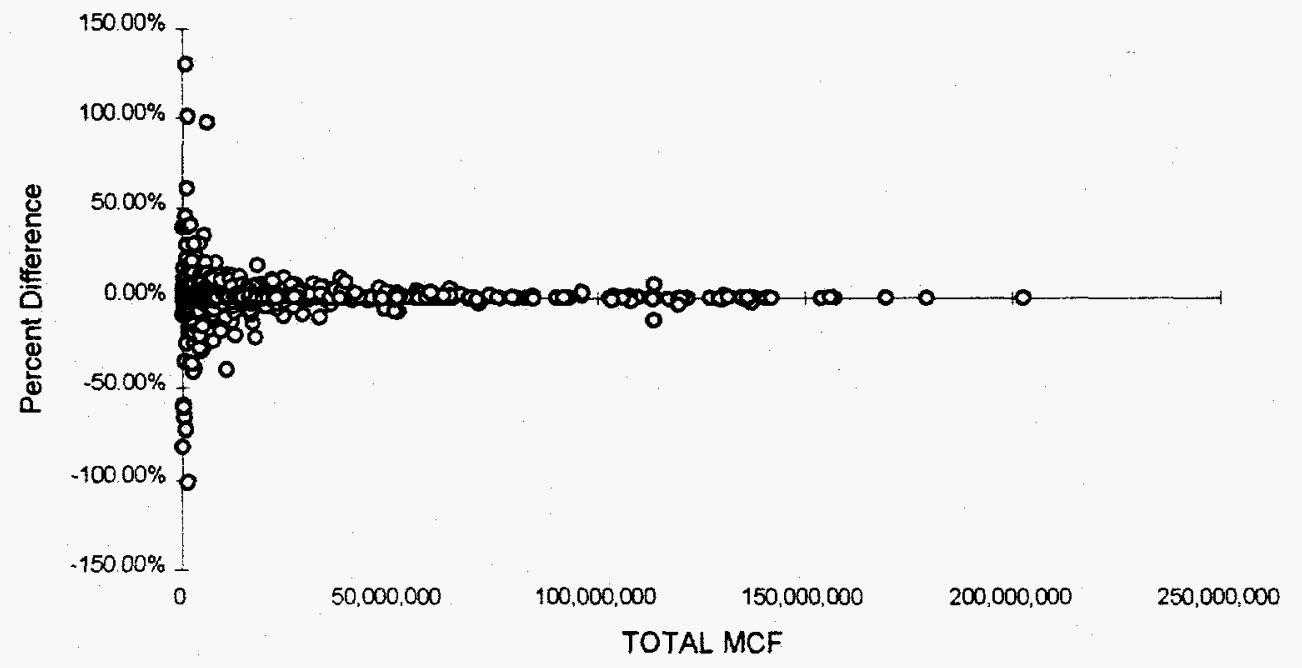


Table 9-9 ElA Monthly Data Example A

\begin{tabular}{|c|c|c|c|c|c|c|c|c|c|}
\hline 1. & $\begin{array}{l}2 . \\
\text { BASE }\end{array}$ & $\begin{array}{l}3 . \\
\text { WORK }\end{array}$ & $\begin{array}{l}4 . \\
\text { TOTAL }\end{array}$ & 5. & $\begin{array}{l}6 . \\
\text { WITH }\end{array}$ & $\begin{array}{l}7 . \\
\text { TOTAL (A) }\end{array}$ & $\begin{array}{l}8 . \\
\text { TOTAL (B) }\end{array}$ & $\begin{array}{l}9 . \\
\%(B)\end{array}$ & $\begin{array}{l}10 . \\
\%(A)\end{array}$ \\
\hline Jan-91 & $3,190,357$ & 798,771 & $3,989,128$ & - & $1,024,346$ & & & & \\
\hline Feb-91 & $3,262,757$ & 519,603 & $3,782,360$ & 125,352 & 330,838 & $3,783,642$ & $3.783,642$ & $-0.03 \%$ & $-0.03 \%$ \\
\hline Mar-91 & $3,262,757$ & 353,564 & $3,616,321$ & 246,553 & 410,408 & $3,618,505$ & $3,619,787$ & $-0.10 \%$ & $-0.06 \%$ \\
\hline Apr-91 & $3,262,757$ & 249,650 & $3,512,407$ & 248,231 & 444,273 & $3,420,279$ & $3,423,745$ & $2.52 \%$ & $2.62 \%$ \\
\hline May-91 & $3,262,757$ & 427,967 & $3,690,724$ & 156,682 & 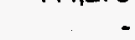 & $3,669,089$ & $3,580,427$ & $2.99 \%$ & $0.59 \%$ \\
\hline Jun-91 & $3,262,757$ & 679,472 & $3,942,229$ & 262,875 & - & $3,953,599$ & $3,843,302$ & $2.51 \%$ & $-0.29 \%$ \\
\hline Jul-91 & $3,262,757$ & 754,738 & $4,017,495$ & 86,540 & - & $4,028,769$ & $3,929,842$ & $2.18 \%$ & $-0.28 \%$ \\
\hline Aug-91 & $3,262,757$ & $1,572,738$ & $4,835,495$ & 836,556 & 10,315 & $4,843,736$ & $4,756,083$ & $1.64 \%$ & $-0.17 \%$ \\
\hline Sep-91 & $3,262,757$ & $2,765,517$ & $6,028,274$ & $1,214,825$ & 23,272 & $6,027,048$ & $5,947,636$ & $1.34 \%$ & $0.02 \%$ \\
\hline Oct-91 & $3,262.757$ & 2813.246 & $6.076,003$ & 518.774 & 461,685 & $6,085,363$ & $6,004,725$ & $1.17 \%$ & $-0.15 \%$ \\
\hline Nov-91 & $3,262,757$ & $3,032,906$ & $6,295,663$ & 465,789 & 302,584 & $6,239,208$ & $6,167,930$ & $2.03 \%$ & $0.90 \%$ \\
\hline Dec-91 & $3,262,757$ & $2,757,684$ & $6,020,441$ & $4 \frac{109,818}{271,995}$ & $\frac{931,754}{3,939,475}$ & $5,473,727$ & $5,345,994$ & $11.20 \%$ & $9.08 \%$ \\
\hline Jan-92 & $3,262,757$ & $2,004,960$ & $5,267,717$ & 12,712 & 760,275 & $5,272,878$ & $4,598,431$ & $12.71 \%$ & $-0.10 \%$ \\
\hline Feb-92 & $3,262,757$ & 1,236777 & $4,499,534$ & 4,244 & 777,531 & $4,494,430$ & 25,144 & $14.99 \%$ & $0.11 \%$ \\
\hline Mar-92 & 3.262 .757 & 619.824 & $3,882,581$ & 14,049 & 632,411 & $3,881,172$ & 3.206 .782 & $17.41 \%$ & $0.04 \%$ \\
\hline Apr-92 & $3,262,757$ & 630,577 & $3,893,334$ & 359,640 & 342,561 & $3,899,660$ & $3,223,861$ & $17.20 \%$ & $-0.16 \%$ \\
\hline May-92 & $3,262,757$ & 489,032 & $3,751,789$ & 89,987 & 258,052 & $3,725,269$ & $3,055,796$ & $18.55 \%$ & $0.71 \%$ \\
\hline Jun-92 & $3,262,757$ & 215,039 & $3,477,796$ & - & 286,702 & $3,465,087$ & $2,769,094$ & $20.38 \%$ & $0.37 \%$ \\
\hline Jul-92 & $3,262,757$ & 266.506 & $3,529,263$ & 104,108 & 41,929 & $3,539,975$ & $2,831,273$ & $19.78 \%$ & $-0.30 \%$ \\
\hline Aug-92 & $3,262,757$ & 736,787 & $3,999,544$ & 477,629 & - & $4,006,892$ & $3,308,902$ & $17.27 \%$ & $-0.18 \%$ \\
\hline Sep-92 & $3,262,757$ & $2,557,715$ & $5,820,472$ & $1,877,326$ & 25,707 & $5,851,163$ & $5,160,521$ & $11.34 \%$ & $-0.53 \%$ \\
\hline Oct-92 & $3,262,757$ & $2,791,510$ & $6,054,267$ & 721,276 & 494,190 & $6,047,558$ & $5,387,607$ & $11.01 \%$ & $0.11 \%$ \\
\hline Nov-92 & $3,262,757$ & $2,692,346$ & $5,955,103$ & 49,126 & 180,739 & $5,922,654$ & $5,255,994$ & $11.74 \%$ & $0.54 \%$ \\
\hline Dec-92 & $3,262.757$ & 2.267 .760 & $5,530,517$ & 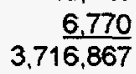 & $4 \frac{420,450}{420,547}$ & $5,541,423$ & $4,842,314$ & $12.44 \%$ & $-0.20 \%$ \\
\hline Jan-93 & $3,262,757$ & $1,334,013$ & $4,596,770$ & 2,777 & $1,132,400$ & 894 & 691 & $19.23 \%$ & $4.26 \%$ \\
\hline Feb-93 & $3,262,757$ & 173,346 & $3,436,103$ & 5,577 & $1,448,672$ & 3,1 & 96 & $33.95 \%$ & $8.22 \%$ \\
\hline Mar-93 & $3,262,757$ & 280,053 & $3,542,810$ & 533,324 & 450,730 & $3,518,697$ & 2,190 & $33.61 \%$ & $0.68 \%$ \\
\hline Apr-93 & $3,262,757$ & 681,955 & $3,944,712$ & 795,494 & 351,798 & $3,986,506$ & $2,795,886$ & $29.12 \%$ & $-1.06 \%$ \\
\hline May-93 & $3,262,757$ & $1,302,829$ & $4,565,586$ & 734,934 & 37,213 & $4,642,433$ & $3,493,607$ & $23.48 \%$ & $-1.68 \%$ \\
\hline Jun-93 & $3,262,757$ & $1,088,951$ & $4,351,708$ & - & 271,519 & $4,294,067$ & $3,222,088$ & $25.96 \%$ & $1.32 \%$ \\
\hline Jul-93 & $3,262,757$ & $1,935,428$ & $5,198,185$ & 991,072 & - & $5,342,780$ & $4,213,160$ & $18.95 \%$ & $-2.78 \%$ \\
\hline Aug-93 & $3,262,757$ & $2,090,156$ & $5,352,913$ & 226,247 & - & $5,424,432$ & $4,439,407$ & $17.07 \%$ & $-1.34 \%$ \\
\hline Sep-93 & $3,262,757$ & $2,457,837$ & $5,720,594$ & 450,288 & 5,488 & $5,797,713$ & $4,884,207$ & $14.62 \%$ & $-1.35 \%$ \\
\hline Oct-93 & $3,649,070$ & $2,404,247$ & $6,053,317$ & 736,162 & 347,069 & $6,109,687$ & $5,273,300$ & $12.89 \%$ & $-0.93 \%$ \\
\hline Nov-93 & $3,484,670$ & $2,603,561$ & $6,088,231$ & 659,960 & 640,375 & $6,072,902$ & 2.885 & $13.06 \%$ & $0.25 \%$ \\
\hline Dec-93 & $3,484,670$ & $2,293,390$ & $5,778,060$ & $5, \frac{68,962}{5,204,797}$ & $5, \frac{389,809}{075,073}$ & $\begin{array}{r}5,767,384 \\
129,724\end{array}$ & $4,972,038$ & $13.95 \%$ & $0.18 \%$ \\
\hline Jan-94 & $3,484,670$ & $1,041,056$ & $4,525,726$ & 42,147 & $1,290,939$ & 268 & 3,7 & $17.73 \%$ & $-0.08 \%$ \\
\hline Feb-94 & $3,484,670$ & 719,182 & $4,203,852$ & 180,815 & 533,706 & $4,172,835$ & $3,370,355$ & $19.83 \%$ & $0.74 \%$ \\
\hline Mar-94 & $3,484,670$ & $696 ; 921$ & $4,181,591$ & 324,016 & 347,736 & $4,180,132$ & $3,346,635$ & $19.97 \%$ & $0.03 \%$ \\
\hline Apr-94 & $3,484,670$ & 795,032 & $4,279,702$ & 115,476 & 16,504 & $4,280,563$ & $3,445,607$ & $19.49 \%$ & $-0.02 \%$ \\
\hline May-94 & $3,484,670$ & 892,889 & $4,377,559$ & 127,455 & 23,688 & $4,383,469$ & $3,549,374$ & $18.92 \%$ & $-0.14 \%$ \\
\hline Jun-94 & $3,484,670$ & 924,540 & $4,409,210$ & 30,765 & - & $4,408,324$ & $3,580,139$ & $18.80 \%$ & $0.02 \%$ \\
\hline Jul-94 & $3,484,670$ & $1,458,120$ & $4,942,790$ & 534,837 & - & $4,944,047$ & $4,114,976$ & $16.75 \%$ & $-0.03 \%$ \\
\hline Aug-94 & $3,484,670$ & $2,428,532$ & $5,913,202$ & 970,752 & - & $5,913,542$ & 5,085728 & $13.99 \%$ & $-0.01 \%$ \\
\hline Sep-94 & $3,484,670$ & $2,522,903$ & $6,007,573$ & 156,669 & 60,956 & $6,008,915$ & $5,181,441$ & $13.75 \%$ & $-0.02 \%$ \\
\hline Oct-94 & $3,484,670$ & $2,618,180$ & $6,102,850$ & 308,926 & 213,232 & $6,103,267$ & $5,277,135$ & $13.53 \%$ & $-0.01 \%$ \\
\hline Nov-94 & $3,484,670$ & $2,552,979$ & $6,037,649$ & 164,692 & 366,708 & $5,900,834$ & $5,075,119$ & $15.94 \%$ & $2.27 \%$ \\
\hline Dec-94 & $3,484,670$ & $2,359,441$ & $5,844,111$ & 169,550 & 364,841 & $5,842,358$ & $4,879,828$ & $16.50 \%$ & $0.03 \%$ \\
\hline
\end{tabular}


Table 9-10 EIA Monthly Data Example B

\begin{tabular}{|c|c|c|c|c|c|c|c|c|c|}
\hline 1. & 2. & $\begin{array}{l}3 . \\
\text { WORK }\end{array}$ & TOTAL & 5. inJ & $\begin{array}{l}6 . \\
\text { WITH }\end{array}$ & $\begin{array}{c}7 \\
\text { TOTAL (A) }\end{array}$ & $\begin{array}{c}8 . \\
\text { TOTAL (B) } \\
\end{array}$ & $\begin{array}{c}9 . \\
\%(B) \\
\end{array}$ & $\begin{array}{r}10 . \\
\%(A) \\
\end{array}$ \\
\hline Jan-91 & $4,428,000$ & $1,705,967$ & $6,133,967$ & - & 143,583 & & & & \\
\hline Feb-91 & $4,428,000$ & $1,362,085$ & $5,790,085$ & - & 339,948 & $5,794,019$ & $5,794,019$ & $-0.07 \%$ & $-0.07 \%$ \\
\hline Mar-91 & $4,428,000$ & $1,255,689$ & $5,683,689$ & - & 105,179 & $5,684,906$ & $5,688,840$ & $-0.09 \%$ & $-0.02 \%$ \\
\hline Apr-91 & $4,428,000$ & $1,346,418$ & $5,774,418$ & 96,039 & 1,806 & $5,777,922$ & $5,783,073$ & $-0.15 \%$ & $-0.06 \%$ \\
\hline May-91 & $4,428,000$ & $1,565,275$ & $5,993,275$ & 223,508 & 3,556 & $5,994,370$ & $6,003,025$ & $-0.16 \%$ & $-0.02 \%$ \\
\hline Jun-91 & $4,428,000$ & $1,699,889$ & $6,127,889$ & 135,919 & 2,286 & $6,126,908$ & $6,136,658$ & $-0.14 \%$ & $0.02 \%$ \\
\hline Jul-91 & $4,428,000$ & $1,704,214$ & $6,132,214$ & 10,020 & 170 & $6,137,739$ & $6,146,508$ & $-0.23 \%$ & $-0.09 \%$ \\
\hline Aug-91 & $4,428,000$ & $1,703,846$ & $6,131,846$ & - & 3 & $6,132,211$ & $6,146,505$ & $-0.24 \%$ & $-0.01 \%$ \\
\hline Sep-91 & $4,428,000$ & $1,810,760$ & $6,238,760$ & 109,276 & 4,073 & $6,237,049$ & $6,251,708$ & $-0.21 \%$ & $0.03 \%$ \\
\hline Oct-91 & $4,428,000$ & $1,732,784$ & $6,160,784$ & 27,655 & 102,137 & $6,164,278$ & $6,177,226$ & $-0.27 \%$ & $-0.06 \%$ \\
\hline Nov-91 & $4,428,000$ & $1,824,774$ & $6,252,774$ & 100,106 & 9,623 & $6,251,267$ & $6,267,709$ & $-0.24 \%$ & $0.02 \%$ \\
\hline Dec-91 & $4,428,000$ & $1,799,607$ & $6,227,607$ & $\frac{1,549}{704,072}$ & $\begin{array}{r}26,435 \\
738,799\end{array}$ & $6,227,888$ & $6,242,823$ & $-0.24 \%$ & $0.00 \%$ \\
\hline $\operatorname{Jan}-92$ & $4,428,000$ & $1,645,514$ & $6,073,514$ & 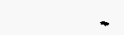 & 153,782 & 3,825 & $6,089,041$ & $-0.26 \%$ & $-0.01 \%$ \\
\hline Feb-92 & $4,428,000$ & $1,320,208$ & $5,748,208$ & - & 335,925 & 37,589 & $5,753,116$ & $-0.09 \%$ & $0.18 \%$ \\
\hline Mar-92 & $4,428,000$ & $1,117,837$ & $5,545,837$ & - & 193,176 & $5,555,032$ & $5,559,940$ & $-0.25 \%$ & $-0.17 \%$ \\
\hline Apr -92 & $4,428,000$ & $1,036,086$ & $5,464,086$ & 11,302 & 87,443 & $5,469,696$ & $5,483,799$ & $-0.36 \%$ & $-0.10 \%$ \\
\hline May-92 & $4,428,000$ & $1,278,584$ & $5,706,584$ & 243,684 & 3,357 & $5,704,413$ & $5,724,126$ & $-0.31 \%$ & $0.04 \%$ \\
\hline Jun-92 & $4,965,000$ & $1,642,592$ & $6,607,592$ & 244.707 & 4,077 & $5,947,214$ & $5,964,756$ & $9.73 \%$ & $9.99 \%$ \\
\hline Jul-92 & $4,428,000$ & $1,545,045$ & $5,973,045$ & 51,577 & 914 & $6,658,255$ & $6,015,419$ & $-0.71 \%$ & $-11.47 \%$ \\
\hline Aug-92 & $4,428,000$ & $1,705,681$ & $6,133,681$ & 162,198 & 3,007 & 32,236 & $6,174,610$ & $-0.67 \%$ & $0.02 \%$ \\
\hline Sep-92 & $4,428,000$ & $1,759,185$ & $6,187,185$ & 54,217 & 1,048 & $6,186,850$ & $6,227,779$ & $-0.66 \%$ & $0.01 \%$ \\
\hline Oct-92 & $4,428,000$ & $1,814,563$ & $6,242,563$ & 57,145 & 1,612 & $6,242,718$ & $6,283,312$ & $-0.65 \%$ & $0.00 \%$ \\
\hline Nov-92 & $4,428,000$ & $1,819,270$ & $6,247,270$ & 6,075 & 873 & $6,247,765$ & $6,288,514$ & $-0.66 \%$ & $-0.01 \%$ \\
\hline Dec-92 & $4,428,000$ & $1,785,403$ & $6,213,403$ & $830,90 \overline{\overline{5}}$ & $\frac{33,605}{818,819}$ & $6,213,665$ & $6,254,909$ & $-0.67 \%$ & $0.00 \%$ \\
\hline Jan-93 & 428,000 & $1,768,487$ & $6,196,487$ & 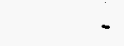 & 16,723 & 96,680 & 38.186 & $7 \%$ & $00 \%$ \\
\hline Feb-93 & $4,428,000$ & $1,377,631$ & $5,805,631$ & - & 388,704 & 07,783 & 49,482 & $6 \%$ & $-0.04 \%$ \\
\hline Mar-93 & $4,428,000$ & $1,082,899$ & $5,510,899$ & - & 286,971 & $5,518,660$ & $5,562,511$ & $-0.94 \%$ & $-0.14 \%$ \\
\hline Apr-93 & $4,428,000$ & $1,139,772$ & $5,567,772$ & 97,772 & 36,434 & $5,572,237$ & $5,623,849$ & $-1.01 \%$ & $-0.08 \%$ \\
\hline May-93 & $4,428,000$ & $1,395,402$ & $5,823,402$ & 256,743 & 3,936 & $5,820,579$ & $5,876,656$ & $-0.91 \%$ & $0.05 \%$ \\
\hline Jun-93 & $4,428,000$ & $1,526,012$ & $5,954,012$ & 138,401 & 2,408 & $5,959,395$ & $6,012,649$ & $-0.98 \%$ & $-0.09 \%$ \\
\hline Jul-93 & $4,428,000$ & $1,669,106$ & $6,097,106$ & 144,120 & 2,610 & $6,095,522$ & $6,154,159$ & $.0 .94 \%$ & $0.03 \%$ \\
\hline Aug-93 & $4,428,000$ & $1,752,516$ & $6,180,516$ & 84,070 & 1,583 & $6,179,593$ & $6,236,646$ & $-0.91 \%$ & $0.01 \%$ \\
\hline Sep-93 & $4,428,000$ & $1,750,888$ & $6,178,888$ & - & 1,620 & $6,178,896$ & $6,235,026$ & $1 \%$ & $0.00 \%$ \\
\hline Oct-93 & $4,428,000$ & $1,714,999$ & $6,142,999$ & 30,396 & 66,313 & $6,142,971$ & $6,199,109$ & $1 \%$ & $0.00 \%$ \\
\hline Nov-93 & $4,428,000$ & $1,726,634$ & $6,154,634$ & 71,836 & 47,453 & $6,167,382$ & $6,223,492$ & $-1.12 \%$ & $-0.21 \%$ \\
\hline Dec-93 & $4,428,000$ & $1,584,843$ & $6,012,843$ & 823,338 & $\frac{137,625}{992,380}$ & $\begin{array}{l}6,017,009 \\
(169,042)\end{array}$ & $6,085,867$ & $-1.21 \%$ & $-0.07 \%$ \\
\hline Jan-94 & $4,428,000$ & $1,349,328$ & $5,777,328$ & 26,248 & 260,480 & 8,611 & 635 & -1 & $-0.02 \%$ \\
\hline Feb-94 & $4,428,000$ & $1,066,574$ & $5,494,574$ & & 282,755 & $5,494,573$ & $5,568,880$ & $-1.35 \%$ & $0.00 \%$ \\
\hline Mar-94 & $4,428,000$ & 838,741 & $5,266,741$ & - & 227,832 & $5,266,742$ & $5,341,048$ & $-1.41 \%$ & $0.00 \%$ \\
\hline Apr-94 & $4,428,000$ & 941,286 & $5,369,286$ & 104,295 & 1,750 & $5,369,286$ & $5,443,593$ & $-1.38 \%$ & $0.00 \%$ \\
\hline May-94 & $4,428,000$ & $1,182,440$ & $5,610,440$ & 246,008 & 4,854 & $5,610,440$ & $5,684,747$ & $-1.32 \%$ & $0.00 \%$ \\
\hline Jun-94 & $4,428,000$ & $1,179,651$ & $5,607,651$ & 10 & 2,799 & $5,607,651$ & $5,681,958$ & $-1.33 \%$ & $0.00 \%$ \\
\hline Jul-94 & $4,428,000$ & $1,179,651$ & $5,607,651$ & - & - & $5,607,651$ & $5,681,958$ & $-1.33 \%$ & $0.00 \%$ \\
\hline Aug-94 & $4,428,000$ & $1,179,646$ & $5,607,646$ & - & 5 & $5,607,646$ & $5,681,953$ & $-1.33 \%$ & $0.00 \%$ \\
\hline Sep-94 & $4,428,000$ & $1,179,641$ & $5,607,641$ & - & 5 & $5,607,641$ & $5,681,948$ & $-1.33 \%$ & $0.00 \%$ \\
\hline Oct-94 & $4,428,000$ & $1,179,011$ & $5,607,011$ & 2 & 632 & $5,607,011$ & $5,681,318$ & $-1.33 \%$ & $0.00 \%$ \\
\hline Nov-94 & $4,428,000$ & $1,181,269$ & $5,609,269$ & 870 & 1,107 & $5,606,774$ & $5,681,081$ & $-1.28 \%$ & $0.04 \%$ \\
\hline Dec-94 & $4,428,000$ & $1,177,466$ & $5,605,466$ & 377,434 & $\begin{array}{r}3,804 \\
786,023\end{array}$ & $5,605,466$ & $5,677,278$ & $-1.28 \%$ & $0.00 \%$ \\
\hline
\end{tabular}

Table No. 9-10 is an example (B) for another storage field which does not exhibit such a large deviation. The running total compared to the month to month calculations (Column 7 and 8 ) are in close agreement. 
One problem encountered in estimating unaccounted for gas developed from inconsistencies in reporting to government agencies and in the discrepancies in reporting by various companies. Based on FERC Form-2 data, 80-152 BCF are unaccounted for annually. The gas prices (current and noncurrent) are $\$ 1.55$ and $\$ 0.72$ per MCF respectively. As shown on Table No. 1614 (appendix), most of the gas losses are reported as transmission losses.

A comparison was done on reported data from ElA-Form 191. Based on a review of this data, approximately 143.4 BCF were unaccounted for from 1992-94. A summary of this unaccounted for gas volumes are shown on Table 11-12 (appendix).

\section{3.) EIA F-191}

Each month, the EIA'S Form EIA-191, "Underground Gas Storage Report," storage operators report their current estimates of total capacity, base gas, and working gas, as well as their estimates of gas withdrawn and injected that month. Base gas levels can fluctuate slightly because of factors such as migration losses, but these are usually very small changes. The cumulative effect of gas migration can be noticeable, however. Base gas will also change if a site is expanded, and will increase as a new site or an aquifer is pressurized. Othenwise, base gas is essentially a constant. Similarly, the total capacity of a reservoir is not expected to change. Base gas thus represents a financial cost that is not recoverable because the gas is ordinarily not withdrawn and sold until the site is abandoned. ${ }^{34}$

Table No. 9-11 summarizes the total volumes of base, working, total, injection, withdrawal and number of fields reported for the evaluation period. Also shown are the net reductions and additions to the base gas and the corresponding number of fields which were added or removed from storage. The volumes are categorized by type of storage reservoir. Data was tabulated so that the summary data would be reviewed by storage classification. Volumes for base, working, and total gases are shown as well as the reported injected and withdrawn volumes. Also included are the number of fields by reservoir classification. Variations in the numbers of fields by classification may vary from EIA reports, due to judgment of the authors.

Also noted are the reductions and additions to base and number of fields. These values reflect the change from the proceeding year, therefore 1991 does not have reductions or additions shown. Downward revisions indicate either a reduction in base gas or a field being abandoned due to leakage. Each individual field was reviewed, summarized and categorized by reservoir type.

Rows $6,17,28$ and 39 reflect the (delta) calculated total gas for each year by reservoir type. This is the difference from the reported total gas (base plus working) versus the calculated total. Much time and analysis were spent trying to understand the inconsistencies in the reported data versus the calculated values. The largest reductions and differences in calculated vs. reported total gas appeared in the depleted reservoir type fields. These also represent the largest number of fields.

Injected and working gas volumes are reported monthly on the F-191. These numbers are either estimated and then later revised or reported as actuals. The base gas is reported, but is seldom changed during the year, unless the working gas is depleted. Generally, in December, however, the base is revised to reflect the fields certificated base volume.

During 1992 to 199412 storage fields were reduced. This amounted to $132 \mathrm{BCF}$ reduction in base gas (sum Row 2). Most of the reducticns 132 BCF occurred in the stratigraphic reservoirs. The amounts for cavern and aquifer reservoirs are also shown.

\footnotetext{
${ }^{34}$ Energy Information Administration. The Value of Underground Storage in Today's Natural Gas Industry, Appendix C, p.71.
} 
Table 9-11 Storage Data by Reservoir Type ${ }^{35}$

\begin{tabular}{|c|c|c|c|c|c|c|}
\hline & & & $\begin{array}{c}\text { MMMcf } \\
1991\end{array}$ & 1992 & 1993 & 1994 \\
\hline 1. & $\overline{\mathrm{ALL}}$ & Base & 3,904 & 3,994 & 4,277 & 4,310 \\
\hline 2. & & Reductions & & $(27)$ & $(77)$ & (28) \\
\hline 3. & & Additions & & 117 & 361 & 61 \\
\hline 4. & & Work & 2,788 & 2,561 & 2,285 & 2,557 \\
\hline 5. & & Total & 6,692 & 6,555 & 6,562 & 6,867 \\
\hline 6. & & Delta Total & & (32) & 40 & (0) \\
\hline 7. & & Inj & 2,563 & 2,505 & 2,701 & 2,678 \\
\hline 8. & & With & 2,636 & 2,673 & 2,654 & 2,374 \\
\hline 9. & & No Fields & 371 & 383 & 387 & 396 \\
\hline 10. & & Reductions & & (1) & (5) & (6) \\
\hline 11. & & Additions & & 13 & 9 & 15 \\
\hline 12. & CAVERN & Base & 22 & 24 & 30 & $\overline{40}$ \\
\hline 13. & & Reductions & & $(0.10)$ & $(0.23)$ & (2.28) \\
\hline 14. & & Additions & & 1.33 & 6.40 & 12.10 \\
\hline 15. & & Work & 51 & 50 & 55 & 70 \\
\hline 16. & & Total & 73 & 73 & 85 & 110 \\
\hline 17. & & Delta Total & & (1) & (8) & (4) \\
\hline 18. & & Inj & 75 & 74 & 101 & 144 \\
\hline 19. & & With & 60 & 75 & 97 & 124 \\
\hline 20. & & No Fields & 15 & 16 & 19 & 21 \\
\hline 21. & & Reductions & & 0 & 0 & 0 \\
\hline 22. & & Additions & & 1 & 3 & 2 \\
\hline 23. & AQUIFERS & Base & 810 & 822 & 910 & $\overline{911}$ \\
\hline 24. & & Reductions & & $(0.000)$ & $(0.000)$ & $(0.032)$ \\
\hline 25. & & Additions & & 12.06 & 88.86 & 0.68 \\
\hline 26. & & Work & 414 & 385 & 310 & 327 \\
\hline 27. & & Total & 1,223 & 1,206 & 1,221 & 1,238 \\
\hline 28. & & Delta Total & & (4) & 3 & (0) \\
\hline 29. & & Inj & 305 & 311 & 343 & 319 \\
\hline 30. & & With & 304 & 332 & 326 & 302 \\
\hline 31. & & No Fields & 47 & 47 & 47 & 41 \\
\hline 32. & & Reductions & & 0 & 0 & (6) \\
\hline 33. & & Additions & & 0 & 0 & 0 \\
\hline 34. & DEPLETED & Base & 3,072 & 3,149 & 3,337 & $\overline{3,359}$ \\
\hline 35. & & Reductions & & (27) & (77) & (26) \\
\hline 36. & & Additions & & 103 & 266 & 48 \\
\hline 37. & & Work & 2,324 & 2,127 & 1,919 & 2,159 \\
\hline 38. & & Total & 5,396 & 5,275 & 5,256 & 5,518 \\
\hline 39. & & Delta Total & & (27) & 45 & 4 \\
\hline 40. & & Inj & 2,183 & 2,119 & 2,257 & 2,215 \\
\hline 41. & & With & 2,272 & 2,266 & 2,231 & 1,949 \\
\hline 42. & & No Fields & 309 & 320 & 321 & 334 \\
\hline 43. & & Reductions & & (1) & (5) & 0 \\
\hline 44. & & Additions & & 12 & 6 & 13 \\
\hline
\end{tabular}

${ }^{35}$ Source: EIA Data F-191 
The largest unaccounted for gas volumes appear to be from conventional depleted gas reservoir storage fields in the Northeast. These fields are primarily sandstone with either structural or stratigraphic trapping mechanisms.

\subsection{GAS MIGRATION MODEL AND HORIZONTAL WELL SIMULATION}

Over $80 \%$ of underground gas storage are in depleted stratigraphic or structural reservoirs. The second portion of the study focused on these reservoir types. A 3 dimensional reservoir simulator was used to study gas migration mechanisms during operation of storage fields. A model was constructed (3stor.dat) which contained about 55 BCF of gas and had 5 injection and withdrawal wells. Original reservoir pressure was 1200 psia. The field was operated on 180 day cycles over a 10 year period. The resulting performance is discussed in the text.

This base model was modified (3storlow.dat) by the inclusion of a very low permeability boundary $(0.001 \mathrm{md})$, which would simulate a stratigraphic trap juxtaposed to a very low permeability formation. Again the model was run and compared to the base case. The results were identical.

A thief zone was included by the use of a well completed in the very low permeability zone. Gas migration effects were studied. Typical $P / z$ calculations indicated that small volumes were lost even in formations with 0.001 md permeability.

Mitigation strategies were then developed to reduce gas migration from thief zones. By drilling horizontal wellbores, gas migration was eliminated or reduced. Sensitivity to horizontal wellbore length was studied. In this example, wellbores over $1000^{\prime}$ in length eliminated gas migration effects.

\section{DISCUSSION}

The 3 main types of storage reservoirs each have specific characteristics which make them subject to certain forms of gas migration. A brief characterization of each reservoir type is followed by common gas migration problems and methods of inventory verification associated with that reservoir type. A 3 dimensional reservoir simulator was used to study gas migration mechanisms during operation of storage fields. A thief zone was included by the use of a well completed in a very low permeability zone. Mitigation strategies were then developed to reduce gas migration from thief zones..

\subsection{DEPLETED RESERVOIRS}

Depleted oil and gas reservoirs are the most commonly used underground storage sites because of their wide availability. They use the pressure of the stored gas and in some cases, water infiltration pressure to drive withdrawal operations. ${ }^{36}$ Most (around $85 \%$ ) of the depleted reservoirs currently used for gas storage are pressure depletion (otherwise known as volumetric expansion) reservoirs. The rest have water as the drive mechanism.

\footnotetext{
${ }^{36}$ Energy Information Administration. The Value of Underground Storage in Today's Natural Gas Industry, p. 46-
} 
Figure 10-1: Location of Depleted Reservoir Storage in the US

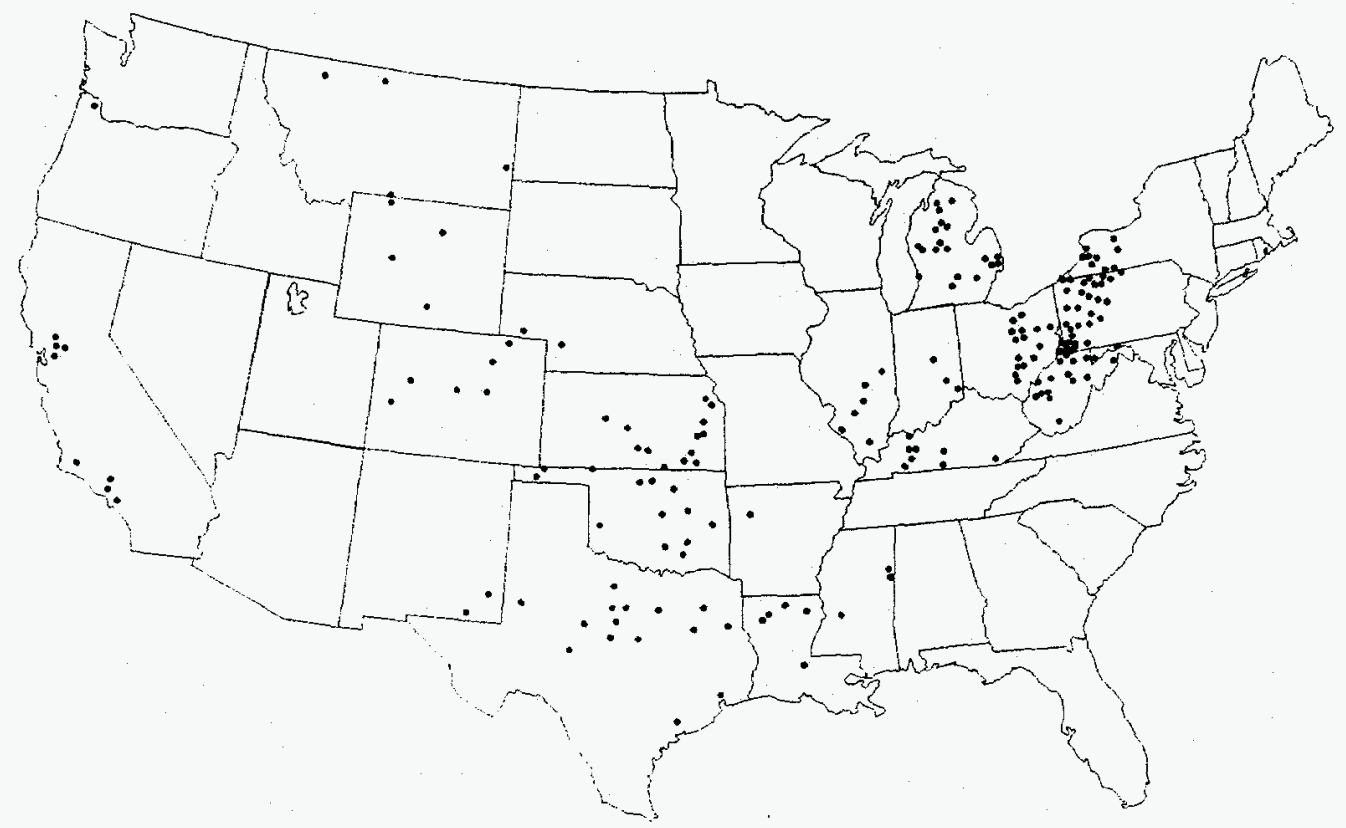

after: Energy Information Administration, "The Value of Underground Gas Storage in Today's Natural Gas Industry", p. 2

Most existing gas storage in the United States is held in depleted natural gas or oil fields located close to consumption centers in the Northeast. Conversion of a field from production to storage duty takes advantage of existing wells, gathering systems, and pipeline connections. The geology and producing characteristics of a depleted field is also well known. However, choices of storage field location and performance are limited by the inventory of depleted reservoirs in any region. Generally, depleted reservoirs are classified as seasonal supply reservoirs rather than high deliverability sites, however, high deliverability can be achieved in a depleted oil or gas reservoir if the reservoir rock has high porosity and permeability (allowing a rapid flow of gas), and the reservoir has sufficient base gas pressure and a sufficient number of wells to maximize withdrawal. ${ }^{37}$

Cycling (number of times a year the total working gas volume may be injected/withdrawn per year) is relatively low, and daily deliverability rates are dependent on the degree of rock porosity and permeability, although the facilities are usually designed for one injection and withdrawal cycle per year. Daily deliverability rates from depleted fields vary widely because of differences in the surface facilities (such as compressors), base gas levels, and the fluid flow characteristics of each reservoir. Retention capability, which is the degree to which stored gas is held within the reservoir area, however, is highest of the three principal types of underground storage. Depleted field storage is also the least expensive to develop, operate, and maintain. ${ }^{38}$

Underground storage in depleted gas/oil fields is used when gas can be injected into reservoirs with suitable pore space, permeability and retention characteristics. All oil and gas reservoirs share similar characteristics in that they are composed of rock with enough porosity so that hydrocarbons can accumulate in the pores in the rock, and they have a less permeable layer of rock above the hydrocarbon-bearing stratum. The hydrocarbon accumulation in the porous rock is pressurized by the weight of hundreds or thousands of feet of rock on top of the reservoir.

${ }^{37}$ Energy Information Administration, The Value of Underground Storage in Today's Natural Gas Industry, p. 4649

${ }^{38}$ Ibid. 
when a well hole penetrates the impermeable cap layer of rock, the hydrocarbon under pressure is exposed to the much lower atmospheric pressure and gas can flow in and out of the well. ${ }^{39}$

Clastic and non-clastic rock types are found in depleted reservoirs. Non-clastic rocks are chemical precipitates such as carbonates (limestone and dolomite) and salt. The clastic rocks are depositional, such as sandstone, conglomerate, siltstone and shale. The reservoir trap confines oil and gas. Traps can be structural (faults, folds), stratigraphic (depositional), or diagenetic (permeability "pinch-outs"). When the reservoir is depleted and converted to storage, the traps contain the storage gas. ${ }^{40}$

\subsubsection{Stratigraphic}

Afthough a wide variety of stratigraphic traps exist, many storage pools are bar and channel deposits found as shoestring sandstones, which are long, narrow sand bodies encased in shale. The low permeability shale encasing the permeable sand forms a stratigraphic trap which keeps the gas from escaping. Channels form as abandoned river (fluvial) channels or as distributary channels on constructive deltas (those building outward due to sufficient sediment supply). Bars form as beaches, offshore bars or beaches on destructive deltas (insufficient sediments supply to overcome wave action, often due to the main feeder channel switching course). A majority of the smaller, older storage fields in the Northeast operated by some of the larger companies were developed in these shoestring bars or channel sands.

Bell-shaped in cross-section, bars are found parallel to the shoreline and exhibit a coarsening upward sand sequence, with permeability increasing towards the top of the bar where there is higher energy due to greater wave action. When a well penetrating a bar is logged, a characteristic gamma ray signature (looking like an inverted triangle) is created by the higher radiation silty sand and shale at the base of the bar grading into the cleaner, low gamma sands at the top. Laterally, offshore bars pinch out into marine silts and shales while beach bars pinch out against marine sitts and shales in a seaward direction, and into delta plain silts and shales landward, forming a trap for gas.

Overall, channel geometry runs perpendicular to the shoreline and forms an inverted bell shape in cross-section. The sands coarsen upward and show a typical triangular looking gamma ray response as the clean, low gamma sands at the base grade into "dirtier" sands toward the top. It is the increasing shale content in these "dirty" sands which causes a progressively higher gamma reading. Permeability is highest in the middle of the channel and decreases horizontally toward the edge and vertically toward the top. Laterally, channel sands cut into the surrounding delta plain and pinch-out against silts and shale, thus sealing the sand and forming a trap for gas. A distributary channel will also pinch out against marine silts and shales at its seaward terminus at the shoreline.

Vertically and laterally, these bars and channel sands pinch out against the silts and shales of either the marine or detta plain environment. However, these sands are not always stratigraphically isolated. Sands stack as the sediment subsides and form a blanket as the sediment progrades, with several combinations and gradations in between, allowing the gas to migrate updip through any permeable conduit which it encounters. Partially stacked or overlapped sands can still make good traps, as long as a vertical and lateral seal exists around the sand group.

Natural fracturing of the seal rock via differential compaction of the sediments or by tectonic stresses can also cause gas migration. Overpressuring of the reservoir during injection may also allow the gas to migrate either by escaping to lower pressure zones, fracturing the seal rock, or forcing the gas into zones of lower permeability where it becomes trapped.

\footnotetext{
39 Ibid.

${ }^{40}$ Underground Storage, p. 8.
} 
Figure 10-2: Stratigraphic Storage Reservoir Characteristics

\section{COMMON STRATIGRAPHIC STORAGE RESERVIOR \\ CHARACTERISTICS}
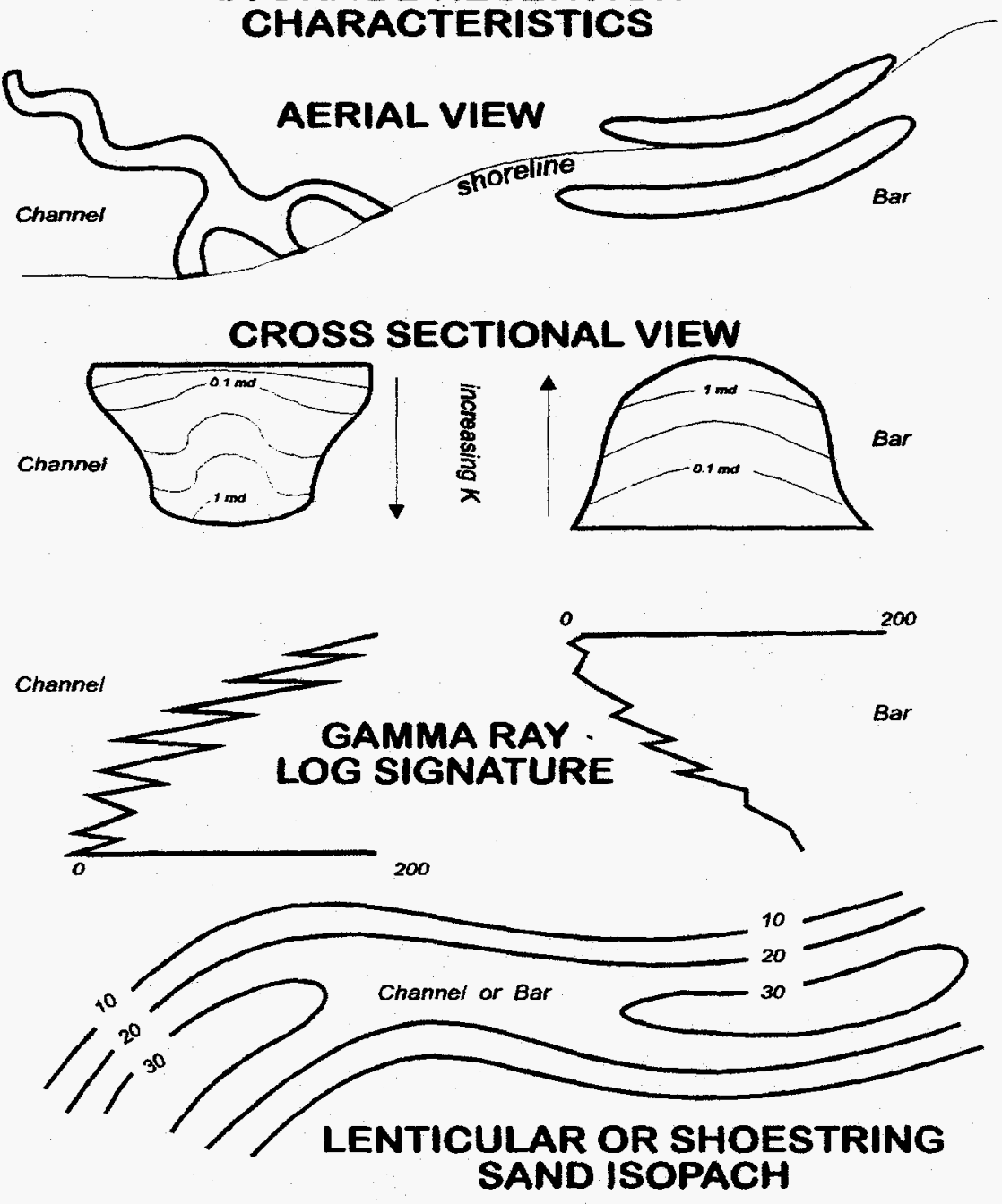

\subsubsection{Structural}

Not as numerous as the stratigraphic reservoirs, but generally larger in size, storage reservoirs having structural traps are also found in the Northeastern US. Structure is also the trapping mechanism for the numerous aquifer storage reservoirs in the Midwest. The structural regime is primarily folding, resulting in the structural trap known as an anticline. Folded fault blocks and faulting also occur in association with some reservoirs.

These structural reservoirs can possess a definite sandstone geometry, but are often found in blanket sands, particularly for the larger reservoirs. Thicker sand deposits also occur within these blanket sands which create or enhance a reservoir's potential, however, since the sand buildup is not isolated (i.e. encased in shale), structure forms the primary trapping mechanism for the gas. In the Northeast, these blanket sands occur in conjunction with unconformities in the Mississippian age Berea (Murraysville) and Devonian age Oriskany formations). The Midwestern sandstone aquifers are primarily of Cambro-Ordovician age and are most commonly found in the 
St. Peter, Galesville and Mt. Simon formations. (Aquifer reservoirs can also occur in carbonate formations, such as the Trenton and Trempeleau, as well.)

Gas is trapped updip in the higher portion of these structures. In the depleted reservoirs of the Northeast and Midwest, the gas zone is bounded downdip either by water or low permeability. The drive mechanism is most frequently gas expansion, also known as pressure depletion. The midwestern aquifers along with a small number of the depleted reservoirs have an active water drive.

Gas migration occurs when there is incomplete structural closure, or during overpressuring of the reservoir, both of which allow the gas to escape through a structurally lower "saddle" into another structurally high portion of the formation. Overpressuring may also cause gas to migrate through the seal, or caprock. This is a common migration mechanism in aquifers, where the gas has to be injected at a higher pressure than the formation pressure.

Gas may also migrate through unknown faults or fracture systems. This migration occurs most frequently during injection in older fields (which may have been put into storage service before modern logging techniques to better delineate the field limits were available) and in structurally complex areas, as shown in the following figure:

Figure 10-3: Gas Migration Mechanisms in a Structural Storage Reservoir

\section{GAS MIGRATION MECHANISMS}

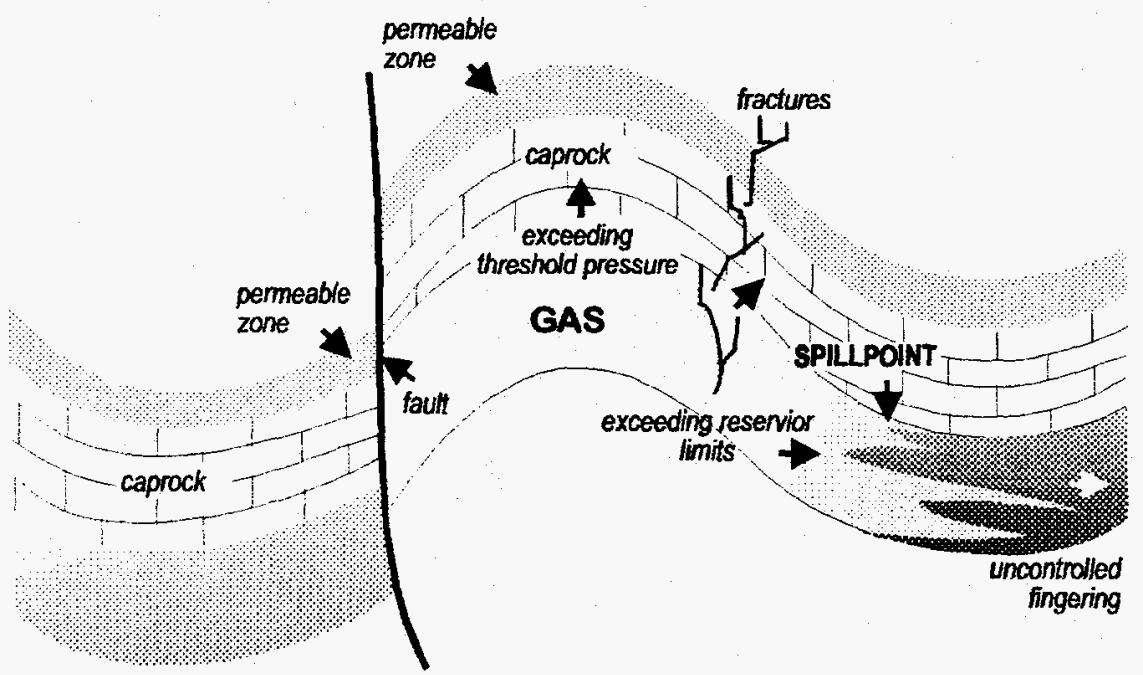

\section{STRUCTURAL STORAGE RESERVIOR}

\subsubsection{Diagenetic And Combination Traps}

Most reservoirs can be classified primarily as either stratigraphic or structural, although all reservoirs are influenced to some extent by both factors. Sometimes these factors create a complex fluid migration and lithologic cementation history in which the obvious stratigraphic and structural features are somewhat obscure in relation to the reservoir limits and production characteristics (although structural discontinuities may provide an association). Referred to as diagenetic, recognizing permeability is often the key to exploiting these reservoirs for storage. An example is certain Medina ${ }^{41}$ reservoirs in the Northeast, which has a strong to moderate

\footnotetext{
${ }^{41}$ Medina is a term used broadly in this instance to encompass the reservoirs in the Silurian Clinton/Medina and Ordovician Queenston deltas.
} 
diagenetic overprint. A likely source of gas migration could presumably occur in the injection phase, where gas could be pushed out into the less permeable portions of the reservoir where it then becomes trapped.

\subsubsection{Fractured Reservoirs}

A natural fracture is defined as a fracture that existed in a volume of rock prior to initiation of drilling. The natural fracture geometry can be simple or complex. A simple geometry may consist of only one pervasive fracture set of regularly spaced, open fractures of similar trend with no evidence of slip or pressure solution. This common fracture trend reflects a fracturing stress field that remained essentially unchanged through a given period of time. Conversely, a complex fracture signature composed of several such fracture sets may reflect the cumulative effect of different stress events that occurred during specific spans of geological time. For example, these diverse stress events may be related to initial basin development, superposition, or orogenic stresses and subsequent epeirogenic uplift. ${ }^{42}$

The most prominent structures in flat-lying sediments, apart from bedding, are systems of steeply dipping joints. These are generally found to have complex patterns, sometimes related geometrically to slight uplifts or depressions in the stratification. Although in many single exposures there may be as few as two prominent joint sets at right angles to one another, it is usual to discover much more complexity than this when an inventory of joints is made over a wide area, and in rocks at different stratigraphic levels. ${ }^{43}$

Joints in a rock are a record of the stresses to which the rock has been subjected during its history. Trends that can be seen on the surface may also exist, for the most part, at depths of several thousand feet in areas of mild tectonic activity. If four sets of joints orient in a stress field, then the presence of eight sets indicates that the stress fields that produced these additional joints must have been related to a previous different principal stress orientation. ${ }^{44}$

The geometrical relationships and relative growth chronology between the fracture sets developed during one or several regional stress episodes are made even more complex by the effect of previously existing fractures and other regional structures such as depositional basins, buried fault zones, folds, and regionally persistent anisotropies inherited from earlier depositional and tectonic events. These preexisting structures at a large scale can affect the regional stress field, giving rise to diverse fracture sets that commonly can be grouped into regional fracture domains, each with a unique fracture signature. Similarly, primary or secondary structures at a local scale can affect later stress states to produce locally persistent fracture sets and domains. In addition, slip or pressure solution can occur along any previously existing planar anisotropies during later burial or tectonic events. ${ }^{45}$

${ }^{42}$ Kulander, B.R., Dean, S.L., and Ward, B.J., Fracture Core Analysis, AAPG Methods in Exploration Series, No. 8, The American Association of Petroleum Geologists, Tulsa, OK, 1990, chapter 2.

${ }^{43}$ Hobbs, B.E., Means, W.D., and Williams, P.F., An Outline of Structural Geology, John Wiley \& Sons, Inc., New York, 1976 , chapter 9 .

${ }^{44}$ Overbey, W.K., Jr., Sawyer, W.K., and Henniger, B.R., Relationships of Earth Fracture Systems to Productivity of a Gas Storage Reservoir, United States Department of the Interior, Bureau of Mines, Washington, DC, 1974, p. 76.

${ }^{45}$ Kulander, B.R., Dean, S.L., and Ward, B.J., Fracture Core Analysis, AAPG Methods in Exploration Series, No. 8, The American Association of Petroleum Geologists, Tulsa, OK, 1990, chapter 2. 
With knowledge of the directional properties of the reservoir added to the information available to reservoir engineers, a more efficient and economic management of a storage reservoir is possible. ${ }^{46}$

\subsubsection{Fracture Origins}

Fracture traces and lineaments which are sedimentary in origin can be produced by:

1. Differential compaction around a sand body contained in a larger shale unit.

2. Sedimentary features associated with reef growth.

3. Abrupt facies change and change in physical properties of rock competency.

4. In carbonate units beneath an unconformity surface as a result of jointing and solution along joints and karst zones.

5. Gravity sliding of certain types of sediments to produce landslides and slumps later buried by younger sediments.

Regions of flat-lying sediments commonly display a peculiar kind of fault known as a growth fault. These are typically normal faults acrnss which there is abrupt thickening of stratigraphic unit, from the hanging wall side to the footwall side, and along which there is a downward increase in the displacement of stratigraphic horizons. Growth faults are interpreted as normal faults that are moving contemporaneously with deposition of sedimentary rocks, particularly in deltaic environments, salt domes and around the margins of intracontinental fault-bounded depositional basins. ${ }^{47}$ Fracture traces and lineaments which are structural in origin can be produced by:

1. Gravity faulting due to loading of formations from sediment accumulation (growth faulting).

2. Fracture traces and lineaments which are inherited from basement rocks and have propagated vertically.

3. Basement rock fractures associated with plate tectonics, extensional faulting (normal faults, horst and graben) ${ }^{48}$

\subsubsection{Stress Relationships}

During injection of gas into a storage field, high pressures can be encountered near the injection wellbore. These local pressures are often higher than the original reservoir pressure. In order to determine whether these pressures will open existing fractures or induce fractures, it is necessary to determine the parting pressure of the reservoir. This is the pressure needed to overcome the lateral pressure of the reservoir. A general rule of thumb is that the lateral pressure is a third of the vertical pressure. This rule of thumb is derived by the relationship of the rock density $(\rho)$ multiplied by the acceleration due to gravity multiplied by the depth multiplied by Poisson's ratio divided by 1 minus Poisson's ratio, or:

$\rho g h \times$ Poisson's ratio/1-Poisson's ratio

\footnotetext{
${ }^{46}$ Overbey, W.K., Jr., Sawyer, W.K., and Henniger, B.R., Relationships of Earth Fracture Systems to Productivity of a Gas Storage Reservoir, United States Department of the Interior, Bureau of Mines, Washington, DC, 1974, p 77-78.

47 Hobbs, B.E., Means, W.D., and Williams, P.F., An Outline of Structural Geology, John Wiley \& Sons, Inc., New York, 1976, chapter 9

${ }^{48}$ Overbey, W.K., Jr., Sawyer, W.K., and Henniger, B.R., Relationships of Earth Fracture Systems to Productivity of a Gas Storage Reservoir, United States Department of the Interior, Bureau of Mines, Washington, DC, 1974, p. 76.
} 
The parting pressure needed to defeat the lateral pressure is affected by variations in the stress field and rock characteristics. If the pore spaces are filled with water, then the equation has to be modified for effective stresses. Also, for example, healed fractures will require higher parting pressures than open fractures. However, anytime that the parting pressure of the reservoir rock is exceeded, the risk of gas migration through fractures is greatly increased.

\subsubsection{Oriented Core Analysis}

A core from a complexly fractured volume of rock may contain representative fractures from any or all existing fracture sets, including fault and stylo-fractures. Cored fractures of any set also may possess unique characteristics that are related to specific tectonic events. In addition, fracture roughness, geometry and type of surface structures, aperture width, type of mineralization and tectonic indicators such as slickensides and styolites may vary from set to set. The fact that the complex history of fracture development often can be determined through examination of the different characteristics of fractures in each set dictates that core investigations be as comprehensive as possible. ${ }^{49}$

Oriented cores can provide the azimuth frequency distribution of natural fractures that might be expected to occur in the reservoir. Determination of the directional permeability of the core and the relationship of this directional flow with respect to the effects of sedimentation features and joints provides the operator with very valuable data for planning gas storage development and operational strategy. It is conceivable that induced fracture orientation could be predicted solely on the basis of directional physical properties alone. ${ }^{50}$ Induced fracture orientation may in some cases be influenced by in-situ stresses or previously existing mechanical anisotropies, or both. This information can also be used to determine the direction of potential gas migration during injection.

\subsubsection{Significance Of Numerical Modeling}

Results of model studies, from the literature, show that the fracture length, well spacing, and the drilling patterns of wells are factors that can influence the withdrawal rates of gas. Drainage patterns in an old section of a field that were fractured several years ago could be modified by refracturing and using more proppants of larger size to increase the fracture permeability and produce a more elliptical drainage pattern. ${ }^{51}$ In one study, conducted on an Ohio storage reservoir in the Clinton formation, the following conclusions were reached:

1. In areas of flat-lying rocks, surface jointing studies provide a very good approximation of the fracture system that may be encountered in the reservoir.

2. The location of a surface stress measurement site must be chosen so that no local changes in stress trajectory will be encountered.

3. One set of joints (which may or may not be the dominant set) mapped on the surface will parallel the principal horizontal stress direction.

4. The fracture system in a reservoir can be readily established by mapping joints in an oriented core from the reservoir.

${ }^{49}$ Kulander, B.R., Dean, S.L., and Ward, B.J., Fracture Core Analysis, AAPG Methods in Exploration Series, No. 8, The American Association of Petroleum Geologists, Tulsa, OK, 1990, chapter 2.

${ }^{50}$ Overbey, W.K., Jr., Sawyer, W.K., and Henniger, B.R., Relationships of Earth Fracture Systems to Productivity of a Gas Storage Reservoir, United States Department of the Interior, Bureau of Mines, Washington, DC, 197, p77-78.

${ }^{51}$ Overbey, W.K., Jr., Sawyer, W.K., and Henniger, B.R., Relationships of Earth Fracture Systems to Productivity of a Gas Storage Reservoir, United States Department of the Interior, Bureau of Mines, Washington, DC, 1974, p 77-78. 
5. Interpretation of three types of aerial photography detected fracture trace trends correlative with major joint directions in the study area.

6. Locating new gas wells based entirely on photo lineaments, for expected increased productivity, is not justified.

7. The mapping of photo lineament for correlation with surface and subsurface fracture trends adds an important bit of data for final analysis and determination of the earth fracture system and stress orientation.

8. After the orientation of induced fractures has been established and reservoir geology and fluid-flow properties have been determined, an efficient field development can be established by mathematically modeling the effects of fracture orientation and length with respect to the geometry and other reservoir properties.

9. The information obtained from earth fracture system studies, as comprised of surface joint and stress measurements, oriented-core analysis, remote sensing studies, and numerical modeling can be a most effective aid to an orderly and economic development in the conversion of an older productive area to gas storage operation ${ }^{52}$, and in subsequent injection well monitoring.

\subsubsection{Inventory Verification}

Each year operators must assure that the inventory of net stored gas resides in the reservoir in communication with the well bores. ${ }^{53}$ In pressure depletion type reservoirs where the gas flows to the wells primarily by gas expansion, 2 methods, which are based on observations of pressure versus gas inventory, are used to verify storage gas inventories. ${ }^{54}$

The first method is based on semi-annual pressure surveys in which all of the wells are shutin for a period of time and pressures are measured to determine field wide average shut in reservoir pressure. The surveys are usually taken in the fall and spring when the field is near its high and low gas inventories respectively. ${ }^{55}$ Closed-pressure measurements for a period from 3 days to 15 days or more are used for all wells, normally at maximum and minimum storage pressures. For constant pore volume reservoirs for which the closed pressures are relatively uniform and stabilized, the use of the pressure content data relates the metered production, or change in inventory to the initial content. When water movement rates are known to occur during withdrawal, the volume change of the reservoir must be used to modify the relationship accordingly. ${ }^{56}$

The second method of establishing possible gas migration from a storage field with a pressure depletion recovery mechanism is based on a comparison of pressure at observation wells and gas inventory. As the name implies, observation wells are used to observe reservoir pressure and the presence of gas at several locations within the field. ${ }^{57}$ For some reservoirs, the key well annual pressure trace versus inventory is used to find whether any changes have occurred from previous years. ${ }^{58}$

Evidence of gas migration can be found in plots of bottom hole pressure divided by supercompressibility factor (BHP/Z) versus gas inventory obtained during semi-annual surveys.

52 Overbey, W.K., Jr., Sawyer, W.K., and Henniger, B.R., Relationships of Earth Fracture Systems to Productivity of a Gas Storage Reservoir, United States Department of the Interior, Bureau of Mines, Washington, DC, 1974, p. 82.

${ }^{53}$ Katz, D.L. and Tek, M.R. "Overview on Underground Storage of Natural Gas", p. 3.

${ }^{54}$ Mayfield, J.F., "inventory Verification of Gas Storage Fields", p. 2.

${ }^{55}$ Ibid.

${ }^{56}$ Katz, D.L. and Tek, M.R. "Overview on Underground Storage of Natural Gas", p. 3

${ }^{57}$ Mayfield, J.F., "Inventory Verification of Gas Storage Fields", p. 2.

${ }^{58}$ Katz, D.L. and Tek, M.R. "Overview on Underground Storage of Natural Gas", p. 3. 
After the first few years the position of the BHP/Z versus inventory values stabilize in the event of no unaccounted for gas migration. A value of $B H P / Z$ versus inventory below the stabilized pressure-inventory line and shifting progressively toward a larger inventory for a given pressure suggests unaccounted for gas migration. ${ }^{59}$

The estimated quantity of such migration is the volume of gas which must be subtracted from the field inventory to obtain a trend of "total inventory per pound" which remains relatively constant from year to year. ${ }^{60}$

While these procedures document gas migration, often this migration is difficult to see in the resultant graphs and hysteresis curves generated from the data. Hence, small amounts of migration per year are often overlooked. This migration, if ongoing, becomes significant with time.

\subsubsection{Gas Migration Mechanisms}

As mentioned above, a variety of geologic formations and traps are currently being utilized as underground natural gas storage reservoirs. The largest category are structural and stratigraphic traps in depleted reservoirs. Major storage development occurred in the 1950's, principally in the Northeast close to end users and along existing major transportation systems and infrastructure.

Gas storage reservoirs were selected based on size, location, deliverability potential and geologic control (seal). The productive limits of the reservoir had to be known in order to prevent gas migration from the storage interval. This knowledge was obtained from conventional logs, cores, well test data, etc. Trap size and geologic limits were also inferred from wells drilled in the area which were nonproductive and plugged and abandoned. In many instances, information on these P\&A'd wells were not available, other than the formation of interest was nonproductive. This inferred low permeability (in the Northeast) or wet (water bearing). Modern advances in well stimulation, formation evaluation and well testing, may have yielded a different view as to the productivity of these P\&A'd wells.

Aside from mechanical leaks through pipe, cement, and pipelines, very little has been written about gas migration from storage formations to adjacent low permeability intervals; and the impact of storage operations on gas migration.

This study evaluates this mechanism. A 3 dimensional fully implicit general purpose compositional model for simulating black oil, gas or gas condensate, volatile oil reservoirs (EXODUS $^{\complement}$ ) was used for this part of the study.

\subsubsection{Homogenous (Base) Reservoir Case}

A base case hypothetical reservoir model was constructed as shown below. The reservoir modeled was a $10 \times 10 \times 4$ (grid) homogenous reservoir. The depth was $4,000 \mathrm{ft}$. and average reservoir pressure was 1,200 psia. Five producing and injection wells were modeled. Total GIP was 55 BCF. Approximately $50 \%$ of the gas was used for working gas and the remainder as base gas. Injection pressures were limited to 1,900 psia. The following table summarizes model parameters.

\footnotetext{
${ }^{59}$ Mayfield, J.F., "Inventory Verification of Gas Storage Fields", p. 2.

${ }^{60} \mathrm{lbid}$
} 
Figure 4: Model Grid

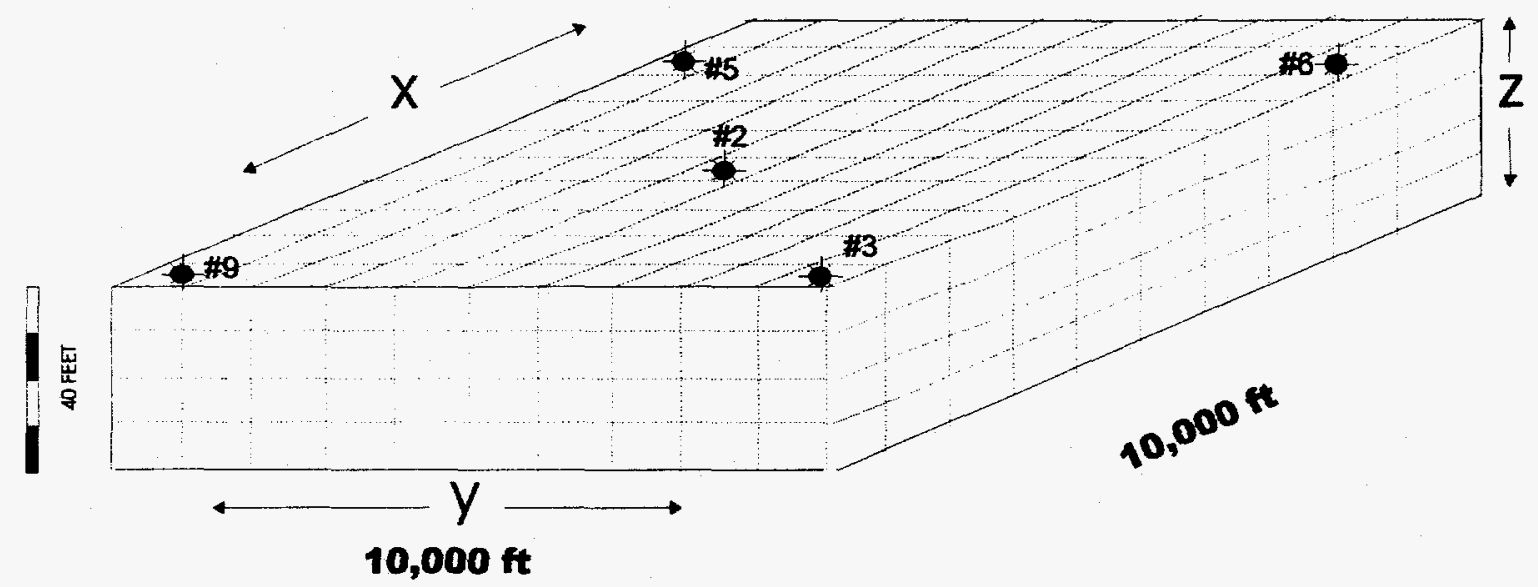

Table 12: Model Input parameters

\begin{tabular}{c|rrrc} 
Layer No & $\mathbf{i}, \mathbf{x}(\mathbf{1 - 1 0})$ & $\mathbf{j}, \mathbf{y}(\mathbf{1 - 1 0})$ & $\mathbf{k}, \mathbf{z}(\mathbf{1 - 1 0})$ & Thickness, $\mathbf{f t}$ \\
\hline 1 & $100 \mathrm{md}$ & $100 \mathrm{md}$ & $10.0 \mathrm{md}$ & 10 \\
2 & $50 \mathrm{md}$ & $50 \mathrm{md}$ & $5.0 \mathrm{md}$ & 10 \\
3 & $25 \mathrm{md}$ & $25 \mathrm{md}$ & $2.5 \mathrm{md}$ & 10 \\
4 & $17.5 \mathrm{md}$ & $12.5 \mathrm{md}$ & $1.25 \mathrm{md}$ & 10 \\
porosity \% & 20 & 20 & 20 &
\end{tabular}

Fluid properties are summarized on the following table.

Table 13: Fluid Properties

\begin{tabular}{r|cccc} 
psia & rcf/scf & $\begin{array}{c}\mu_{g} \\
\text { cp. }\end{array}$ & $\begin{array}{c}\mathbf{B}_{w} \\
\text { rb/stb }\end{array}$ & $\begin{array}{l}\mu_{w} \\
\text { cp. }\end{array}$ \\
\hline 14.7 & 1.11344 & 0.01191 & 1.01075 & 0.6148 \\
1014.7 & 0.01417 & 0.01342 & 1.00742 & 0.6148 \\
2014.7 & 0.00655 & 0.01660 & 1.00409 & 0.6148 \\
3043.8 & 0.00438 & 0.02097 & 1.00066 & 0.6148 \\
4014.7 & 0.00357 & 0.02497 & 0.99743 & 0.6148 \\
5014.7 & 0.00315 & 0.02856 & 0.99410 & 0.6148 \\
6014.7 & 0.00289 & 0.03170 & 0.99077 & 0.6148 \\
7014.7 & 0.00272 & 0.03448 & 0.98744 & 0.6148 \\
8014.7 & 0.00259 & 0.03698 & 0.98411 & 0.6148 \\
9014.7 & 0.00249 & 0.03927 & 0.98078 & 0.6148
\end{tabular}

The field simulation assumed 180 days injection and 180 days withdrawal cycle in the following examples. In reality the field may be produced only during the heating season which may be only 5 months, depending on weather conditions. Injection may only be for a few months depending on gas prices and storage conditions. 
The following figure illustrates the injection/withdrawal cycle and average reservoir pressure the base case (stor3.dat). For this and all examples, twin injection and producers were used due to modeling constraints and for flexibility in changing storage operations.

Figure 5: 10 Year Inj.MD Base Case

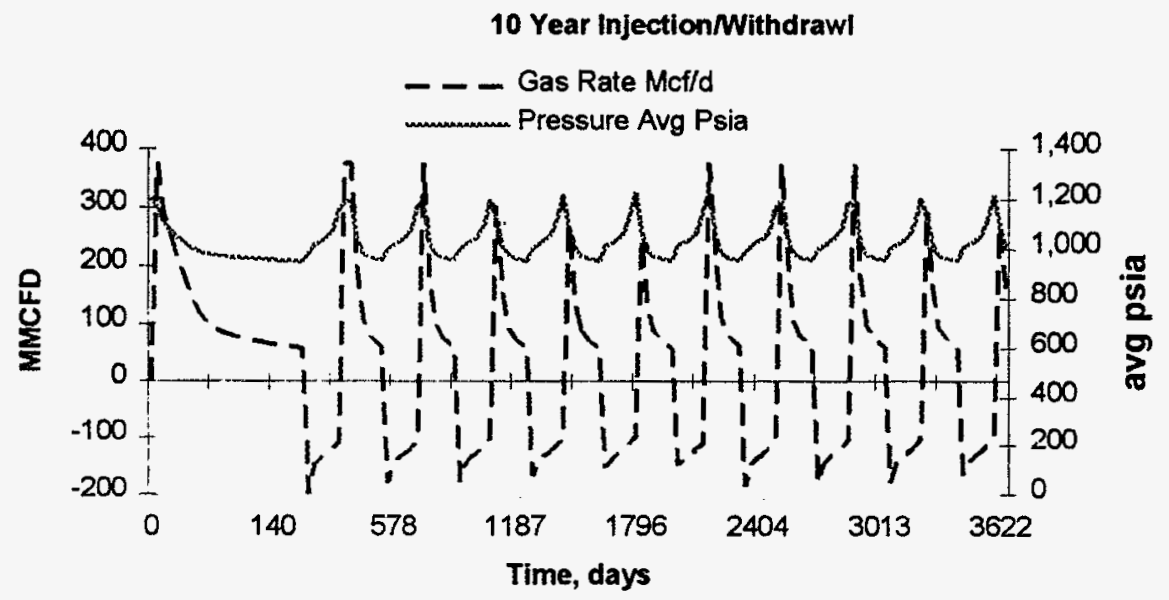

An examination of the average reservoir pressure versus the gas in place (GIP) shows that as gas is withdrawn from the storage reservoir the pressure declines as a function of the ratio of the current gas in place to the original gas in place as shown below. In this example, the reservoir was over pressured and the ratio exceeded 1 . The original reservoir pressure was 1200 psi.

Figure 6: Average Storage Reservoir Pressure Performance

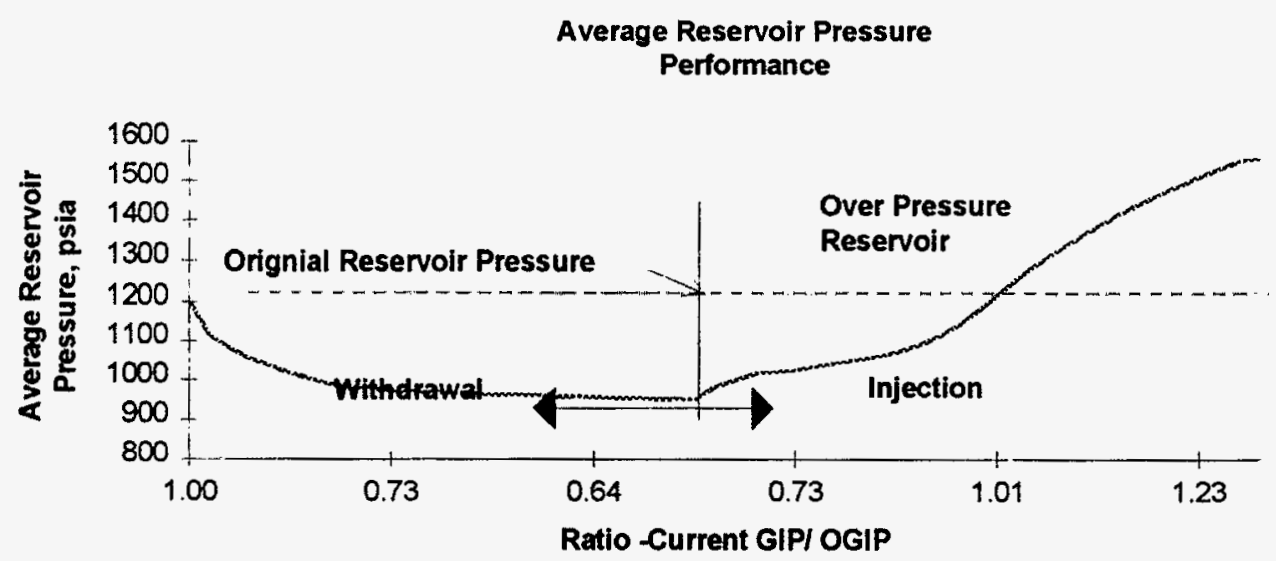

Verification of inventory is similar to estimating reserves. The volumetric calculation involves estimates of the net pore volume occupied by storage gas and either calculation or direct measurement of equalized reservoir pressure. Pressure surveys are conducted in general at times corresponding to turnaround to injection and/or withdrawal seasons. A P/z plot versus the total inventory is commonly used. This plot is shown below. Analysis of the pressure content curve can infer either losses or increases in storage volume, as shown. 


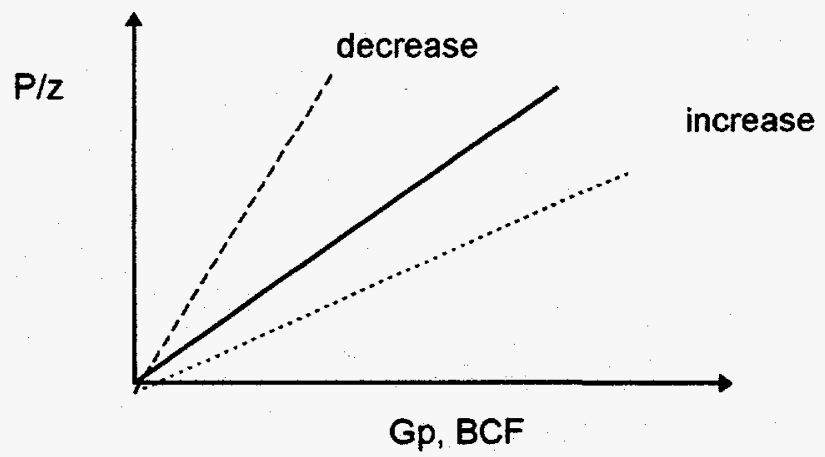

Another type of inventory plot for the base case is shown below. This plot is expressed in reservoir MMCF vs. reservoir MMCF/psia. During the model runs, more gas was injected $(<3 \%)$ than was produced; therefore the curve shows a shift to the right.

\section{Figure 7: Pressure-Content Curve}

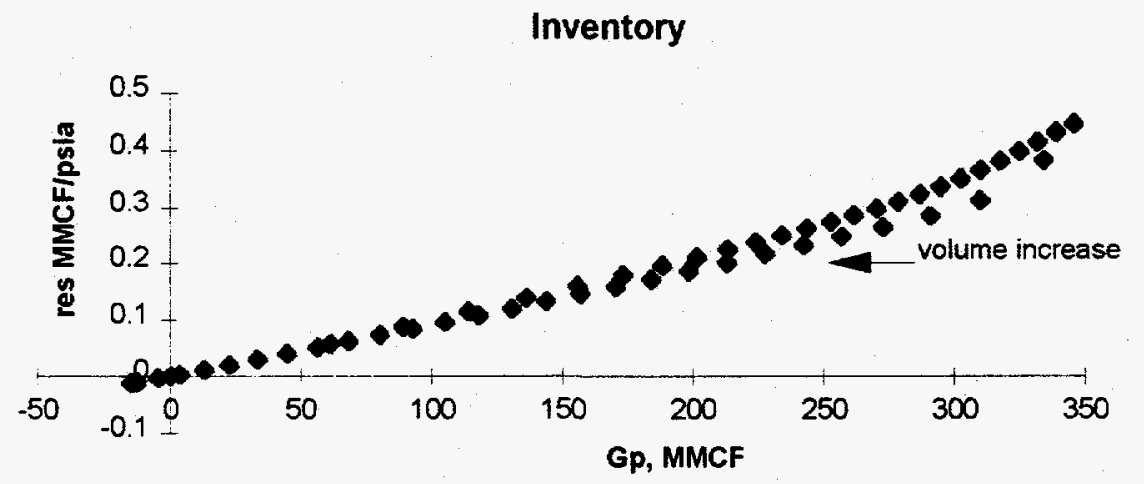

This plot is derived as follows:

\begin{tabular}{|c|c|c|c|c|}
\hline & \multicolumn{3}{|c|}{ Time, days } \\
\hline & & 0 & 180 & 365 \\
\hline 1. & Base BCF & 32.37 & 32.37 & 32.37 \\
\hline 2. & Working BCF & $\underline{22.83}$ & $\underline{0}$ & $\underline{24.15}$ \\
\hline 3. & Total, BCF & 55.20 & 32.37 & 56.52 \\
\hline 4. & avg., psia & 1,201 & 870 & 1,197 \\
\hline 5. & $\mathrm{Bg}$ res./scf & 0.01173 & 0.014635 & 0.011293 \\
\hline 6. & Working res. MMCF & 267.7767 & 0 & 272.7227 \\
\hline 7. & res. MMCF/Psia & 0.223048 & 0 & 0.227799 \\
\hline
\end{tabular}

The resulting plot of 365 days of production and injection follows (row 6 and 7 ). 
Figure 8: Pressure-Content Reservoir MMCF

Base Case Inventory Curve from Working/Base

Volumes, res MMCF

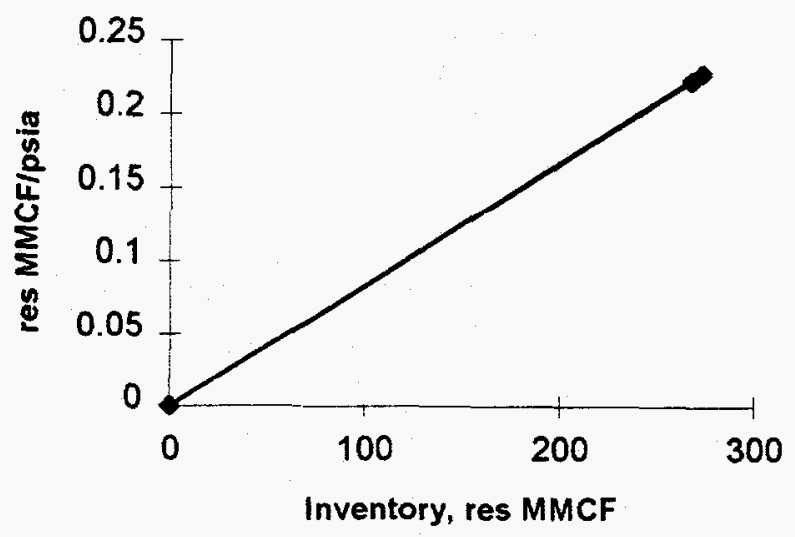

Figure 9: Well Summary MMCFD vs Time

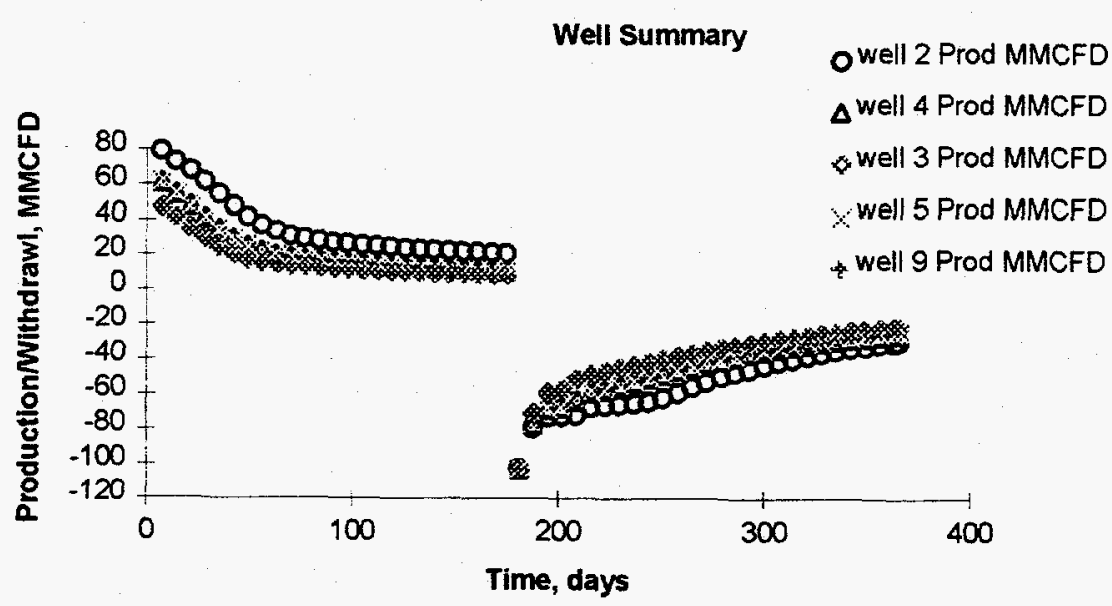

The following figure illustrates individual cell (grid) pressures with time and shows the relative production and injection rates for this case.. As shown the average reservoir pressure is 1,200 psia, but during injection, some areas of the reservoir exceed initial reservoir pressure. 
Figure 10: Cell Pressures*

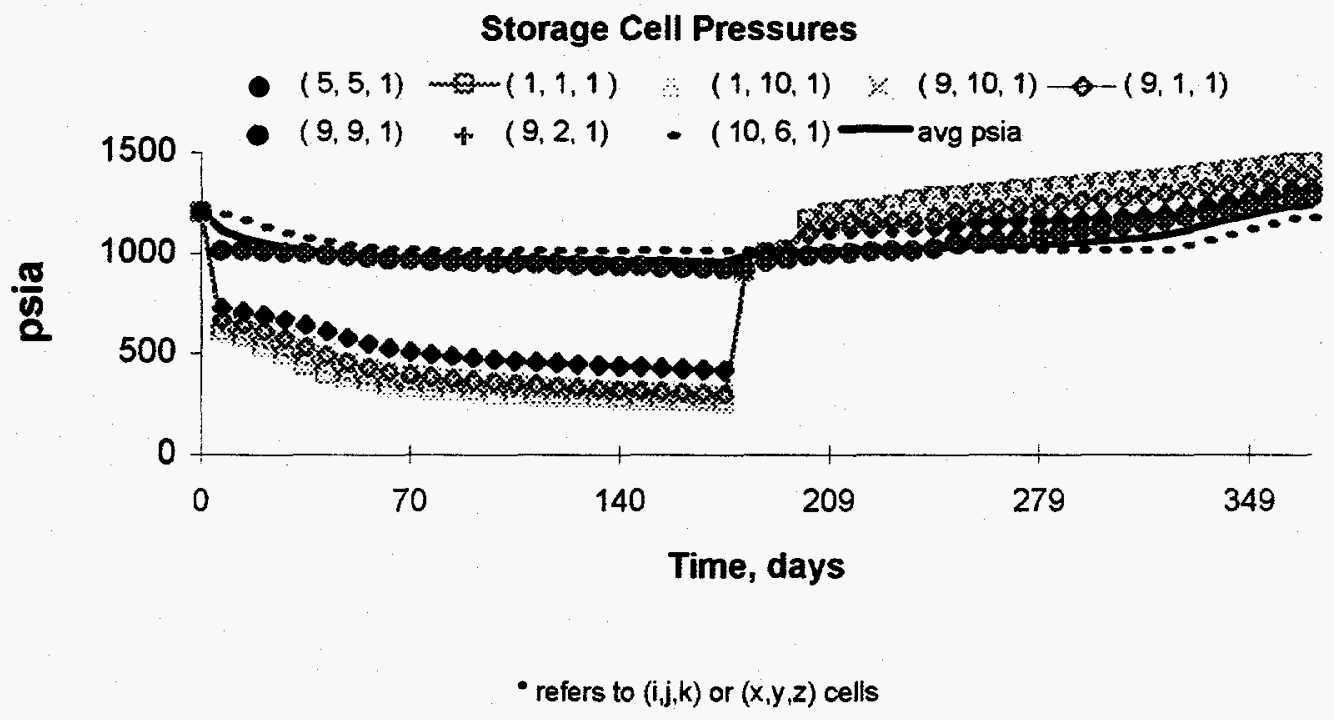

\subsubsection{Boundary Conditions}

The preceding example assumed a perfect barrier existed around the storage field. In reality, storage reservoirs are juxtaposed to rocks with very low permeability. The following example assumes the same input parameters as the base case (stor3.dat), but a very low permeability boundary was included as shown below.

Figure 11: Low Permeability Boundary

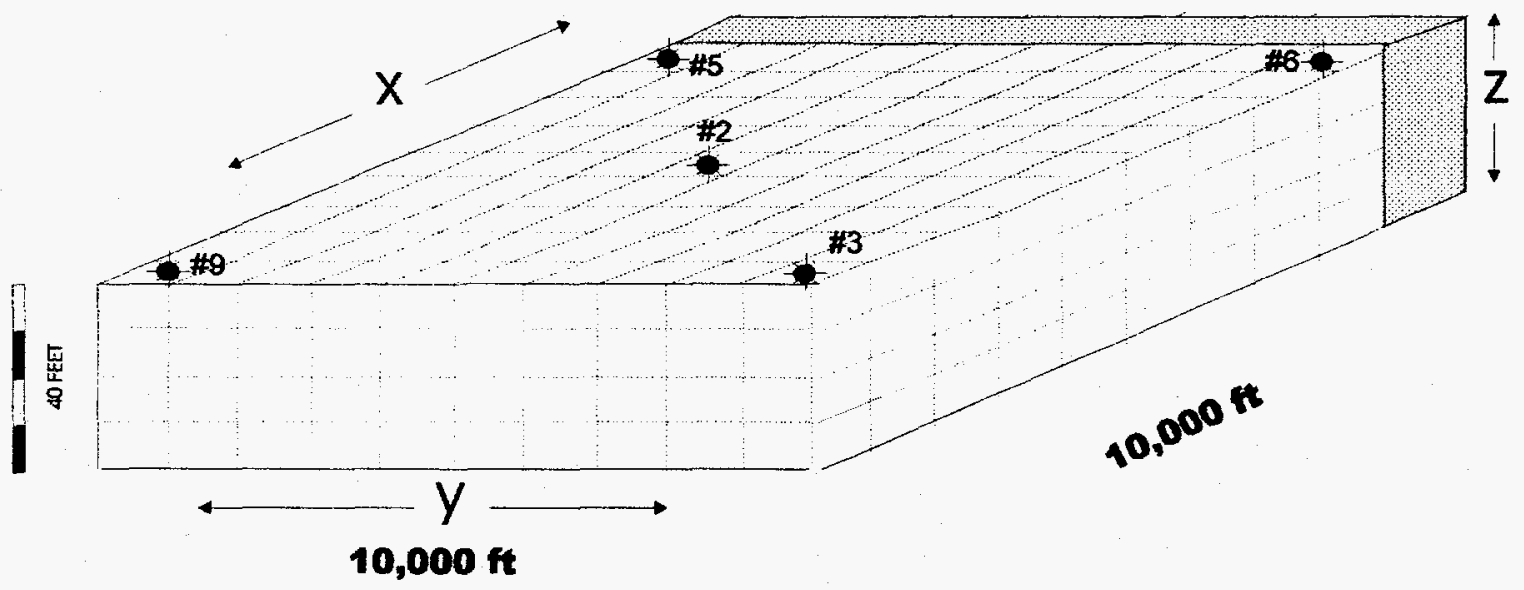

The permeability barrier has a permeability of $0.001 \mathrm{md}$, all other parameters remained the same. The following figure compares average reservoir pressures for the Base (3stor.3dat) and Low (stor3low.dat) Cases. As shown they are identical. 
Figure 12: Base \& Low Case Comparison

Storage Base \& Low Cases

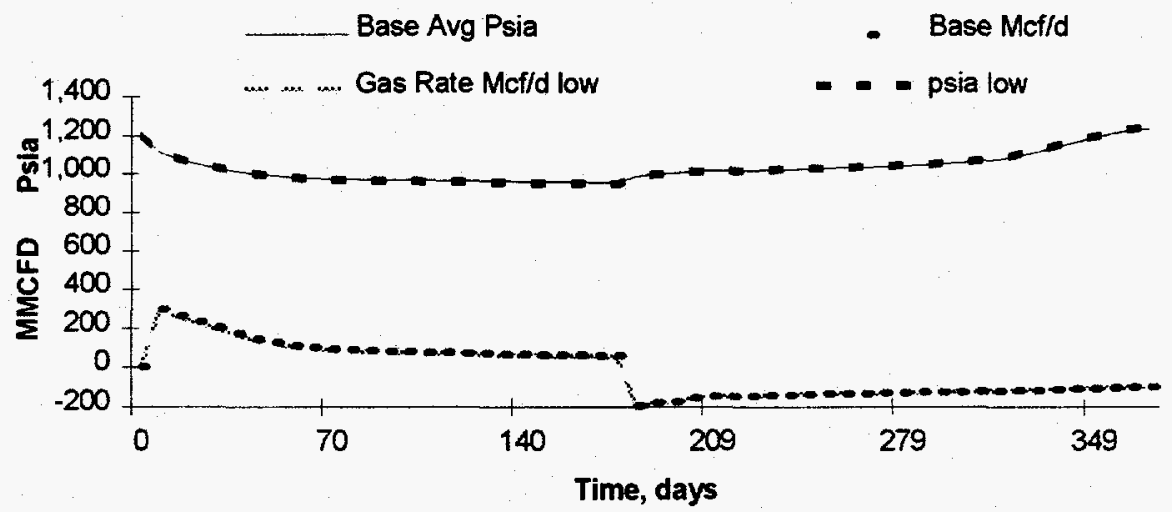

A close examination of individual grid pressures for grid blocks $(10,1,4)$ and $(10,1,1)$ are shown below for the base and low case model runs. 
Figure 13: Cell $(10,1,4) \&(10,1,1)$ Pressure

Stor3 Base \& Low Case Pressure comparison Cell $(10,1,4)$

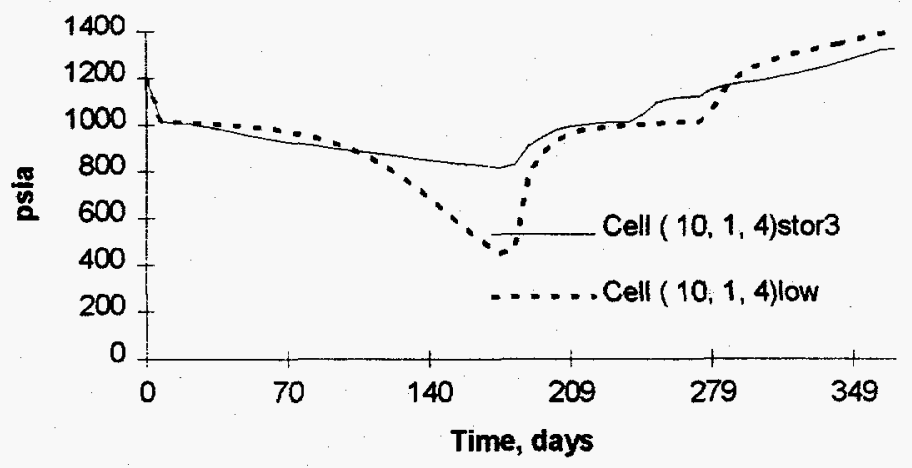

Stor3 Base \&. Low Case Pressure comparison Cell $(10,1,1)$

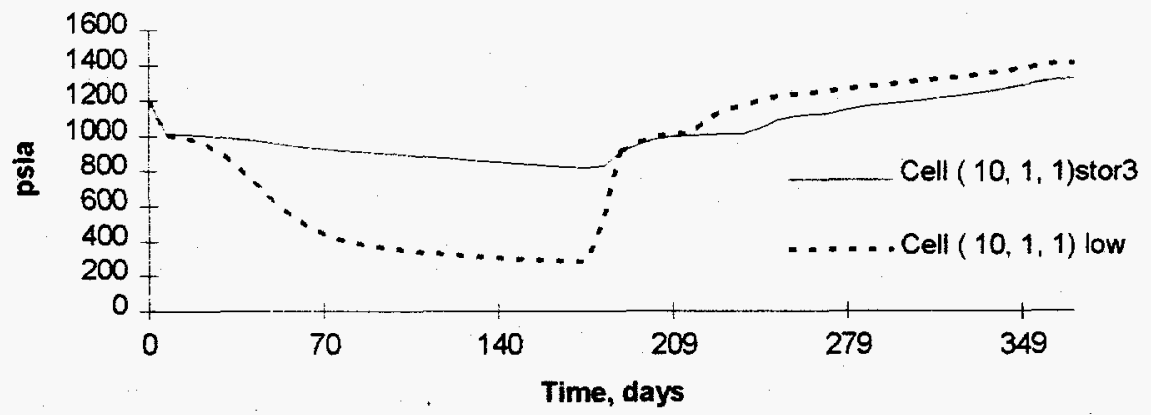

These grid cells are located $1000^{\prime}$ from an injector/producer (\#5). Cell $10,1,1$ is juxtaposed from a 100 md cell and cell 10,1,4 is opposite a 12.5 md cell.

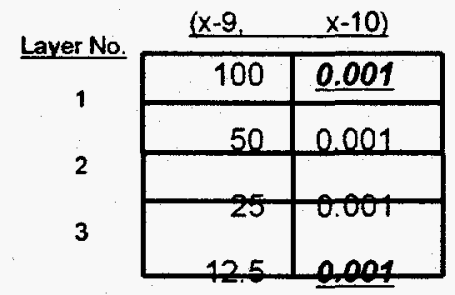

Frequently, based on past practical experience, one well is designated as a key well or indicator well because its surface (or bottom hole) reading correlates with the prevailing average reservoir pressure. Based on the large pressure differences shown above, careful selection of the key well must be made, in order to insure proper representative pressure indications. Also, during the injection cycle, the grid pressures exceeded the average reservoir pressure of 1,200 psia. 


\subsubsection{Gas Migration Mechanisms}

The low permeability boundary case was modified to include a leak via a "tight" wellbore (shown below \# 11) completed in cell 10,1,4. The minimum flowing bottom hole pressure was restricted to 1,200 psia. All other conditions remained the same. This case would simulate an old well drilled and abandoned and plugged with mud and cement. Pre-modern (pre-1960's) completion technology would not have identified this well as a producer due to the very low permeability. State maps would only reflect that this well was $D \& A^{\prime} d$ (drilled and abandoned).

The grid is shown below.

Figure 14: Low Permeability Boundary

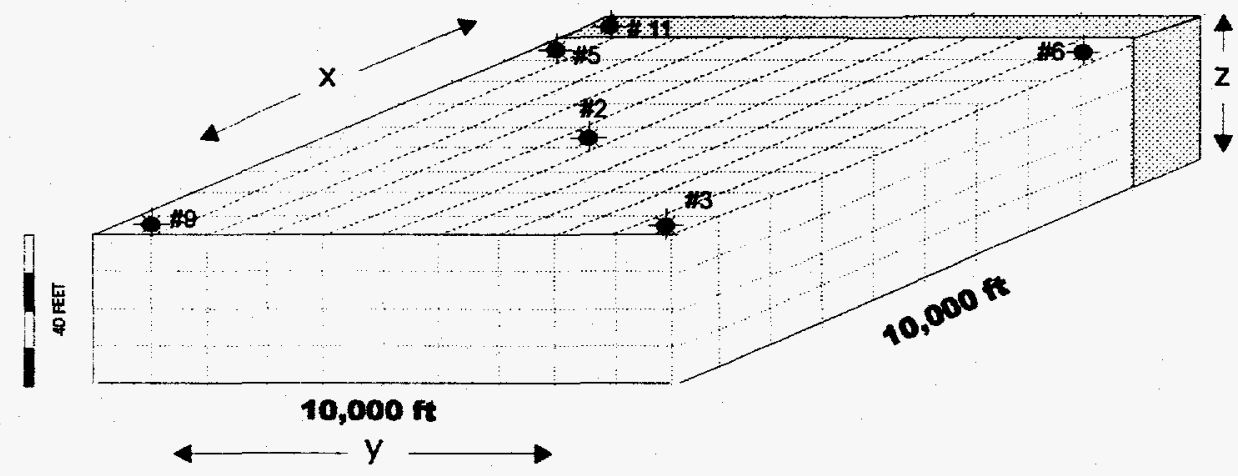

The following figure illustrates the average reservoir pressures and cell pressure of the thief well during withdrawal and injection over a 365 day cycle ( 180 days injection and 180 days withdrawal). Also shown is the cumulative gas production (or gas migration) from the storage reservoir into the thief interval. Total gas migration (loss) during the injection cycle is 75 MMCF. The average reservoir pressure is shown below and is around $1200 \mathrm{psi}$ at the beginning and end of the withdrawal and injection cycle. At the end of the withdrawal cycle the pressure at the thief zone was around $400 \mathrm{psi}$ and gas did not migrate out of the storage formation. Migration did not occur until gas injection commenced. Average injection pressure was $1900 \mathrm{psi}$ in this case.

The gas migration during the injection cycle represents $0.33 \%$ of the working gas or $0.14 \%$ of the GIP.

Figure 15: Gas Migration - 1900 psi inj 
Thief Zone Migration Affect

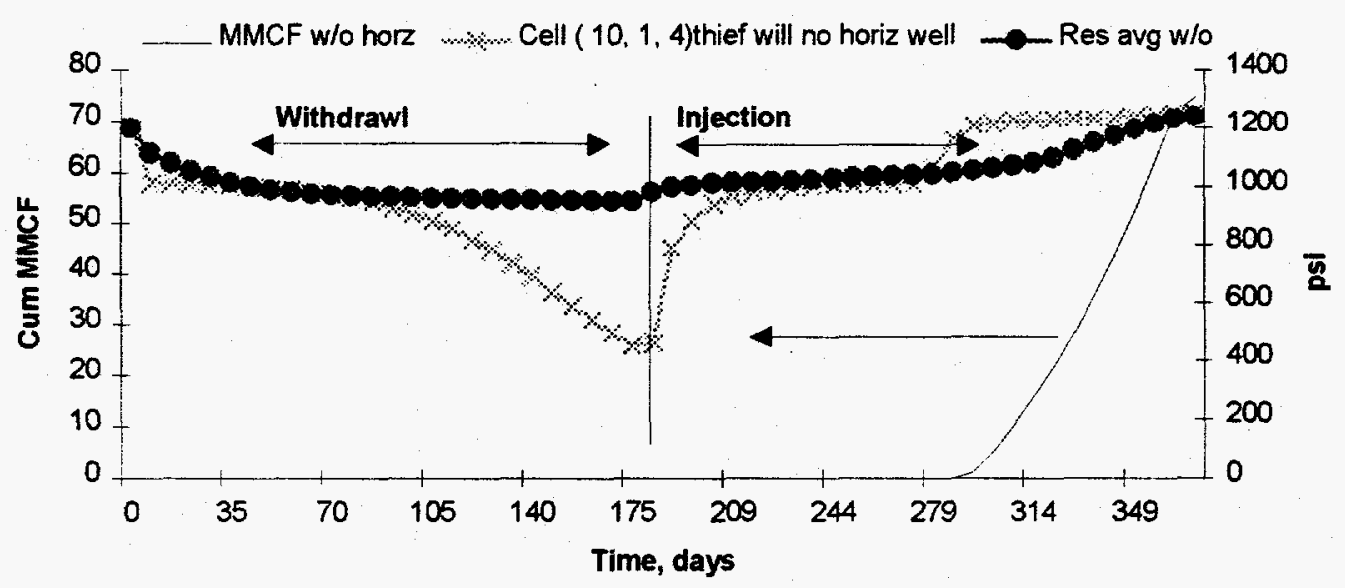

The following graph illustrates the effect of increased injection pressure on gas migration in comparison to the previous slide. At 2500 psi injection pressure gas migration totals 350 MMCF compared to $75 \mathrm{MMCF}$ at $1900 \mathrm{psi}$ injection pressure. The total gas migration at increased injection pressures represents $1.62 \%$ and $0.7 \%$ of the working and gas in place respectively. This situation could arise when storage operators have opted to inject gas into storage over a shortened injection period at higher pressures. Also shown, is the gas migration associated with a horizontal injection well at 2500 psi injection pressure. This will be discussed later.

Shown below is the volume (MMCF) versus the ratio (Current GIP/ OGIP). At initial withdrawal, this ratio is 1 , while during withdrawal the original gas in place (OGIP) remains constant while the current GIP declines with production. Under normal operating conditions, the reservoir is filled and the ratio again is 1 at fill up. If the storage reservoir is over-pressured, such as shown in the following example, the ratio exceeds 1 . In this example, injection commences at a ration of 0.6 . 
Figure 16: Gas Migration - 1900 \& 2500 psi inj

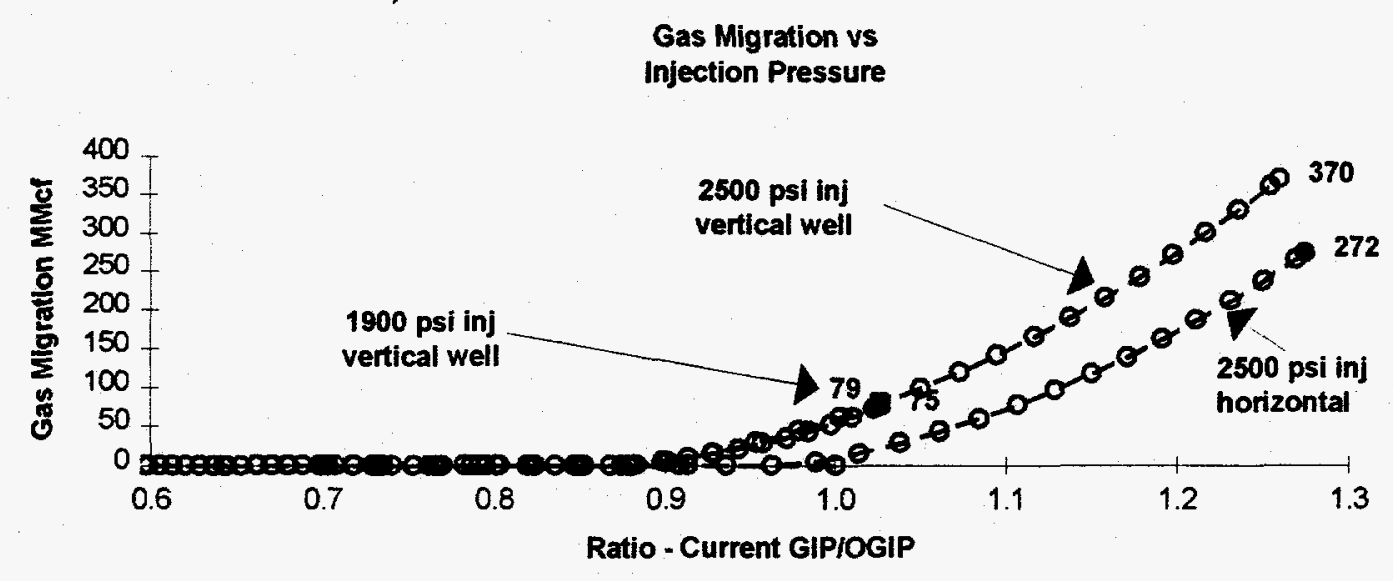

\subsubsection{Mitigation Strategies}

One method to reduce injection pressures are to drill horizontal wells. This will reduce the delta pressure during injection and still allow the operator to maintain higher injection rates. This strategy was evaluated next.

The following figure shows the placement of the horizontal well $(3,000$ ') in length completed in layer $1(100 \mathrm{md})$ as shown below.

Figure 17: Horizontal Grid

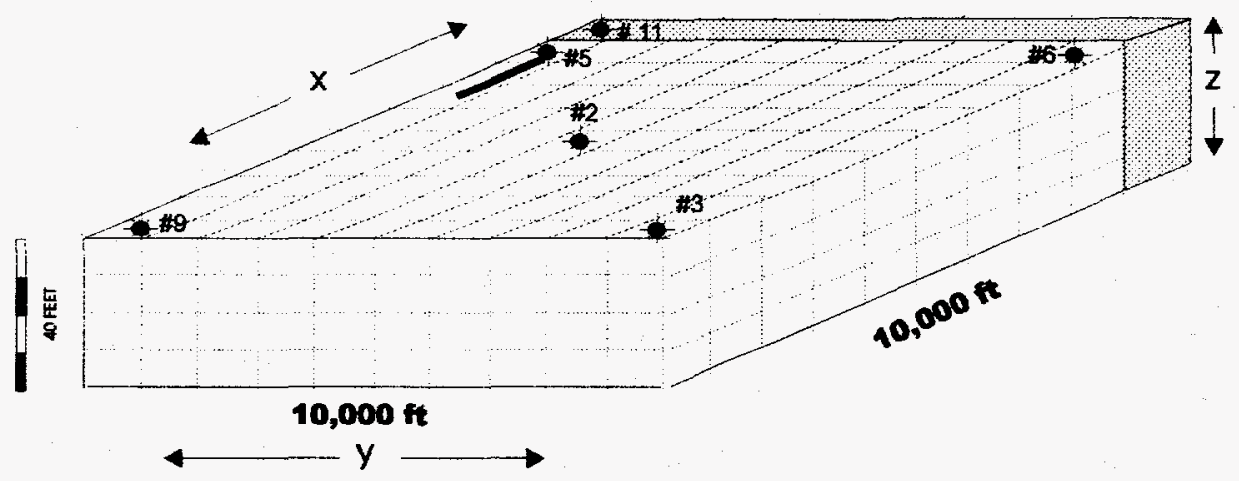

Gas migration was evaluated for vertical well injection at 2,500 psi injection pressure and compared with horizontal injection at $2,500 \mathrm{psi}$. This comparison is shown below for wells of varying lengths. The at 2,500 psi at the end of a 365 day cycle totaled 370 MMCF. Net migration loss as a result of horizontal injection was reduced from 370 to $165 \mathrm{MMCF}$ for a 3,000 ft horizontal well. Gas migration for 1,000 and 2,000 wellbores are also shown below. 
Figure 18: Horizontal and Vertical Injection Comparison on Migration

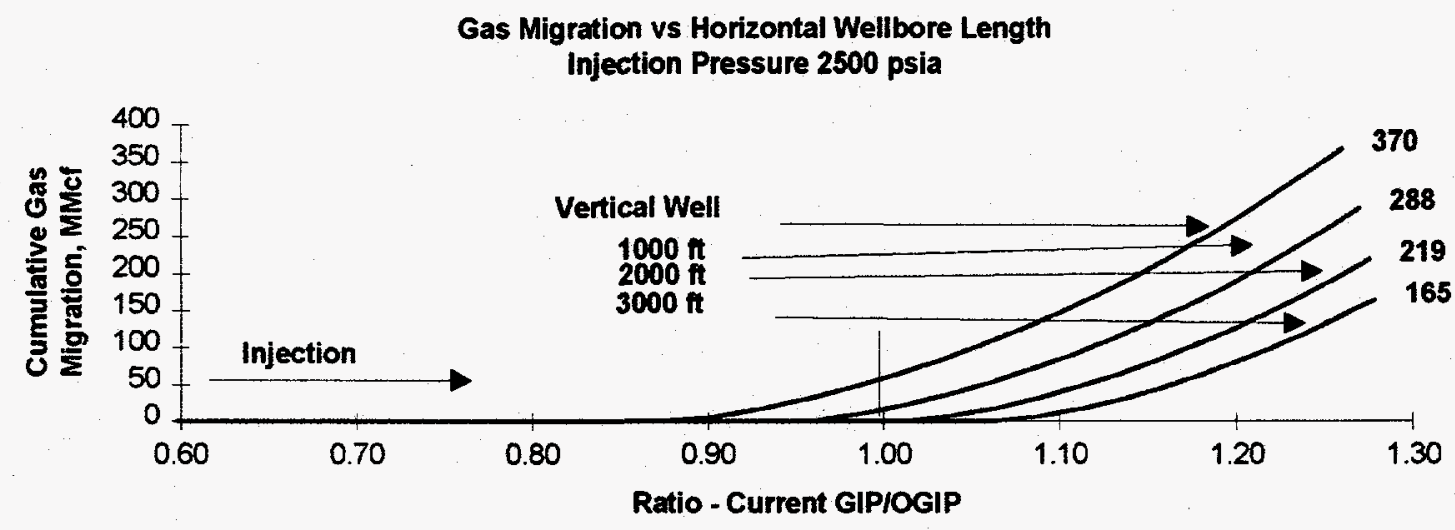

The following graph shows the same relationship for each case evaluated in addition to the average reservoir pressure as a function of the ratio is also shown. The vertical arrows indicate a ratio of 1 for each case. For the vertical well at the original reservoir pressure the gas migration is $75 \mathrm{MMCF}$ and decreases with horizontal wellbore length. No gas is has migrated from the storage formation at well bore lengths in excess of one thousand fee. $\left(1,000^{\prime}\right)$. Ratios exceed 1.2 which indicates over pressure of the storage reservoir.

Figure 19: Gas Migration vs. Horizontal Wellbore Length

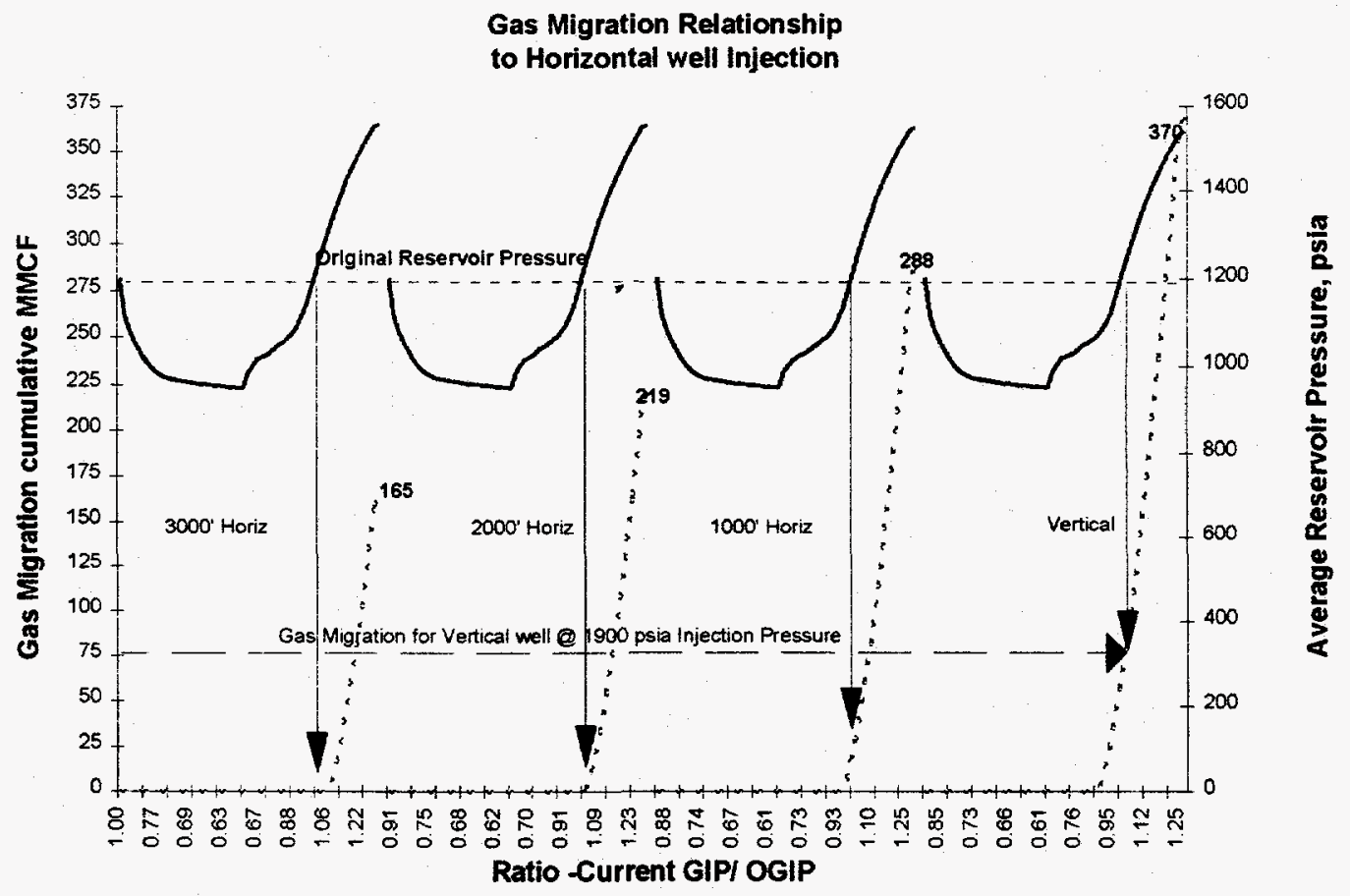




\subsection{AQUIFERS}

Today, aquifer storage accounts for $18 \%$ of the total working gas capacity and daily deliverability in the United States. Most of the aquifer storage is located in the Midwest in the states of Illinois, Indiana, and lowa. ${ }^{64}$

Figure 10-20: Location of Aquifer Storage Reservoirs in the US

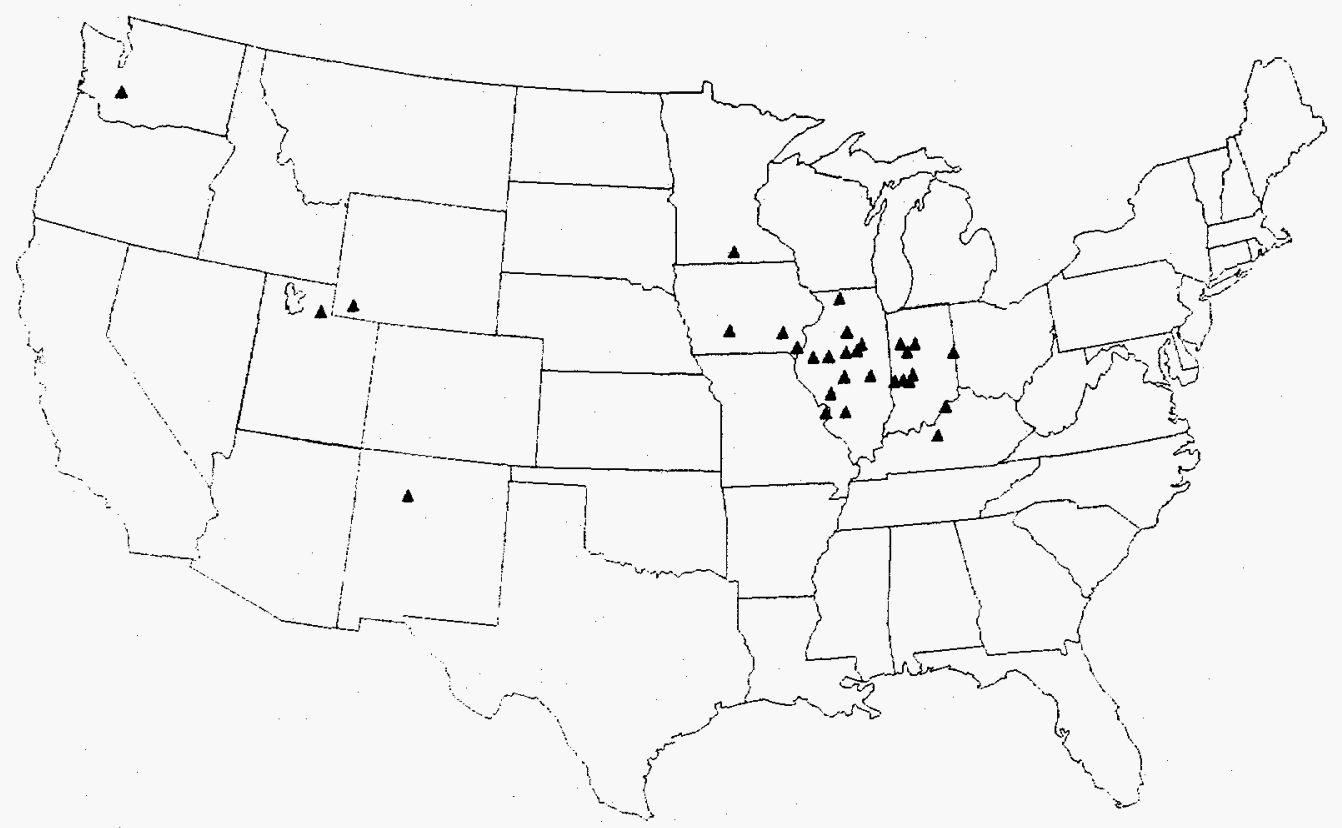

atter: Energy Information Administration, "The Value of Underground Gas Storage in Today's Natural Gas Industry", p. 2

An aquifer storage site is a water-only reservoir conditioned to hold natural gas. Such sites are usually used as storage reservoirs only when depleted gas or oil reservoirs are not available. Aquifers have been developed exclusively in market areas. In general, aquifer storage is more expensive to develop and maintain than depleted gas or oil reservoir storage. ${ }^{62}$ In all but 2 cases, the traps are structural anticlines. (The exceptions are stratigraphic traps in carbonate reefs.) The storage reservoir is selected on the basis of geological or geophysical data that indicate the presence of an anticline, which is an underground structural "hill". The anticline helps contain the storage system, which is started as a bubble of natural gas. The aquifer is tested for porosity, permeability and integrity. A caprock must cover the aquifer and must be highly impermeable and impervious (such as shale or dense carbonate rocks). ${ }^{63}$

Aquifer storage fields, located exclusiveiy in the Midwest, are generally newer than those in the Northeast, and gas migration from aquifer reservoirs tends to be identified earlier in the operation of the field. Small, ongoing gas migration in aquifers is usually tolerated, and corrective measures (such as trapping and reinjecting the migrating gas) were reportedly taken to mitigate problems. In cases with significant or untreatable gas migration, the problem field was abandoned. In any case, operators are generally aware of migration in aquifer reservoirs.

\footnotetext{
${ }^{61}$ Ibid.

${ }^{62}$ Energy Information Administration, The Value of Underground Storage in Today's Natural Gas Industry, p. 48

${ }^{63}$ Underground Storage, p. 5
} 
However, there are several reasons why an aquifer is a less desirable site for natural gas storage, if depleted gas fields are available. An average of 4 years is needed to condition the site, which is twice as long as for an average depleted gas or oil field. Unlike a depleted site, the geology of an aquifer site is unknown beforehand. As a result, seismic testing must be performed to determine its geologic profile. Confinement area of the reservoir, the location and type of the caprock ceiling barrier, existing reservoir pressure, and the porosity and permeability of the reservoir rock are important characteristics. The potential capacity of the reservoir is also unknown and can only be determined as the site is further developed. ${ }^{64}$

All new facilities must be installed, including wells, pipelines, dehydration facilities, and compressor operations. Aquifer storage sites may also require additional facilities such as greater compression for injection purposes (to push back the water), more extensive dehydration facilities (which are not always needed at gas reservoir sites), and collector wells drilled into formations above the caprock, which recover gas that may penetrate out of the storage zone. However, because of the additional pressure support behind an aquifer's water drive, in most instances, higher sustained deliverability rates than gas or oil reservoirs can be designed and incorporated at the site. ${ }^{65}$

No native gas is present in an aquifer formation. Thus, base or cushion gas must be introduced into the reservoir to build and maintain deliverability pressure. While base gas in depleted gas/oil storage reservoirs usually is about $50 \%$ of total capacity, base gas in aquifer storage may constitute as much as $80-90$

$\%$ by the time the site is fully developed for gas storage. ${ }^{66}$

The sustained delivery rate cannot exceed design limits. Otherwise, unlike depleted oil and gas reservoir storage, where cushion gas can be tapped when needed, tapping cushion gas in an aquifer storage site can have an adverse effect upon reservoir performance. ${ }^{67}$

\subsubsection{Gas Migration}

The possible migration of gas from the connected gas body in an aquifer via wells or otherwise consists of the following:

- gas migration through imperfect cementing at casing shoe or opposite any leak in casing joints or cementing tool,

- gas displacing water through a saddle separating it from the gas bubble,

- gas migration vertically through imperfections in caprock or due to low local threshold pressures. $^{68}$

Gas storage losses are often reported as an increase in cushion (base) gas, particularly for gas storage in aquifers (FERC-personal communication) or in depleted reservoirs with active water drive. Migration of gas, into tighter areas of the formation, or solution of gas in the water or the creation of isolated non-recoverable pockets of gas are the primary mechanisms of gas migration in these instances. Approximately $25 \%$, or one-quarter of the storage fields (incl. aquifers) have an active water drive. Aquifers, which constitute $11 \%$ of the storage reservoirs and $18 \%$ of the stored gas volume, are used for gas storage exclusively in the Midwest

\footnotetext{
${ }^{64}$ Energy Information Administration. The Value of Underground Storage in Today's Natural Gas Industry, p. 48

${ }^{65}$ Ibid.

66 Ibid.

${ }^{67}$ Ibid., p. 49

${ }^{68}$ Tek, M.R. and Katz, D.L., New Cancepts in Underground Storage of Natural Gas, American Gas Association (AGA), New York, NY, March, 1966, p. 11.
} 
The major testing on aquifer reservoirs is done on the caprock. This cap must be so impermeable that gas cannot escape into shallower strata. In some cases leaks occur, but remedial work is done to capture the low-pressure gas by production and redirect it into the aquifer. When gas migration cannot be stopped, or the escaped gas cannot be recovered, the project may have to be abandoned. ${ }^{69}$

To assure that no anomalies exist in the caprock integrity, water pump tests are conducted to create a pressure differential across the caprock. Absence of direct fluid communication is ascertained from water levels observed in wells completed across the caprock. ${ }^{70}$

Aquifer storage reservoirs require gas injection at pressures above the initial value in order to displace the water when creating the gas reservoir. In Illinois and lowa, the delta pressure above discovery ranges from some small value like 25 psi to some 300 or 400 psi. $^{71}$ Aquifers can exhibit a low operating pressure differential. Gas can be injected into the aquifer at almost any pressure above the pressure of the actual stratum, although the best differential is in the range of 100 to 200 psi. This low differential pressure is also the main disadvantage to an aquifer. The very fact that the pressure in the reservoir must be raised above the hydrostatic pressure may cause the worst problem encountered with aquifers: leaks. Anytime an aquifer is raised above its natural pressure limit there is a possibility of a leak. ${ }^{72}$

The reservoir has limits to its volumetric capacity. The anticline that determines the limits of the gas bubble may cease its downward trend and a syncline can form. When the size of the bubble increases past the limits of the anticline trap, the storage gas that escapes is usually unaccounted for. ${ }^{73}$ For aquifers or converted gas fields with water drive, this problem may arise especially when there is not sufficient closure along the caprock. It is well known that some of the injected inventory fingers away from the main bubble. ${ }^{74}$ If the vertical permeabilities of the aquifer formation are very low, then lateral movement of the gas bubble will be more pronounced, causing undue finger of the gas bubble if too high a pressure differential is used. ${ }^{75}$ Without satisfactory withdrawal wells to produce gas from these thin gas zones, the gas does not depressurize. Should it remain at higher pressures, it will continue to grow in size. At some point it can be out of control and pass a saddle to separate it from the main gas body. ${ }^{76}$

The time to develop the desired size of a gas bubble is difficult to predict since there are variations in pressure gradients in the water as injected gas compresses the water surrounding it. One difficulty is predicting the effective compressibility of the aquifer system. Another is handling the long time effects for storage reservoirs after many years of operation. ${ }^{77}$ Also, gas migration can occur through fingering of the gas bubble during injection.

Aquifer storage has at least one other characteristic that is unique among storage reservoirs: water. Water dissolves almost any material, given enough time, temperature, and pressure. The molecules of natural gas, like other gaseous compounds, have a wide lattice structure. Because of this structure, gas goes into solution rather easily with water, consequently, some storage gas is dissolved in the water and can never be economically recovered. ${ }^{78}$ Hence, there is usually a higher cushion to top gas ratio than in conventional depleted-reservoir storage fields. Whether

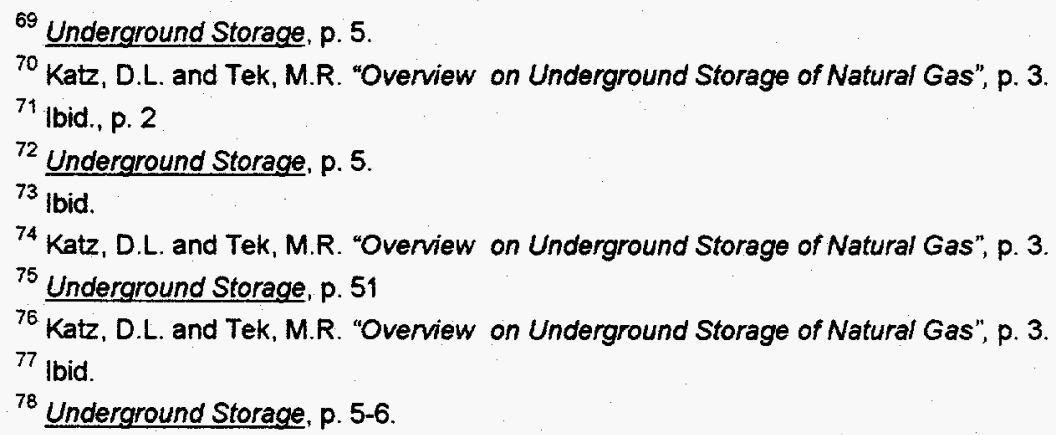


the use of a cheaper inert gas for cushion gas could allow further aquifer storage development is debatable. $^{79}$

\subsubsection{Inventory Verification}

Gas storage reservoirs with an active water drive require a different method of inventory verification because of pressure support received from encroaching water. The method used to determine migration in fields with an active water drive (native gas or aquifer fields) is based on changes from year to year in the cumulative volume of gas withdrawn before the fields are essentially flooded by encroaching water. The abilitys of a field with an active water drive to produce gas is nearly constant until encroaching water floods the wells and causes their ability to produce gas to rapidly decline and approach zero. The rate of decline of deliverability as water encroaches has been similar from year to year and it is clear that the fields are near depletion when the point of rapid deliverability decline is reached. Therefore, the difference in cumulative production when the deliverability has declined to a given daily volume, for any two withdrawal seasons that are compared, plus any increase in total field inventory that may have occurred between such withdrawal seasons, will indicate the extent of the gas migration. ${ }^{80}$

A non-leaking aquifer undergoing gas injection during the summer is over-pressured and is pushing water out. A good test for migration is to close the reservoir in (i.e. cease injection) and observe the pressures. The pressure on a non-leaking aquifer will fall off gradually and come to the original aquifer pressure asymptotically. A leaking aquifer will have a sudden drop in reservoir pressure down though the original aquifer pressure. Then as the pressure goes below the original aquifer pressure, water enters the leak passages and restricts or shuts off the leak ${ }^{81}$ as illustrated by the following graph:

Figure 10-21: Leaking vs. Non-Leaking Aquifer Pressure Curves

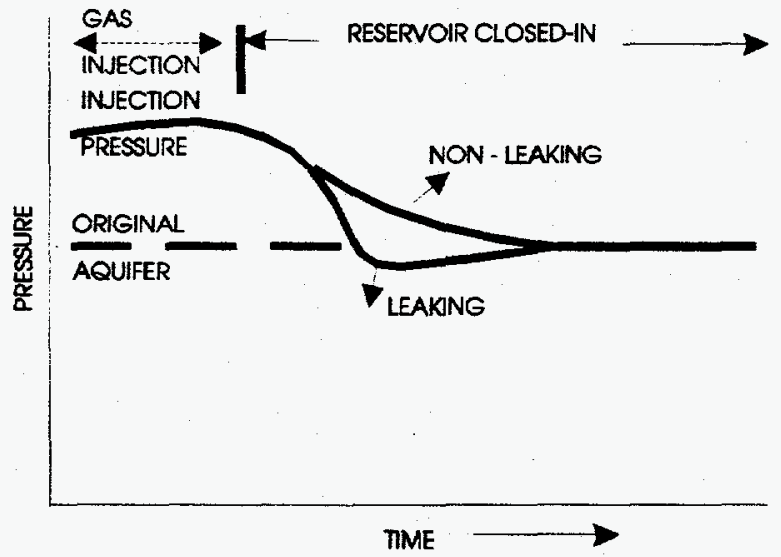

from Katz, D.L. and Coats, K.H., Underground Storage of Fluids, 1968.

Soon the pressure will cease dropping and may be expected to rise a few pounds back up to the original aquifer value should the migration be stopped. The power of water to reseal a leaking aquifer in essence make possible the pilot trials of gas storage when there is a secondary

\footnotetext{
79 Ibid, p. 41

${ }^{80}$ Mayfield, J.F., "Inventory Verification of Gas Storage Fields", SPE Paper No. 9391, presented at the 55th Annual Fall Technical Conference \& Exhibition of the SPE of AIME, Dallas, TX, Sept. 21-24, 1980., p. 3.

${ }^{81}$ Katz, D.L. and Coats, K.H., Underground Storage of Fluids, Malloy Lithographing, Inc., Ann Arbor, MI, 1968.
} 
caprock which will withstand a nominal overpressure. Another characteristic of a leaking aquifer is for the injection wells to go to water as the injected gas moves upward. ${ }^{82}$

\subsubsection{Mitigation Strategies}

\subsubsection{Horizontal Wells}

Horizontal wells can be an effective mitigation strategy for both depleted reservoirs and aquifers in fractured reservoirs, thin reservoirs and reservoirs with gas and water coning problems.

\subsection{Fractured Reservoirs}

In naturally fractured reservoirs, especially those with vertical fractures, severe coning can occur despite high reservoir permeability. This is because bottom water and top gas travel through high-permeability (vertical) fractures. This is especially true in fractured reservoirs with low matrix permeability, and large matrix blocks where water imbibition in the matrix is very slow. There are several fractured limestones and reef reservoirs, where coning problems are severe due to high vertical fracturing. The only way to reduce coning is to minimize pressure drawdown. ${ }^{83}$ In some wells, especially those drilled in a fractured reservoir with a bottom water, water may break through in a certain portion of the long horizontal well.

\subsection{Thin Reservoirs}

Horizontal wells offer an alternative in thin, low-permeability gas reservoirs. These reservoirs are characterized as tight formations which produce at low rates. Factors influencing the effectiveness of horizontal boreholes include:

1. Penetration Length

2. Reservoir Thickness

3. Formation Anisotropy

For equal surface area the production from horizontal boreholes is expected to be greater than that of hydraulic fractures in a vertical well. Production rates increase with an increase in penetration lengths. The reservoir thickness is a critical factor in determining the feasibility of a horizontal borehole. Positive results using horizontal boreholes are more apparent in thinner reservoirs and tighter formations. In the case of anisotropic reservoirs it is suggested that horizontal boreholes be drilled perpendicular to the largest permeability direction ${ }^{84}$

Often, repeated hydraulic stimulations (fracturing) of injection and withdrawal wells cause damage to the formation (skin) around the wellbore. This skin lowers deliverability rates on withdrawal wells and increases the injection pressure for injection wells. Increasing the injection pressure can cause the gas to migrate into low permeability zones beyond the reservoir limits. Horizontal wells can provide an alternative to this scenario. The horizontal borehole allows for greater communication with the formation without resorting to the necessity of hydraulic stimulation and the resultant formation damage. The delta $P$ (relative difference in formation pressure vs. the higher pressure used to inject gas) is less than for vertical wells, so there is less possibility of injecting gas beyond the reservoir limits.

82 Ibid., p. 331-332.

83 Joshi, J.D., Horizontal Well Technology, PennWell Publishing Company, Tulsa, OK, 1991.

${ }^{84}$ after Sung, W., and Ertekin, T., "Performance Comparison of Vertical and Horizontal Hydraulic Fractures and Horizontal Boreholes in Low Permeability Reservoirs: A numerical Study", SPE/DOE Paper No. 16407, SPE/DOE LOW Permeability Reservoirs Symposium, Denver, CO, May, 1987. 
Another alternative for dealing with formation damage is to cement and perforate the horizontal well, as is done for vertical wells. Perforations may extend past the drilling damage. A cemented horizontal well is preferred if the well is to be fractured. The well can be isolated in several zones along its length by using bridge plugs and each zone can be fractured independently

\subsection{Reservoirs With Gas And Water Coning Problems}

In reservoirs where the bottom water or top gas cap renders fracturing difficult, a horizontal well offers an alternative to obtain high production rates without gas and water coning. ${ }^{85}$ This technology can therefore be an alternative to vertical wells in an aquifer or depleted water drive reservoir, where coning can be a problem, especially during withdrawal season on peak days where high flow rates occur.

One of the main reasons for coning is pressure drawdown. A vertical well exhibits a large pressure drawdown near the wellbore, which causes coning. Inversely, the a low pressure drawdown exhibits minimum coning tendency. To achieve a given production rate, a larger pressure drawdown has to be imposed in a low-permeability reservoir than in a high-permeability reservoir. Thus, low-permeability reservoirs (less than one darcy) have a greater tendency to exhibit coning. ${ }^{86}$ The only way to reduce coning is to minimize pressure drawdown.

High pressure drop occurrence is mainly due to turbulent flow in the wellbore. To minimize the wellbore pressure drop, it is desirable to have laminar flow through the wellbore, or at least to have the minimum possible flow velocities through the wellbore. One way is to consider drilling the largest possible size hole, and choosing the largest possible liner sizes that can be sagely inserted in a hole without getting stuck. For a given production rate, by increasing the well diameter twofold, the pressure drop can be reduced by at least thirty-two fold. For single phase flow, the pressure drop is inversely proportional to the fifth power of the diameter.

Pressure drop along the well length can be minimized by controlling fluid production rates along the well length. (Critical rate is defined as a rate below which flow will be laminar.) This can be accomplished by manipulating the area open for fluid entry into a wellbore. If the well is to be completed using a slotted or pre-drilled liner, one can vary the hole or slot sizes along the well length so as to minimize pressure drop along the well length. In the case of a cemented hole, on can change not only shot density, but also perforated interval length to minimize pressure drop along the length.

In a high-permeability formation, where pressure drop through a horizontal wellbore is comparable to the reservoir pressure drawdown, a gravel pack will probably be used to complete the well. In such cases, if the well is completed with a perforated liner, then fluid entry points into the wellbore, i.e., sots, should be placed as far apart as possible. This will let gravel pack act as a choke for each slot and facilitate maintaining minimum pressure drops along the well length. Thus, if wellbore pressure drop is found excessive, then in the well planning stage an appropriated completion scheme can be designed to minimize well bore pressure drop.

In a horizontal well, fluid enters the wellbore along its length. A maximum possible pressure drop can be obtained by assuming that all flow enters the wellbore at the nonpumping end of the wellbore. Conversely, minimum pressure drop can be calculated by assuming that the total flow enters the wellbore in the last foot of the pumping end. These two would give a range of numbers within which actual pressure drop would occur. It is easier to calculate maximum pressure drop first and compare it with the drawdown. If the maximum pressure drop is very

\footnotetext{
${ }^{85}$ Joshi, S.D., "A Review of Horizontal Well and Drainhole Technology", SPE Paper No. 16868, 62nd Annual Technical Conference and Exhibition of the Society of Petroleum Engineers, Dallas, TX, Sept. 1987.

${ }^{86}$ Joshi, J.D., Horizontal Well Technology, PennWell Publishing Company, Tulsa, OK, 1991, chapter 8.
} 
small as compared to the reservoir drawdown, then pressure drop through the wellbore can be ignored. In contrast, if wellbore pressure drop is significant as compared to the reservoir drawdown additional calculations are necessary.

The pipe diameter plays an important role in the magnitude of the pressure drop. Drilling large holes is important for horizontal wells that are expected to produce at high rates.

Pressure drop through a horizontal wellbore also depends upon the fluid-entry profile. Assuming a single phase with all fluid entering at the nonpumping end of the horizontal wellbore, would give an uppermost limit of the expected pressure drop. The other entry profile is uniformflux profiles, which assume the same amount of fluid entry per unit length of a horizontal well. Different flow profiles for the fluid entry into the wellbore depends upon the well-boundary condition-either infinite-conductivity or uniform-flux. Additionally, several other fluid entry profiles are possible, depending upon the reservoir heterogeneity along the well length and the pipe frictional pressure drop. The magnitude of wellbore pressure drop could have a significant influence on well productivity, provided reservoir drawdown is also on the same order of magnitude as the wellbore pressure drop (which is most likely to occur in high-permeability reservoirs)

\subsubsection{Use Of Foam To Reduce Gas Migration}

One specific aspect of underground storage of. natural gas--migration of gas beyond the designated storage area during the gas injection cycle--is being addressed by $G R I$ in its research Project being undertaken at Lawrence Berkeley Laboratory (LBL) in Berkeley, California. During the formation of the initial storage volume in an underground aquifer, some of the injected gas will ringer away from the main bubble, sometimes for long distances, because of the adverse mobility ratio between water and gas. This migrated gas is often difficult to recover, thereby, leading to a reduced percentage of working gas. It is, thus, important to devise effective means of controlling such migration in underground gas storage fields.

As early as 1970, Bernard and Holmes proposed to take advantage of the ability of foam to block-gas flow to seal natural leaks in the gas storage facility. By injecting a slug of surfactant solution before basis injected, a foam blanket is formed between the initially water-filled aquifer and the gas behind it. The foam blanket acts to stabilize the interface between the gas and water during the injection phase, thereby, improving the displacement efficiency, minimizing gravity heterogeneity to a multi-well configuration to lower the "spill point" in an existing storage aquifer.

One possible solution that GRI is perusing at LBL calls for using a natural gas/water foam as a mobility control agent. Because the proposed foam would contain over $95 \%$ by volume of natural gas, it would provide a compatible and an easily applied source of mobility control Specifically, the LBL research effort is designed to answer the following analytical and technological

- What is the applicable state-of-the-art as far as the use of foam as a mobility control agent is concerned?

- What are the desirable properties of foam stabilizing chemicals? What are the selection criteria governing the choice of a given foam stabilizer?

- How is the foam generated in the porous media? How does it actually flow? Can this behavior be simulated mathematically?

- Is the foam barrier concept technically feasible? If yes, how can it be verified or validated experimentally?

- What are the preliminary economics of foam-protected gas storage reservoirs? 
The primary objectives of the LBL research project were to assess feasibility of using foam as a mobility control agent to reduce migration in aquifers, to understand the foam flow behavior, to develop foam stabilizing/breakup agents, and to experimentally verify the foam barrier concept.

\subsubsection{Completion Planning For Elimination Of Sand Production In Thinly-Bedded Aquifer Gas Storage Wells}

Sand and fines produced during withdrawal from thin, friable beds in aquifer gas storage reservoirs abrade and constrict production hardware, damage seals, and eventually fill the wellbore, leading to costly clean out and repair operations. The chief cause of sand production and its subsequent reduction of injection and withdrawal efficiency is a high-pressure drop across the completion.

Completion planning to minimize pressure losses are difficult because it must account for fluctuating pressures, relative permeability, and reservoir flow characteristics across a wide range of operating conditions. In the case of anisotropic formations, planning and evaluation become still more complicated because individual rock and fluid properties deviate substantially from the collective average. A new type of high shot-density perforator simplifies planning and execution of new completions by shortening the distance fluid must travel across the lowest permeability of any given bed.

The perforator provides a unique geometrical pattern of perforations along the axis and around the radius of the wellbore which also minimizes pressure-dependent problems associated with variable rock strength. Downhole videophotography confirms that sand influx has been averted in a well completed with this perforator after two injection and withdrawal cycles and that high shot-density did not damage casing. The completion technique circumvents the high costs of plastic consolidation used in other wells or other remedial techniques that were considered.

- Fixed, average characteristics of formation and fluid properties are difficult to apply when planning compilations in thinly-bedded or otherwise anisotropic formations. Core analysis can be helpful to evaluate potential sources of high-pressure drops in the flowing well system during normal injection and production operations.

- Sequentially-spaced, high shot-density perforators simplify planning and minimize completion pressure drops caused by effective reductions of interval height and relative permeability as completion attributes fluctuate.

- Casing is not damaged by high shot-density hollow carrier perforators.

- The technique described has proven to be cost effective when compared to plastic consolidation techniques, which do not address the sources of destructively highpressure drops. The incremental cost of additional perforations is less than $8 \%$ of total expenditures required for furnace resin injection.

- In the case of completions in anisotropic formations, production systems analysis is more useful for sensitivity studies and limited, post completion evaluation to determine the model's dependence on uncertain input variables than for selection of a specific initial shot density.

\subsection{LEACHED CAVERNS}

Leached (solution-mined) cavern storage, also called salt dome storage, is developed by injecting fresh water into a salt formation (leaching) and removing the resulting brine. The size of the cavern increases as more fresh water is injected and the resulting brine removed. The 
reservoir shape can be controlled by this method of salt water removal, and the size of the needed storage space determines the actual size of the cavern. ${ }^{87}$

Figure 10-22: Location of Cavern Storage in the US

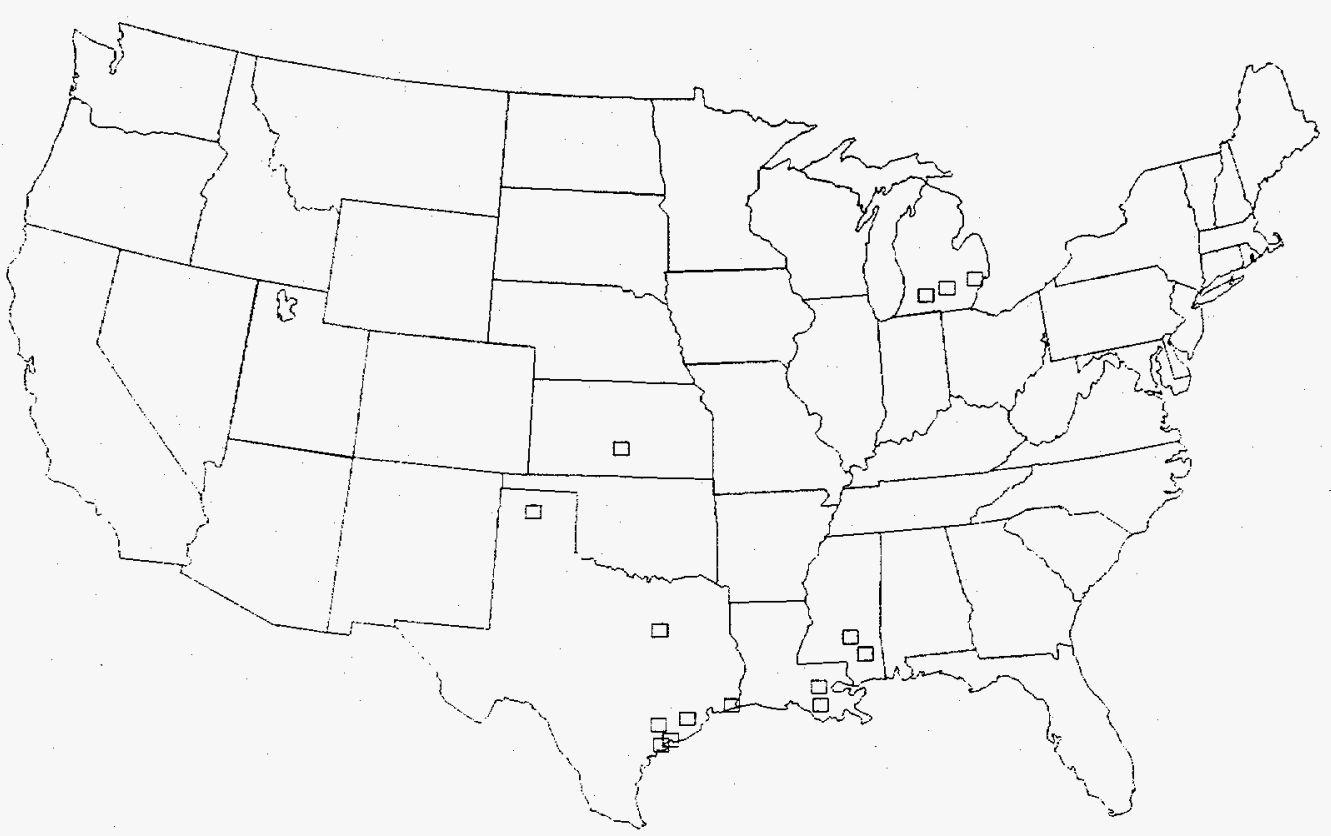

after: Energy Information Administration, "The Value of Underground Gas Storage in Today's Natural Gas Industry" , p. 2

Salt dome storage is an excellent method of storage for peak shaving. The only problem is that salt domes in the United States occur primarily in the Gulf Coast region. Salt also can be found in other parts of the United States in layers or beds. It is possible to leach a storage cavern in these salts. However, bedded salts are often not very pure (sometimes containing interbedded layers of insoluble materials that complicate the leaching process) and are often not thick enough for a large cavern. ${ }^{88}$

Most of the nation's salt dome storage facilities are located in Texas, Mississippi, and Louisiana. Although used effectively by electric utilities in the South to satisfy daytime peak cooling loads during the summer, several salt cavern operations located in Louisiana and Mississippi has attracted LDC's as well as other types of customer located in the North Eastern US. Perhaps in response to this demand, several salt storage sites are being developed in New York State in bedded salt formations. These facilities would augment directly the operations of nearby gas distribution companies. ${ }^{89}$

Salt cavern storage is the most costly of the three types of facilities to develop, often 2 to 3 times more expensive. Because they are susceptible to cavern wall deterioration over time and to salt water incursion, these facilities may incur high workover costs, as well as additional expenses for special equipment on site. ${ }^{90}$

However, deliverability rates are high because a salt formation reservoir is essentially a highpressure storage vessel (that is, an underground tank $^{91}$ or closed container with infinite

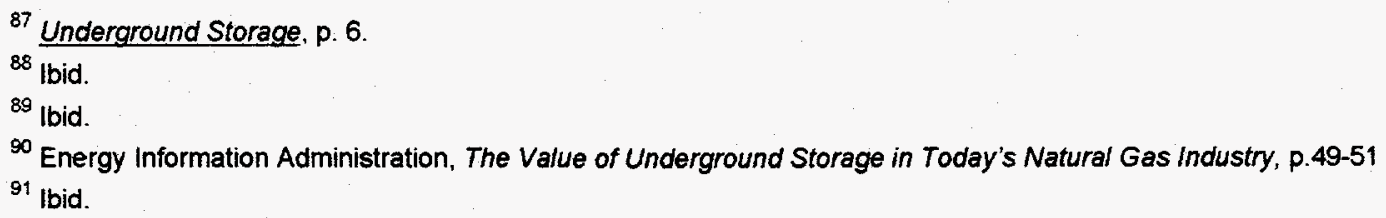


permeability.) Deliverability is determined by pressure, production casing size, and surface facilities. ${ }^{92}$ Base gas requirements are low (about $25 \%$ ) and can usually be with drawn fully in an emergency. On average, salt formation storage is well suited for meeting large swings in demand ${ }^{93}$ Consequently, salt dome storage is an excellent peak-shaving means of storage. ${ }^{94}$

Development time is also much less for salt formation storage than for gas/oil field reservoirs. On average, it takes about 18 to 24 months to develop a salt reservoir while a gas/oil field reservoir takes 24 to 36 months. Thus, a new salt formation storage site will begin to pay off sooner than a gas/oil field reservoir. ${ }^{95}$

For the same working gas capacity, new salt formation storage reservoirs are also capable of yielding much greater revenues in a heating season than conventional gas/oil field reservoirs. This is because the working gas capacity of a salt formation storage facility can be turned over three, four, or more times during a heating season while generally a depleted field operation can be turned over only once. ${ }^{96}$

In comparison to salt domes, a salt bed storage site is generally developed from a much thinner salt formation (1,000 feet or less) located at shallower depth. As a result, the height-to width ratio of the leached cavern is much less than with dome reservoirs, which are relatively high and narrow. Salt bed storage formations also contain much higher amounts of insoluble particles (shale and anhydrite rock) than salt dome formations., These materials remain in the reservoir after the leaching process and affect the flow velocity and capacity of the reservoir itself. In addition, because the height/width aspect is thin, the flatter reservoir ceiling is subject to greater stress and potential wall deterioration. As a result of these as well as other factors, salt bed storage development and operation can be more expensive than that of salt dome storage. ${ }^{97}$

\subsubsection{Gas Migration}

Salt formations have several properties that make them ideal for storing natural gas. A salt cavern is virtually impermeable to gas and once formed, a salt reservoir's walls have the structural strength of steel. Thus, gas cannot easily escape the large hollowed-out shape that forms a salt storage cavern. ${ }^{98}$

\subsubsection{Mitigation Strategies}

A salt cavern site occupies a much smaller area than an oil or gas reservoir. On average, the amount of acreage taken up by a depleted gas/oil field reservoir is more than a hundred times the amount of acreage taken up by a salt dome. Consequently, a salt cavern storage operation is generally easier to monitor than a gas/oil field reservoir operation made up of many wells. ${ }^{99}$

There are 2 basic types of salt formations used to store natural gas: domes and beds. Salt domes are very thick salt formations. A salt dome formation might be a mile in diameter, 30,000 feet in height, and begin about 1,500 feet below the surface of the earth. The depth of the caverns that are hollowed out within the formation is critical for reasons of pressure and structural integrity. The pressure at which the gas can be stored is a function of the depth of the cavem. However, at extreme depth, as temperature and pressure increases, salt behaves as a plastic

\footnotetext{
92 Underground Storage, p. 6.

${ }^{93}$ Energy information Administration, The Value of Underground Storage in Today's Natural Gas Industry, p.49-51

${ }^{94}$ Underaround Storage, p. 6.

${ }^{95}$ Energy Information Administration, The Value of Underground Storage in Today's Natural Gas Industry, p.49-51.

${ }^{96}$ Ibid.

${ }^{97}$ Ibid.

98 Ibid.

99 Ibid.
} 
and will creep or flow, which can become a major consideration in cavern construction possibly leading to cavern closure. Thus, salt storage is generally limited to depth shallower than 6,000 feet. $^{100}$

The problem with salt dome storage is the salt. As mentioned, salt, especially at higher temperatures, is a plastic substance with a tendency to flow. The salt cavern shrinks over time, and with it the reservoir size. The amount of shrinkage can be controlled to a certain extent by the shape of the caverns, pressure, and depth. A mushroom shape and high operating pressures seem to retard shrinkage, but, when gas is needed and withdrawn, the pressure is lowered and shrinkage occurs. The caverns must be releached periodically to maintain an approved design size. The frequency of releaching is governed by cavern pressure, design size, temperature, depth, and economics. The releaching process is lengthy and expensive, lasting a year or longer and costing several million dollars, depending on the size of the cavern. The cavern cannot be used for storage of natural gas during the releaching operation, but other caverns of the facility can. ${ }^{101}$

In Germany, a total of 36 storage caverns, at 8 locations, are currently in operation. The following measurements are carried out at regular intervals to monitor stability and convergence:

- Annual surface leveling using a fixed grid system covering the overall surface area over the cavern field and linked to trigonometric surveying points outside the cavern field.

- Regular monitoring of the depth of the cavern floor and brine/gas interface level. Greater changes in these two values indicate spacing from the roof and walls.

- Regular cavern shape monitoring using echometric surveying.

- A complete survey of each cavern is carried out and compared with the previous survey. The accuracy of these surveys has been consistently improved over recent years. The accuracy is about $\pm 20 \mathrm{~cm}$ for distance measurements and about $\pm 2- \pm$ $5 \%$ (depending on cavern shape) in volume measurements.

With these measurements it is possible to ensure safe cavern operation and recognize possible convergence or stability problems in time to undertake remedial action. ${ }^{102}$

\subsection{MINED CAVERNS}

Mined cavern storage is done in the United States only in one abandoned coal mine. Mined cavern storage has the same high deliverability as leached cavern storage because it is also a closed container with infinite permeability. The storage operation is excellent for peakshaving requirements because the cycle turn-around is so fast. The gas withdrawn during a high peak day can be replaced virtually overnight, depending on gas supply and operating conditions. ${ }^{103}$

The amount of gas that can be stored depends on the size of the caverns and the pressure maintained in them. A mined cavern is maintained at a low operating pressure; reinjection is therefore accomplished by free flow, because the pipeline pressures are higher than the cavern pressures. Withdrawal is done by compression for the same reason. Care must be exercised not to exceed the hydrostatic limits of the host rock, because current mined storage is very shallow compared to other storage methods, and the operating pressure of the mine must be kept at low levels. ${ }^{104}$

100 lbid.

101 Underground Storage, p. 6.

${ }^{102} \mathrm{Gomm}, \mathrm{H}$. and Quast, P., "Status of Gas Storage inSalt Caverns in West Germany", SPE Paper No. 19084

presented at the SPE Gas Technology Symposium, Dallas, TX, June, 1988.

103 Underground Storage, p. 7.

104 Ibid. 
That only one mined cavern storage facility operates in the United States is an indication of how few favorable areas exist. Although abandoned coal mines are plentiful, they are not always convertible to gas storage. No mined cavern in existence was mined solely for storage (leached caverns excluded). Economics, need, and host rock dictate the favorable areas for mined cavern storage. A favorable area has basement rock close enough to the surface to be mined for storage. Examples are the granites of Georgia and the schists of New Jersey. ${ }^{105}$

\subsubsection{Gas Migration}

The conventionally mined cavern is one of the most expensive methods of storage today, partly because of several factors that are not controlled by the gas companies:

- When ore is being removed from a mine, no care is taken to prevent cracks, microfissures, or other openings that could contribute later to the migration of storage gas.

- There are natural fissures or openings in the rock that are characteristically associated with coal deposits.

- The shafts that are created in coal mines for ingress and egress must also be sealed to ensure against migration. ${ }^{106}$

These cracks, fissures and seals create potential sources of gas migration. The pressure at which the gas is injected and stored must be high enough to meet deliverability requirements, but must not be overpressured to the extent that gas will migrate through the cracks, fissures and seals.

\subsubsection{Mitigation Strategies}

Optimizing the reservoir pressure will probably involve an iterative process between modeling calculations and actual reservoir performance determined by careful monitoring practices.

The one storage reservoir currently operating in an abandoned mine recently had to reduce reservoir pressure due to gas migration.

\subsection{SUMMARY}

\subsubsection{Gas Migration Mechanisms}

A problem which may be more widespread than is generally realized or accepted is the potential existence of abandoned wells or low permeability zones outside or possibly within the reservoir boundaries into which the storage gas will migrate, primarily during the injection phase. This situation can be of concern, especially in older depleted reservoirs, where abandoned former production wells may exist or the reservoir limits may not be adequately mapped due to the vintage of the well data. Abandoned production wells may or may not have been plugged. A record may not exist of all the production wells or the dry holes in a field. Modeling these reservoir conditions shows that gas will flow into these wells or low permeability zones at the pressures used for injection.

The reservoir limits in older fields were initially defined using criteria which is not applicable to modern drilling and production methods. Often, older fields were produced naturally and the reservoir limits were defined by the dry holes drilled at the margins of the field. Because they did not have a natural flow, these holes were assumed to be dry. However, they may have

\footnotetext{
${ }^{105}$ Ibid., p. $7-8$.

106 Ibid., p. 6.
} 
low permeability which, when hydraulically stimulated, would result in the flow of gas. During injection, gas may migrate into these tighter areas of the formation, which would have sufficient permeability to take the gas, but not necessarily enough to allow the gas to be withdrawn.

Storage gas may migrate if the reservoir storage pressure exceeds the original field pressure. A producing field's original pressure may or may not be at the maximum threshold. Because of natural compression caused by fautting or other geologic movement, some fields contain only the amount of fluids that can be trapped at the discovery pressure. Some fields can be delta pressured because they have never reached the maximum pressure possible during geologic history. However, exceeding the maximum threshold pressure will cause the gas to migrate.

Production and storage wells are another source of gas leaks from the depleted reservoir. Old production wells must be plugged and abandoned in a manner that prevents gas from migrating into shallower sands. New storage wells must be completed with good cement integrity, which prevents migration behind the casing. A downhole logging program can be devised to detect corrosion in the casing and poorly cemented intervals.

Many depleted reservoirs were bounded downstructure by water. Primary production of the gas reduced the field pressure and allowed water to expand into the gas reservoir. This water must be moved back during gas injection. Bypassing of encroached water and movement of gas beyond the original gas/water contact has been observed during gas injection in numerous storage fields. This is because of pressure depletion, allowing the gas to flow through the path of least resistance. The result is gas migration that is now unrecoverably tied up in water filled areas of the formation as residual gas saturation. ${ }^{107}$

\subsubsection{Horizontal Well Technology}

During the last decade, significant advances in drilling technology have made it possible to drill horizontally. Over the past several years, horizontal drilling technology has rapidly developed in the oil and gas production industry to the point where thin target zones can be drilled with a high degree of accuracy. Along with this development, areas of particular concern to the storage operator, such as minimizing formation damage and cementing casing to insure caprock integrity, have also been advanced. Since most storage operators are reluctant to fracture stimulate wells, a horizontal well offers a viable alternative for enhancing deliverability in many fields. Horizontal wells can also minimize gas migration from the storage reservoir. Horizontal wells are found to be an effective technology for:

1. thin reservoirs (especially those which have vertical fractures)

2. naturally fractured reservoirs

3. reservoirs with gas and water coning problems

Horizontal wells and drainholes represent wells with limited fracture height, where fracture height is equal to the wellbore diameter. A properly designed horizontal well would be equivalent to a vertical well with a fully penetrating fracture. A horizontal well represents a long, controlled vertical fracture. In most fracture jobs it is difficult to obtain infinite conductivity and, moreover, fracture conductivity decreases over time. In contrast, a horizontal wellbore offers an almost permanent infinite conductivity fluid flow path.

- Horizontal drilling can be used to significantly enhance the deliverability from a storage well and minimize the gas migration from an injection well, with the proper reservoir conditions.

- Existing analytical solutions can be used in lieu of or in combination with full reservoir simulations to predict injection/withdrawal rates from horizontal wells with reasonable accuracy, given the proper geological and reservoir variables.

${ }^{107}$ after Mayfield, J.F., "Inventory Verification of Gas Storage Fie/ds", p. 1. 
- Existing medium radius drilling technology can be used to accurately drill horizontally in relatively thin formations.

- Pipe can be set and cemented to isolate the storage reservoir and protect caprock integrity.

- Horizontal wells can be drilled with minimial storage formation damage.

- Depending on both the existing reservoir conditions and the results anticipated, a new well may be more favorable, economically, than a reentry.

- There is a steep learning curve associated with the first horizontal well in a field and actual cost may exceed initial estimates. Lessons learned can hopefully be used to significantly lower the cost of subsequent wells.

- Because of lower delta pressures required for a given flow rate, horizontal wells hold the potential for reducing base gas requirements in some storage reservoirs. For the same reason, horizontal wells will reduce compression requirements.

- Larger drainage radii, a be fully developed with drilled horizontally, if geologic and reservoir exist. This may be particularly applicable in new field development.

- Because of larger drainage ratio, a field could be fully developed with fewer wells, drilled horizontally, if the proper geologic and reservoir conditions exist.

\subsubsection{Completion}

Recently, several papers have been published which discuss the orientation of induced fractures with respect to drilled direction of a horizontal well. In principal, fractures perpendicular to the drilled wellbore direction enhance drainage. ${ }^{108}$

One of the main reasons for stimulating horizontal wells is to enhance vertical permeability. Ideally on would like to create fractures which are perpendicular to the horizontal wells in the vertical plane. The direction of the fracture orienting from the horizontal well is the same as that for vertical wells, i.e., parallel to the plane of minimum principle stress. Therefore, if a horizontal well is drilled along the low principle stress, direction, then the stimulated fractures will be perpendicular to the horizontal well. However, if the horizontal well is also drilled along the maximum principle stress direction, then the stimulated fractures will be parallel to the horizontal well. Therefore, if the horizontal well is to be stimulated, it is important to consider the local stress directions. In an enhanced recovery application, artificial fractures perpendicular to the horizontal wellbore would have an adverse effect on well productivity. ${ }^{109}$

At present the local stress directions can be estimated using the following techniques:

1. Microfracturing. While drilling using mud, the formation is fractured, and then the oriented core is taken. This microfracture indicates the direction of the induced fracture.

2. Strain relaxation. In this case, a well is cored under pressure, and this pressurized, oriented core is brought to the surface pressure and temperature conditions. Because of stress relaxation, the core will also relax, with maximum core relaxation, i.e., the maximum core expansion occurring along the direction of the maximum stress. In contrast, a minimum relaxation, and therefore, minimum core expansion, will occur along the direction of the least principle stress. This will identify maximum and minimum principle stress directions.

${ }^{108}$ Joshi, J.D., Horizontal Well Technology, PennWell Publishing Company, Tulsa, OK, 1991, chapter 1.

109 Joshi, J.D., Horizontal Well Technology, PennWell Publishing Company, Tulsa, OK, 1991, chapter 5. 
3. Caliper logs. In some cases it is possible to identify stress direction by looking at caliper logs. In many cases, a drilled vertical wellbore may not be circular but rather highly elliptical because of the difference in the stresses in the horizontal plane. One expects a maximum borehole along the minimum stress direction and a minimum borehole size along the maximum stress direction. To identify borehole shape, a tool with four arms will be very useful. The tool can be either a caliper tool, preferably with orientation, or a dipmeter. ${ }^{110}$

\section{CONCLUSIONS}

\subsection{GAS MIGRATION IMPACT}

A certain amount of ongoing gas migration appears to occur in all storage field types. Solution of gas can occur in aquifers and also in any brine present in salt cavities. If the formation threshold pressure is exceeded in aquifers or depleted reservoirs, gas can migrate from the reservoir through the caprock, via a structural saddle or by gas fingering. Gas can also migrate through fractures, faults or incomplete stratigraphic isolation or structural closure. The largest gas migration appears to be from conventional depleted gas reservoir storage fields in the Northeast. These fields are primarily sandstone with either structural or stratigraphic trapping mechanisms.

Certain cases from the literature have demonstrated that a certain amount of gas migration from the reservoir does not necessarily prevent it from serving a market very effectively. The impact of this migration may be offset by economic factors, such as geographical location and proximity to market, and the availability, or lack, of a suitable replacement field. The gas migration reported is approximately $7 \%$ of the operating revenues for the largest storage operators. The costs of maintaining the storage field, along with the cost and success of various mitigation measures in eliminating or containing migration must therefore be considered.

\subsection{RESERVOIR MODELING IMPLICATIONS}

A thief zone was simulated by the use of a well completed in the very low permeability zone. Gas migration effects were studied. Typical $P / z$ calculations indicated that small volumes were lost even in formations with 0.001 md permeability.

By drilling horizontal wellbores, gas migration was eliminated or reduced. Sensitivity to horizontal wellbore length was studied. In the simulation example, wellbores over $1000^{\prime}$ in length eliminated gas migration effects.

Horizontal wellbores have been utilized for deliverability enhancement by some operators, but their use to reduce delta pressures and gas migration also has an important role in the reduction of gas migration. Industry has been aware of over-pressuring storage reservoirs to increase storage capacity and deliverability, but caution should be exercised it's implementation. Gas migration could be increased.

Storage operators commonly limit the amount of time to recharge (reinject) gas into storage during the summer months. Operators may limit reinjection time due to operational consideration (equipment repair), optimize gas costs, or to reduce gas migration losses. Based on the results of this study, increased gas migration effects could result.

The key elements of this study show that gas migration can result if reservoir limits have not been properly identified, gas migration can occur in formation with extremely low permeability

110 Joshi, J.D., Horizontal Well Technology, PennWell Publishing Company, Tulsa, OK, 1991, chapter 5. 
(0.001 md), horizontal wellbores can reduce gas migration losses and over-pressuring (unintentionally) storage reservoirs by reinjecting working gas over a shorter time period may increase gas migration effects. 


\section{REFERENCES}

In order of first citation:

1. Katz, D.L. and Tek, M.R. "Overview on Underground Storage of Natural Gas", SPE Paper No 9390 , presented at the 55th Annual Fall Tech. Conference \& Exhibition of the SPE and AIME, Dallas, TX, Sept. 21-24, 1980

2. Energy Information Administration, The Value of Underground Storage in Today's Natural Gas Industry, DOE/EIA-0591, Washington, DC, March 1995

3. Underground Storage, Volume I-Supply, Gas Engineering and Operating Practices Series, American Gas Association (AGA), Arlington, VA, 1990

4. Shikari, YA, "Gas Research Institute Underground Gas Storage Program: An Overview", SPE Paper No. 17739 presented at the SPE Gas Technology Symposium, Dallas, TX, June, 1988

5. FERC, "A Guide to the Public Information at the Federal Energy Regulatory Commission", Washington, DC, February, 1994

6. Young, F.S., and Deskins, G., "State-of-Technology Assessment and Evaluation of Gas Storage Well Productivity Enhancement Techniques", Topical Report \#1, GRI-93/0001, Gas Research Institute, Chicago, IL, December, 1993

7. Tek, M.R., Underground Storage of Natural Gas, Vol. 3, Contributions in Petroleum Geology and Engineering Series, Gulf Publishing Co., Houston, TX, 1987

8. Tek, M.R. and Katz, D.L., New Concepts in Underground Storage of Natural Gas, American Gas Association (AGA), New York, NY, March, 1966

9. Mayfield, J.F., "Inventory Verification of Gas Storage Fields", SPE Paper No. 9391, presented at the 55th Annual Fall Technical Conference \& Exhibition of the SPE of AIME, Dallas, TX, Sept. 21-24, 1980

10. Gomm, H. and Quast, P., "Status of Gas Storage in Salt Caverns in West Germany", SPE Paper No. 19084 presented at the SPE Gas Technology Symposium, Dallas, TX, June, 1988

11. Hobbs, B.E., Means, W.D., and Williams, P.F., An Outline of Structural Geology, John Wiley \& Sons, Inc., New York, 1976.

12. Overbey, W.K., Jr., Sawyer, W.K., and Henniger, B.R., Relationships of Earth Fracture Systems to Productivity of a Gas Storage Reservoir, United States Department of the Interior, Bureau of Mines, Washington, DC, 1974.

13. Kulander, B.R., Dean, S.L., and Ward, B.J., Fracture Core Analysis, AAPG Methods in Exploration Series, No. 8, The American Association of Petroleum Geologists, Tulsa, OK, 1990

14. Beckman, K.L., Determeyer, P.L., Mowrey, E.H. (International Gas Consulting, Inc.), "Natural Gas Storage: Historical Development and Expected Evolution", GRI-95/0214, Gas Research Institute, Transmission \& Storage Group, June 1995 


\section{BIBLIOGRAPHY}

- DOE / EIA

1. EIA, Natural Gas Annual 1992, Volume I, US DOE/EIA-131(92)/1, Washington, DC, Nov. 1993, p. 40-41.

2. USDOE, Natural Gas Strategic Plan and Multi-year Program Crosscut Plan, FY 1994-1999, DOE/FE-0297P, Washington, DC, Dec. 1993, p. 4:159-4:185.

3. EIA, Emissions of Greenhouse Gases in the United States, 1985-1990, US DOE/EIA-0573, Washington, DC, Sept. 1993, p. 29-30.

4. EIA, Energy Facts, 1992, USDOE/EIA-0469(92), Washington, DC, Oct. 1993, p. 40-41.

5. DOE/EIA, The Value of Underground Storage in Today's Natural Gas Industry, DOE/EIA0591, Washington, DC, March 1995.

- BOOKS \& OTHER PUBLICATIONS

6. Tek, M.R., Underground Storage of Natural Gas, Contributions in Petroleum Geology \& Engineering Series, Volume 3, Gulf Publishing Company, Houston, TX 1987, 389p. ISBN 087201-913-6* *

7. Katz, D. L. and K. H. Coats, Underground Storage of Fluids, Ulrichs Book Store, Inc., Ann Arbor, Michigan, 1968, reprinted 1978.

8. Joshi, S.D., Horizontal Well Technology, Penn Well Publishing Company, Tulsa, OK, 1991.

9. Duann, D.J., Nagler, P.A., et al., Gas Storage: Strategy, Regulation. And Some Competitive Implications, The National Regulatory Research Institute, September 1990

10. Pennsylvania Public Utility Commission, "Statements of Policy, Recovery of FERC Order 636 Transition Costs", Pennsylvania Bulletin, Vol. 23, No. 13, March 27, 1993, p. 1478-1484

11. Anderson, D., Report Of The Commission Of Inquiry Into Fraser Valley Petroleum Exploration, Province of British Columbia Jan. 1991.

12. Ball, D. and Burnett, P. G., "Storage of Gas in Water Sands." In Beebe, B. W., Natural Gases of North America, V. 2. Tulsa: American Association of Petroleum Geologists, 1890-1898 (1968)

13. Schwendeman, T.G., and Wilcox, H.K., Underground Storage Systems-Leak Detection and Monitoring, Lewis Publishers, Chelsea, MI, 1989.

14. Kulander, B.R., Dean, S.L., Ward, B.J., Jr., Fractured Core Analysis: Interpretation, Logging, and Use of Natural and Induced Fractures in Core, AAPG Methods in Exploration Series, No. 8, American Association of Petroleum Geologists, Tulsa, OK, 1990.

15. Allen, J.R.L., "An Interpretation and Analysis of Recumbent-folded Deformed Crossbedding", Sedimentology, 1972, Vol. 19, pp. 257-283.

16. Wonsiewicz, B.C., and Chin, G.Y., "Inhomogeneity of Plastic Flow in Constrained Deformation", Metall. Trans., 1970. Vol. 1, pp.57-61.

17. Williams, P.F., Collins, A.R., and Wittshire, "Cleavage and Penecontemporaneous Deformation Structures in Sedimentary Rocks", J. Geol., 1969. Vol. 77, pp. 415-425.

18. Hobbs, B.E., Means, W.D., Williams, P.F., An Outline of Structural Geology, John Wiley \& Sons, Inc., New York, NY, 1976.

19. LaPointe, P.R., and Hudson, J.A., Characterization and Interpretation of Rock Mass Joint Patterns, GSA Special Paper 199, The Geological Society of America, Boulder, CO, 1985.

20. Barnds, R.M., Playa Del Rey Oil Field. Los Angeles County, California Natural Gas Storage. Mem. - Am. Assoc. Pet. Geol. 1: 9, 169-173 (1968).

- A.G.A / GRI 
21. Ball, D. and Burnett, P. G., "The Storage of Gas in Water Sands." Proceedings of American Gas Association, Operating Section, 1959, T63-T48, (GSTS-59-9) New York, N. Y., 1959.

22. Balogh, D.R., "Detection and Monitoring of Gas Bubble Growth in Underground Gas Storage Field Through the Use of High Resolution Reflection Seismology." Evergreen, CO: Evergreen Geophysical Association, Inc. (1985) February. AGA Research Project PR-160154.

23. Fogler, H.S. and Crain, E.R., "Stimulation of Gas Storage Fields to Recovery Deliverability." A.G.A. Oper. Sect. Proc. T403-411 (1980).

24. Gas Research Institute. Critical Performance Parameters for Horizontal Well Applications in Gas Storage Reservoirs, Chicago, IL. (PB94-103793.)

25. Gas Research Institute. "The Deliverability Issue, Final Report. November 1990--March 1991", Chicago, IL.

26. Gas Research Institute. "The Load Balancing Issue Final Report November 1990-June 1991", Chicago, IL.

27. Beckman, K.L., Determeyer, P.L., Mowrey, E.H. (International Gas Consulting, Inc.), "Natural Gas Storage: Historical Development and Expected Evolution", GRI-95/0214, Gas Research Institute, Transmission \& Storage Group, June 1995, p.5.

28. Gas Research Institute. "State-of-Technology Assessment and Evaluation of Gas Storage Well Productivity Enhancement Techniques", GRI, Chicago, IL, December 1993.

29. Katz, D. L. and Tek, M. R., "Storage of Natural Gas in Saline Aquifers." Trans. Paper No. H69, 50th Annual AGA Meeting, April 21-25, 1969.

30. Katz, D. L. , Tek, M. R. and Ibrahim, M. A., "Threshold Displacement Pressure in Gas Storage." AGA Oper. Sect. Proc. - 1969, 69-T-33.

31. Martinson, E. V., "Review of Aquifer Gas Storage Projects." A.G.A. Oper. Sect. Proc., GSTS-61-23 (1961).

32. Pandey, G. N., Tek, M. R., and Katz, D. L., "Studies of Front-End Threshold Pressure Measurements," A.G.A. Operating Section Proceedings, T-112 (1973).

33. Tek, M. R., et al., Inventory-Migration-Deliverability In Underground Storage. Arlington, VA: American Gas Association (1987).

34. Colonna, J. and Carriere J-F, "Cushion Gas and Working Volume: for Each Geological Structure, Its Optimal Management." A. G. A. Operating Section Proceedings, 665 (1985.)

35. Kelley, W. M., "Underground Storage of Gas in the United States." AGA Oper. Sect. Proc., 64-T-184 - 64-T-185, (1964).

36. Tek, M. R. et al., "New Concepts in Underground Storage of Natural Gas." AGA Monograph on Project P050, New York (1966).

37. Byrne, J. J. and Lu, T. A., "Fully Automated Gas Storage Field." A.G.A. Oper. Sect. Proc., T16-T21 (1975).

38. Clark. W. H., "Use of Storage Field Automation by the Reservoir Engineer." A.G.A. Operating Section Proceedings, T-230 (1975).

39. Wallis, G. B., Slug Frequency in Horizontal Gas-Liquid Flow. Arlington, VA: American Gas Association (1990).

40. Katz, D. L., "A Look Ahead in Gas Storage Technology." A. G. A. Oper. Sect. Proc., T28390 (1981).

41. Hardy, H. Reginald, Jr., et al., A Study to Evaluate the Stability of Underground Gas Storage Reservoirs, (project 12-43), American Gas Association, Inc., Arlington, VA, 1972.

42. AGA, Underground Storage Volume I-Supply, Gas Engineering and Operating Practices Series, American Gas Association, printed in USA, 1990.

- JPT/ OIL \& GAS JOURNAL / SPE.

43. Aronofsky, J. S. and Jenkins, R., "A Simplified Analysis of Unsteady Radial Gas Flow." J. Pet. Tech. 6, 23 (1954) July. 
44. Bagrodia, V. and Katz, D. L.., "Gas Migration by Diffusion in Aquifer Storage." J. Petrol. Tech. 29, 121-122 (1977) February.

45. Bailey, P. E., "Accident Field Proves No Accident to Texas Eastern." Pipeline Eng. 41:1, 50, 52, 54 (1969) January.

46. Baird, J. L., "Clay Basin Storage Project - Development of a Nearly Depleted Gas Reservoir (Dakota Reservoir) to Gas Storage." In Society of Petroleum of AIME. Rocky Mountain Regional Meeting, Cody, Wyoming, May 17-18, 1978, (SPE-7171) Dallas: Society of Petroleum Engineers, 1978.

47. Batten, R.B. and Elenbaas, J. R., "Giant Storage Enables Sendouts Ranging from 150 to 1,270 MMCFD." Oil Gas J. 57, 164-168 (1959) March 9.

48. Bell, A.H., "Underground Gas Storage in Illinois." Paper presented at Illinois Geological Survey \& Illinois Basin Chapter of the S.P.E. of the A.I.M.E. Petroleum Engineering Conference, Urbana, Illinois, May, 1961.

49. Bell, J. S. and J.M. Shepherd; "Pressure Behavior in the Woodbine Sand", Trans. AIME, Vol. 92, p 19 (1952).

50. Berger, L.C., Arnoult, J. R., "Production of Inert Gas for Partial Replacement of Natural Gas Trapped in an Underground Aquifer Storage Reservoir." Proceedings: 1989 SPE Gas Technology Symposium, Dallas, TX (June 7-9, 1989) p. 309-320. Bernard, G. G. et al., "Model Study of Form as a Sealant for Leaks in Gas Storage Reservoirs." Soc. Pet. Eng. J., 10, 9-16 (1970) March.

51. Bond, D.C. and Cartwright, K., "Pressure Observations and Water Densities in Aquifers and Their Relation to Problems in Gas Storage." J. Pet. Tech. 22, 1492-1498 (1970) December.

52. Briggs, J. E. et al., "Water Drainage From Sand in Developing Aquifer Storage." Oil Gas J. 66, 61-66 (1968) December.

53. Coats, K. H. and others. "Calculation of gas recovery upon ultimate depletion of aquifer storage." Proceedings of 42 Annual SPE of AIME Fall Meeting, Oct. 1-4, 1967. 1967. Preprint No. SPEC-1815. $8 \mathrm{pp}$.

54. Coats, K. H. and Richardson, J. G., "Calculation of Water Displacement by Gas in Development of Aquifer Storage." Soc. of Pet. Eng. J., 7, 105-112 (1967) June.

55. Coats, K. H. et al., "Determination of Aquifer Influence Functions from Field Data." J. Pet. Tech. 16, 1417-1424 (1964) December.

56. Coats, K. H. "Some Technical and Economic Aspects of Underground Gas Storage." J. Pet. Tech. 18, 1561-1566 (1966) December.

57. Collier, R. S. Monash, E. A. and Hultquist, P. F., "Modeling Natural Gas Reservoirs - A Simple Model." Soc. Pet. Eng. J. 21, 521-26 (1981) Oct.

58. Ellington, D. M., "Frac Plan Pays Off in Gas Storage." Pet. Eng. 13, No. 33, 75-80 (1961) December.

59. Kumar, A. and Kimbler, D. K. , "The Effect of Mixing and Gravitational Segregation Between Natural Gas and Inert Cushion Gas on the Recovery of Gas From Horizontal Storage Aquifers." SPE Paper 3866, 4th Biannual Natural Gas Technology Symposium of SPE, Omaha, 1972.

60. Mayfield, J. F., "Inventory Verification of Gas Storage Fields." J. Pet. Technol. 33, 173034 (1981) Sept.,

61. McMinn, R. E., "Production Techniques for Aquifer-Type Gas Storage Fields." Paper No. SPE 1685, SPE of AIME Northern Plains Sect. Reg. Gas Technol. Symp. 1966.

62. Bleakley, W. B., "Old Coal Mine Converted to Gas Storage." Oil Gas J. 59, No. 51, 88-94 (1961) December 18.

63. Katz, D. L. and Tek, M. R., "Overview on Underground Storage of Natural Gas." J. Pet. Technol. 33, 943-51 (1981) June.

64. Knepper, G. A. and Cuthbert, J. F. "Gas Storage Problems and Detection Methods," AIME, SPE Paper No. 8412, Dallas, 1979

65. Van Horn, H.G. and Wienecke, D. R., "A Method for Optimizing the Design of Gas Storage Systems." Preprint No. SPE-2966, presented at 45th Annual SPE of AIME, Fall Meeting, 
1970.

66. “How Northern Natural Operates Aquifer Storage." Oil Gas J. 59, No. 6, 116-117 (1961) March 13.

67. Shotts, S.A., J. R. Neal, R.J. Solis, "Spindletop Salt-Cavern Points Way for Future NaturalGas Storage", Oil \& Gas Journal, Vol. 92, No. 37, Sept. 12, 1994, p. 68-75

68. Barron, Thomas F. "Regulatory., technical pressures prompt more U. S. salt-cavern gas storage", Oil \& Gas Journal, Sept. 12, 1994, p. 55-67

69. "Underground Natural Gas Storage Fields, Table 1", Pipeline Report Issue, Oil \& Gas Journal, Vol. 92, No. 37, Sept. 12, 1994, p. 47-54.

70. Katz, D. L. and Tek, M.R., "Overview On Underground Storage Of Natural Gas." SPE Paper No. 9390, presented at the 55th Annual Fall Tech. Conf. and Exhibition of the SPE and AIME; Dallas, TX, Sept, 21-24, 1980.

71. Mayfield, J.E., "Inventory Verification Of Gas Storage Fields." SPE Paper No. 9391 presented at the 55th Annual Fall Tech. Conf. Exhibition of the SPE of AIME held in Dallas, TX. Sept. 21-24 1980

72. Shikari, Y.A., "Gas Research Institute Underground Gas Storage Program; An Overview." SPE Paper No. 17739 presented at the SPE Gas Technology Symposium, Dallas, TX; June 13-15. 1988.

73. Misra, B.R., and Foh, S. E., Shikari, Y.A., Berry, R.M., Labaune, F. "The Use of Inert Base Gas in Underground Natural Gas Storage." SPE Paper No. 17741 presented at the SPE Gas Technology Symposium, held in Dallas, TX, June 13-15, 1988.

74. Weaver, J.D., and Morgan, J.A., "Furan Resin Process Replaces Workovers in Gas Storage Reservoirs." SPE Paper No. 17742 presented at the SPE Gas Technology Symposium, held in Dallas, TX, June 13-15, 1988.

75. Gomm, H. and Quast, P., "Status of Gas Storage in Salt Caverns in West Germany." SPE Paper No. 19084 presented at the SPE Gas Technology Symposium held in Dallas, Texas, June 7-9, 1989.

76. Toneyl, J.B., Morgan, J.A., Barnetter, J.C., and Bieleckil, D.L., "Completion Planning for Elimination of Sand Production in Thinly-Bedded Aquifer Gas Storage Wells." SPE Paper No. 19756, presented at the 64th Annual Technical Conference and Exhibition of the Society of Petroleum Engineers held in San Antonio, TX October 8- 11, 1989.

77. Hower, I., Fugate; M. W.and Owens, R. W., "Improved Performance in Aquifer Gas Storage Fields Through Reservoir Management." SPE Paper No. 26172.

78. Bergin, and Shikari, Y.A., "A Horizontal Well in Gas Storage: A Case Study." SPE Paper No. 26165 presented at the SPE Gas Tech. Symposium, Calgary, Alberta, Canada.

79. Chierici, Gottardi, G., and Guidorzi, R., "Identified Models For Gas Storage Dynamics." SPE Paper 8862 (unsolicited).

80. Reiss, L.H., "Production from Horizontal Wells After 5 Years", SPE Paper No. 14338, Journal of Petroleum Technology (JPT), November 1987.

81. Joshi, S.D., "A Review of Horizontal Well and Drainhole Technology, SPE Paper No. 16868, 62nd Annual Technical Conference and Exhibition of the Society of Petroleum Engineers, Dallas, TX, September, 1987.

82. Kossack, C.A., and Kleppe, J., "Oil Production From the Troll Field: A Comparison of Horizontal and Vertical Wells, SPE Paper No. 16869, 62nd Annual Technical Conference and Exhibition of the Society of Petroleum Engineers, Dallas, TX, September, 1987.

83. Sung, W., and Ertekin, T., "Performance Comparison of Vertical and Horizontal Hydraulic Fractures and Horizontal Boreholes in Low Permeability Reservoirs: A Numerical Study", SPE/DOE Paper No. 16407, SPE/DOE Low Permeability Reservoirs Symposium, Denver, CO, May, 1987.

84. Giger, F.M., "Low-Permeability Reservoirs Development Using Horizontal Wells", SPE/DOE Paper No. 16406, SPE/DOE Low Permeability Reservoirs Symposium, Denver, CO, May, 1987.

85. Ozkan, E. and Raghavan, R., "Horizontal Well Pressure Analysis", SPE Paper No. 16378 , 
SPE California Regional Meeting, Ventura, CA, April, 1987.

86. Salamy, S.P., Saradji, B.S., Okoye, C.O., Mercer, J.C., and Yost, A.B. II, "Recovery Efficiency Aspects of Horizontal Well Drilling in Devonian Shale" SPE/DOE Paper No. 16411.

87. Giger, F.M., "Analytic 2-D Models of Water Cresting Before Breakthrough for Horizontal Wells", SPE Paper No. 15378, 61st Annual Technical Conference and Exhibition of the Society of Petroleum Engineers, New Orleans, LA, October, 1986.

88. Chaperon, I., "Theoretical Study of Coning Toward Horizontal and Vertical Wells in Anisotropic Formations: Subcritical and Critical Rates", SPE Paper No. 15377, 61st Annual Technical Conference and Exhibition of the Society of Petroleum Engineers, New Orleans, LA, October, 1986.

89. Joshi, S.D., "Augmentation of Well Productivity Using Slant and Horizontal Wells", SPE Paper No. 15375, 61st Annual Technical Conference and Exhibition of the Society of Petroleum Engineers, New Orleans, LA, October, 1986.

90. Giger, F.M., "The Reservoir Engineering Aspects of Horizontal Drilling", SPE Paper No. 13024, 59th Annual Technical Conference and Exhibition of the Society of Petroleum Engineers, Houston, TX, 1984. 


\section{CODE OF FEDERAL REGULATIONS ON GAS STORAGE}

CFR 18, "CONSERVATION OF POWER AND WATER RESOURCES, parts 150 to 279

117 Gas stored underground -Noncurrent

(Major Only). Page 188

A. This account shall include the ccst of recoverable gas purchased or produced by the utility which is stored in depleted or partially depleted gas or oil fields, or other underground reservoirs, and held for use in meeting service requirements of the utility's customers

B. Gas stored during the year shall be priced at cost according to generally accepted methods of cost determination consistently applied from year to year. Transmission expenses for facilities of the utility used in moving the gas to the storage area and expenses of storage facilities shall not be included in the inventory of gas except as may be authorized or directed by the Commission.

Note B-1: In general, gas stored from the supply in an integrated system shall be priced at the average cost of the gas, constituting the common supply system, although this general rule may be departed from where conditions of system operation of gas supply and utilization permit a valid presumption that the gas stored may be considered to be from specific sources, as indicated below.

Note B-2: When in harmony with the over-all system, operation of gas supply and utilization, and the presumption is consistently observed from year to year, gas stored during the year may be presumed to be from total gas purchases, or purchases from specified sources. When either of these presumptions is proper, the cost of gas stored shall be priced at the weighted average cost of all gas purchased, or at the specified sources, as appropriate. The weighted average cost may be the average for the preceding twelve months, except where a significant change occurs in the cost of gas, the full effect of such change shall be reflected for the period after the change is affected.

Note B-3: When in harmony with the over-all system operation of gas supply and utilization, and the presumptions are consistently observed from year to year, gas stored during the year may be presumed to be from identified sources of the utility's own production. Such stored gas shall be priced at the weighted average cost of gas produced from the specified production areas. Where this presumption is made, or where the stored gas is identified as a matter of fact under circumstances which do not permit a proper application of the theory of displacement, the utility shall maintain separate records of the cost of gas produced from such areas and the derivation of cost used for stored gas from such sources.

Note B-4: Where gas is purchased specifically for storage, or a price concession received because of the storing of purchased gas, such gas shall be priced at the net contract price of the gas so purchased and stored.

Note B-5: The provisions of this instruction and the related footnotes shall not be construed as permitting or authorizing a restatement of the amount at which stored gas inventories are stated on the utility's books at the affective date of the instructions, except as may be authorized by the Commission.

C. Withdrawals of gas may be priced according to the first-in-first-out, last-in-first-out, or weighted average cost method, in connection with which a "base stock" may be employed provided the method adopted by the utility is used consistently from year to year and the inventory records are maintained in accordance therewith. Approval of the Commission must be obtained for any other pricing method, or change in pricing method adopted by the utility.

D. If the gas of any storage project is withdrawn below the amount established as "base stock" or encroaches upon native gas of a storage reservoir, and such gas is to be replaced 
within 12 months. It shall be permissible to price such gas at the estimated cost of replacement with purchased gas and to record a deferred credit therefor. For the purpose of this instruction, Account 808 , Gas Withdrawn from Storage--Debit, shall be charged with the estimated cost of such replacement gas and account 253 shall be cleared and this account credited. When replaced the gas is made the amount in account 253 shall be cleared and this account credited. This accounting will not effect normal accounting for inputs and withdrawals from storage.

E. Separate records shall be maintained for each storage project of the Mcf of gas delivered to storage, withdrawn from storage, and remaining in storage. The projects shall be grouped, however, for the purpose of maintaining inventory cost records of the cost of gas in storage. Exceptions to this rule are permitted in any of the following circumstances:

(a) Projects at the supply end of long transmission lines,

(b) Projects located on separate non-interconnected pipeline systems, and

(c) Projects which by contractual arrangements approved by the Commission are devoted exclusively to the service of spesified customers, and no portion of the gas withdrawals from any such project becomes part of the common system gas supply by displacement or otherwise.

Where the utility establishes specified volumes of gas as "base stock," separate inventory cost records by projects shall be maintained therefor.

F. Amounts debited to this account for gas placed in storage shall be credited to account 809. Gas Delivered to Storage--Credit. Amounts credited to this account for gas withdrawn from storage shall be debited to account 808 . Gas Withdrawn from Storage--Debit.

G. Adjustments for Inventory migration due to cumulative inaccuracies of gas measurements, or from other causes, shall be charged to account 823 , Gas Migration. In the operation of storage projects, the utility shall maintain such procedures of verification as will disclose and result in prompt accounting recognition of significant migration.

This account shall be credited with an amount equal to that debited to account 164.1, Gas Stored Underground--Current, to classify for balance sheet purposes such portion of the total inventory of gas stored underground as constitutes a current asset according to conventional rules for classification of current assets.

164.1 Gas stored underground--current Page 196.

This account shall be debited with such amounts as are credited to account 117. Gas Stored Underground--Noncurrent, to reflect classification for balance sheet purposes of such portion of the inventory of gas stored underground as represents a current asset according to conventional rules for classification of current assets.

Note: It shall not be considered conformity to conventional rules of current asset classification if the amount included in this account exceeds an amount equal to the cost of estimated withdrawals of gas from storage for purposes of sale within the 24-month period from date of the balance sheet, or if the amount represents a volume of gas that, in fact, could not be withdrawn from storage without impairing the pressure level of any project for normal operating purposes.

352.2 Reservoirs, Page 227.

This account shall include costs to prepare underground reservoirs for the storage of natural gas.

\section{ITEMS}

1. Geological, geophysical, and seismic costs.

2. Plugging abandoned wells.

3. Fuel and power.

4. Drilling and equipping fresh water wells, disposal wells, and solution wells.

5. Leaching of salt dome caverns. 
6. Rentals on storage rights and leases incurred during construction and development period.

7. Gas used during the development period.

8. Cost incident to maintaining covenants of production leaseholds during the period required to convert them to storage leaseholds.

9. Other rehabilitation work.

352.3 Nonrecoverable natural gas, Page 227.

A. This account shall include the cost of gas in underground reservoirs, including depleted gas or oil fields and other underground caverns or reservoirs used for the storage of gas that will not be recoverable.

B. Such nonrecoverable gas shall be priced at the acquisition cost of native gas or, when acquired for storage by purchase or presumed to be supplied from the utility's own production, priced as outlines in Paragraph B of account 117, Gas Stored Underground-Noncurrent (for nonmajor companies, account 164.1 Gas Stored Underground). After devotion to storage, the cost of the gas shall not be restated to affect prior price changes in purchased gas or changes in the cost of gas produced by the utility. When the utility has followed the practice of adjusting Nonrecoverable gas to the weighted-average cost of gas purchased or supplied from its own production, cost shall be weighted-average cost of such gas at the affective date of this account.

808.1 Gas withdrawn from storage-Debit. Page 274.

A. This account shall include debits for the cost of gas withdrawn from storage during the year. Gas Stored Underground--Noncurrent (in the case of Nonmajor companies, account 164.1, Gas Stored Underground) or 164.2, Liquefied Natural Gas Stored, as appropriate.

B. Withdrawal of gas from storage shall not be netted against deliveries to storage. (See account 808.2.)

Note: Adjustments for gas inventory migration due to cumulative inaccuracies in gas measurement, or from other causes shall be entered account 823 , Gas Migration. If, however, any adjustment is substantial, the utility may, with approval of the Commission, amortize the amount of the adjustment to account 823 over future operating periods.

808.2 Gas delivered to storage--Credit. Page 275.

A. This account shall include credits for the cost of gas delivered to storage during the year. Contra debits for entries to this account shall be made to accounts 117, Gas Stored Underground--Noncurrent (in the case of Nonmajor companies, account 164.1, Gas Stored Underground) or 164.2, Liquefied Natural Gas Stored, as appropriate.

B. Deliveries of gas to storage shall not be netted against withdrawals from storage. (See account 808.1.)

823 Gas migration. Page 278.

This account shall include the amounts of inventory adjustments representing the cost of gas unaccounted for or unaccounted for in underground storage operations due to cumulative inaccuracies of gas measurements or other causes. (For Major companies, see paragraph $G$ of account 117, Gas Stored Underground--Noncurrent.) If, however, any adjustment is substantial, the utility may, with approval of the Commission, amortize the amount of the adjustment to this account over future operating periods.

846.1 Gas migration (Major only). Pages 284-285.

This account shall include the amounts of inventory adjustments representing the cost of gas unaccounted for or unaccounted for in liquefied natural gas operations due to cumulative inaccuracies of gas measurements or other causes. (See paragraph $E$ of account 164.3, Liquefied Natural Gas Held for Processing.). If, however, any adjustment is substantial, the utility may, with approval of the Commission, amortize the amount of the adjustment to this account over future operating periods. 


\section{\$260.1 FERC Form No. 2 Annual report for natural gas companies. Page 342.}

(a) The form of Annual Report of Natural Gas Companies (Class A and Class B), designated herein as FERC Form No. 2, is prescribed for the reporting year 1980 and thereafter.

(b) Each natural gas company, as defined in the Natural Gas Act (15 U.S.C. 717, et seq.) which is a major company (as defined in Part 201 of Subchapter $F$ of this chapter) must prepare and file with the Commission for the calendar year beginning January 1, 1980, and for each calendar year thereafter, on or before April 30 following the close of such calendar year, FERC Form No. 2.

(1) Before December 30,1988 , an original and such number of conformed copies of the above-designated FERC Form No. 2 as indicated in the general instructions set out in that form all properly filled out and verified. One copy of the report should be retained by the respondent in its files. The conformed copies may be carbon copies, or other reproductions, if legible.

(2) On or after December 30,1988 , the form must be filled as prescribed in $\$ 385.201$ of this chapter and as indicated in the general instructions set out in that form, all properly filled out and verified. One copy of this report should be retained by the respondent in its files.

[Order 121, 46 FR 6887, Jan. 22, 1981; and amended by Order 390, 49 FR 32527, August 14, 1984; Order 493, 53 FR 15030, Apr. 27, 1988.]

\section{$\$ 260.11$ Form No. 8, Underground gas storage report. Page 345.}

(a) The Form of Underground Gas Storage Report as FPC Form No. 8, is prescribed.

(b) Each person found by the Commission to be a natural gas company, as defined by the Natural Gas Act, as amended, including any jurisdictional affiliate as defined in $\S$ 157.40 (a) (3) of the Commission's regulations, that operates an underground natural gas storage field located in the United States must prepare and file with the Commission by the tenth day of each month an Underground Gas Storage Report, FERC Form No. 8, before November 30 , 1988, an original and four copies and, on or after November 30, 1988 as prescribed as $\S$ 385.2011 of this chapter. Parts IV, V, VI, and VII (page Nos. 2 and 3) of FERC Form No. 8 are only required to be completed for the initial filing of FERC Form No. 8, and thereafter, whenever any changes or additions of information initial reported are made.

[Order 534, 40 FR. 43894, Sept. 24, 1976, ad amended by Order 493, 53 FR. 15031, Apr. 27, 1988; Order 493-A, 53 FR. 30031, Aug. 10, 1988.] 


\section{GLOSSARY}

Annulus

ANSI

API

Approximate acreage: reservoir

Approximate acreage: total

Aquifer

Average pay thickness of storage formation

Balancing item:

Barrel

Base (cushion) gas:

Base gas

Baselogs

Bled-off

Blooey line

British thermal unit

(btu):

Caprock

Casing

Casing, injectionwithdrawal

Cement bond - the space between the outer wall of the pipe suspended in a well bore and the side of the open hole or the inner side of a larger pipe.

American National Standards Institute (formerly American Standards Association)

American Petroleum Institute

The approximate number of acres occupied by the gas bubble.

The approximate number of acres occupied by the gas bubble plus those acres used for protective or buffer zone.

water bearing rock strata

The average thickness of the pay zone occupied by gas. In aquifer storage, it may also indicate the thickness being developed or pressurized.

Represents the difference between the sum of the components of natural gas supply and the sum of the components of natural gas disposition. These differences may be due to quantities unaccounted for or to the effects of data reporting problems. Reporting problems include differences due to the net result of conversions of flow data metered at varying temperature and pressure bases and converted to a standard temperature and pressure base; and pressure base; the effect of variations in company accounting and billing practices; differences between billing cycle and calendar period time frames; and imbalances resulting from the merger of data-reporting systems that vary in scope, format, definitions, and type of respondents.

a unit of measure to $\mathbf{4 2}$ gallons

The volume of gas needed as a permanent inventory to maintain adequate underground storage reservoir pressures and deliverability rates throughout the withdrawal season. All native gas is included in the base gas volume.

The volume of gas required in a storage reservoir to provide the volume and pressure to cycle the normal working storage volume.

any number and type of logs which are recorded for reference as the original condition of the well and strata after completion.

to release pressure from a well or a pressure vessel

a pipe line connected to the drilling equipment and extended some distance from the rig through which the drill cuttings are blown out as dust in air and/or gas drilling operations

The heat required to raise the temperature of one pound of water by one degree Fahrenheit at or near 39.2 degrees Fahrenheit

a comparatively impervious stratum immediately overlying the gas storage-bearing rock

a term applied to steel or iron pipe used in a well to prevent caving of the walls or ingress of water, or both

refers to the last casing string in the well through which gas is injected and withdrawn

the adhesion of the cement to the casing and wall of the hole 
Christmas tree -

Circulating time-

Commercial

consumption:

Commingling-

Compressed natural

gas (cng):

Compressor station:

Cycle, closing-

Cycle, opening-

Delivered:

Delta pressure-

Density-overburden-

Depletion:

Depreciation:

Distribution use:

Drill pipe-

Drill stem test-

Drilling logs-

Drilling- an assembly of valves and fittings located $\mathrm{Ft}$. the casing head of an oil and/or gas well for the purpose of controlling the flow of gas or oil from the well

that time element required to complete one circuit of the hole displacement

Natural gas used by nonmanufacturing establishments or agencies primarily engaged in the sale of goods or services. Included are organizations such as hotels, restaurants, wholesale and retail stores; agriculture, forestry and fisheries; and gas used by local, State, and Federal agencies engaged in nonmanufacturing activities.

the ability of two or more compatible substances to join as a unit compressive strength, the unit compressive force that a material will stand prior to failure

Natural gas which is comprised or primarily methane, compressed to a pressure at or above 2,400 pounds per square inch and stored in special high pressure containers. It is used as a fuel for natural gas powered vehicles.

Any combination of facilities which supplies the energy to move gas in transmission lines or into storage by increasing the pressure.

an operation wherein a device ends up in a closed position, stile as a valve

An operation wherein advance (is tip in an open position, such as a valve

The physical transfer of natural, synthetic, and/or supplemental gas from facilities operated by the responding company to facilities operated by others or to consumers.

the act of raising the pressure of a formation above the original or discovery pressure

the specific gravity or relative density of the overlying rocks or substances

The migration in service value incurred in connection with the exhaustion of the natural gas reserves in the course of service.

The migration in service value not restored by current maintenance, incurred in connection with the consumption of respective retirement of a gas plant in the course of service from causes that are known to be in current operation and against which the utility is not protected by insurance; for example, wear and tear, and decay, obsolescence, changes in demand and requirements of public authorities, and the exhaustion of natural resources.

Natural gas used as fuel in the respondent's operations.

a pipe of the best quality, cleanliness, all new, best- of rating in selecting in drilling

a test to determine the size of the flow of a well by attaching a drill stem tester to the drill stem so that the medium from the producing sand can flow into the pipe

a detailed drilling record which gives color, utility, thickness and content of the formations encountered

an operation whereby a vertical hole is made from the surface down to a specific horizon level. Two systems generally used are percussion 
Dry natural gas production:

Electric utilities:

Electric utility consumption:

Exchange agreement:

Exports:

Extraction migration:

Fee ownership-

Flared:

Flow potential, well -

Future undeveloped or unused capacity

Gas condensate well:

Gas well:

Gas, entrained-

Gas, storage -

Gas, sweet-

Gas, toxic -

Geological sections-

Geophysical

programs-

Gross withdrawals:

Heating value: and rotary

Marketed production less extraction migration.

Establishments primarily engaged in the generation, transmission, and/or distribution of electricity for sale or resale.

Natural gas used as fuel for gross generation, providing standby service, start-up and/or flame stabilization in electric utility plants.

A contractual agreement whereby one company agrees to deliver gas either directly or through intermediates to another company at one location, or in one time period, in exchange for the delivery by the second company to the first company of an equivalent volume or heat content at a different location or time period.

Natural gas deliveries out of the continental United States and Alaska to foreign countries.

The reduction in volume of natural gas due to the removal of natural gas liquid constituents such as ethane, propane, and butane at natural gas processing plants.

land operated for oil or gas under a right of ownership as contrasted with land operated under a lease

The volume of natural gas burned in flares on the base site or at gas processing plants.

the estimated yield or flow capacity of a well for a specific time under specific pressure conditions

The difference between the volume of gas stored on $12 / 31 / 87$ and the ultimate storage capacity. This value is also the sum of the unused capacity on 12/31/87 and the present undeveloped capacity.

A gas well that produces from a gas reservoir containing quantities of liquid hydrocarbons in the pentane and heavier range generally described as "condensate."

A well completed for the production of natural gas from one or more gas zones or reservoirs.

a substance carrying gas along with it gas, sour-a gas having excessive sulfur content

the placing of gas in a geological formation by mechanical means for future use

a gas which is comparatively free of sulfur

a gas which is determined to behave a detrimental effect on living organisms

those layers of rocks which make up the earth's subsurface and are classified by time

programs designed to use devices based on principles of abysses for the purpose of determining subsurface structures

Full well stream volume, including all natural gas plant liquid and nonhydrocarbon gases, but excluding lease condensate. Also includes amount delivered as royalty payments or consumed in field operations.

The average number of British thermal units per cubic foot or natural gas as determined from tests of fuel samples. 
Hinshaw pipeline:

Hole displacement-

Hole, dry-

Hydrocarbons -

Hydrogen sulfide-

Hydrostatic pressure -

IN-

Imports:

Independent

producers:

Industrial consumers:

Industrial

consumption:

Inhibitor -

Injected gas

Injection-

Interstate companies:

Intransit deliveries:

Intransit receipts:

Intrastate companies:

Lease and plant fuel:

Lease-

Lines, treating-

Liquefied natural gas (Ing):

Logging-

Logs, caliper-
A pipeline or local distribution company that has received exemption, (by Section 1 (c) of the Natural Gas Act), from regulations pursuant to the Natural Gas Act. These companies transport interstate natural gas not subject to regulations under NGA.

the volumetric content of the hole

usually referred to as a hole which is void of oil and/or gas

that series of alkaline hydrocarbons generally found in petroleum, including methane, propane, butane, pentane, etc.

a toxic compound found in sour gas hydrostatic head - the weight of a liquid column computed by density and height in pounds per square inch

the pressure caused by the weight of fluid which fills the pore space of the host rock

injection/withdrawal

Gas receipts into the United States from a foreign country.

Any person who is engaged in the production or gathering of natural gas and who sells natural gas in interstate commerce for resale but who is not engaged in the transportation of natural gas (other than gathering) by pipeline in interstate commerce.

Establishments engaged in a process which creates or changes raw or unfinished materials into another form or product. Generation of electricity, other than by electric utilities, is also included.

Natural gas used by manufacturing and mining establishments for heat, power, and chemical feedstock.

a substance which slows or interferes with a. chemical reaction (such as corrosion)

All gas injected from extraneous sources into the storage reservoir to bring the reservoir pressure and volume up to the desired level.

the placing of a fluid into storage

Natural gas pipeline companies subject to FERC jurisdiction.

Redeliveries to a foreign country of foreign gas received for transport across U.S. territory and deliveries of U.S. gas to a foreign country for transportation across its territory and redelivery to the United States.

Receipts of foreign gas for transportation across U.S. territory and redelivery to a foreign country and redeliveries to the United States of U.S. gas transported across foreign territory.

Companies not subject to FERC jurisdiction.

Natural gas used in well, field, and lease operations (such as gas used in drilling operations, heaters, dehydrators, and field compressors), and as fuel in natural gas processing plants.

a contract for the possession or use of lands for full determined period or consideration of payment or rent

lengths of connected pipe through which fluids are pumped for treating purposes

Natural gas (primarily methane) that has been liquefied by reducing its temperature to minus 260 Degrees Fahrenheit at atmospheric pressure.

a method of determining subsurface information by mechanical, electrical or sonic means

a log used to determine the diameter of a hole logs, correlation-logs 
Logs, downhole casing inspection -

Major interstate pipeline company:

Manufactured gas:

Map, gathering system -

Marketed production:

Mining operations, subsurface -

Native gas:

Natural gas policy act of 1978 (ngpa):

Natural gas, wet after lease separation: which may be related one, to another

logs used to determine the integrity of the casing logs, neutron-logs used to determine hydrogen content of the strata which is obtained by running a device in the hole

A company whose combined sales for resale, and gas transported interstate or stored for a fee, exceeded 50 million thousand cubic feet in the previous year.

A gas obtained by destructive distillation of coal, or by the thermal decomposition of oil, or by the reaction of steam passing through a bed of heated coal or coke. Examples are coal gases, coke oven gases, producer gas, blast furnace, blue (water) gas, carbureted water gas. Btu content varies widely.

a sketch of the pipelines and associated equipment connecting the wells to the compressor station or market lines

Gross withdrawals less gas used for repressuring, quantities vented and flared, and nonhydrocarbon gases removed in treating or processing operations. Includes all quantities of gas used in field and processing operations.

physical mining of material through tunnels or shafts under the surface by men and machinery

Gas in place at the time that a reservoir was converted to use as an underground storage reservoir, i.e. gas that is indigenous in the storage reservoir, as in contrast to injected gas volumes.

Signed into law on November 9, 1978, the NGPA is a framework for the regulation of most facets of the natural gas industry.

The volume of natural gas remaining after removal of lease condensate in lease and/or field separation facilities, if any, after exclusion of nonhydrocarbon gases where they occur in sufficient quantity to render the gas unmarketable. Natural gas liquids may be recovered from volumes of natural gas, wet after lease separation, at natural gas processing plants.

Natural gas:

Non-hydrocarbon gases:

Offshore reserves and production:

Oil well (casinghead)

gas:

Onsystem sales:

Onsystem:

Original reserves

Original reservoir pressure
A mixture of hydrocarbon compounds and small quantities of various non-hydrocarbons existing in the gaseous phase or in solution with crude oil in natural underground reservoirs at reservoir conditions.

Typical nonhydrocarbon gases that may be present in reservoir natural gas are carbon dioxide, helium, hydrogen sulfide, and nitrogen.

Unless otherwise indicated, reserves and production that are in either State or Federal domains, located seaward of the coastline.

Associated and dissolved gas produced along with crude oil from oil completions.

Sales to customers where the delivery points on, or directly interconnected with, a transportation, storage, and/or distribution system operated by the reporting company.

Any point on or directly interconnected with, a transportation, storage, or distribution system operated by a natural gas company.

Those storage reservoirs which were originally gas reservoirs. This figure represents the original gas reserve.

The pressure (psig) of the formation at the time of discovery. 
Outer continental

shelf:

Perforating tool-

Perimeter of field -

Permeability-

Pipeline fuel:

Pipeline:

Plugs, cement-

Pore space -

Pressure, abnormal -

Pressure, fracturing -

Pressure, low vapor-

Pressure, maximum reservoir -

Pressure, threshold -

Production, wet after lease separation:

Propane-air:

Proved reserves:

Receipts:

Reciprocating-

Recondition -

Repressuring:

Reservoir, a real extent-
Offshore Federal domain.

a device, a mechanical instrument normally containing an explosive which is lowered into a well and discharged at a desired depth to open the casing so that the gas may be injected and withdrawn from the formation.

a line that establishes the estimated outside boundaries of a field including both the reservoir and buffer zone

a measure of conductivity of a rock to the movement of fluids through it, expressed in darcies or millidarcies

Gas consumed in the operation of pipelines, primarily in compressors.

A continuous pipe conduit, complete with such equipment as valves, compressor stations, communications systems, and meters, for transporting natural and/or supplemental gas from one point to another, usually from a point in or beyond the producing field or processing plant to another pipeline to points of use. Also refers to a company operating such facilities.

a device made of various materials which is pumped down the casing behind the cement and seated against a holder which will effectively shut off flow back of cement

the space between the grains of sediment in a elastic rock or the space caused by chemical reaction in a nonclastic rock

that unit of force exerted which is either substantially higher or lower than the normal hydrostatic gradient at relative depth

the unit of force required to physically part the rock

a minimal force caused by the constant motion of the molecules in a fluid and their impact on each other which tends to make the molecules fly apart

that unit of force which is established as the biggest possible pressure

that pressure which initiates first movement of the connate water contained in the caprock.

Gross withdrawals less gas used for repressuring and nonhydrocarbon gases removed in treating or processing operations.

A mixture of propane and air resulting in a gaseous field suitable for pipeline distribution.

The estimated quantities that analysis of geological and engineering data demonstrate with reasonable certainty to be recoverable in future years from known oil and gas reservoirs under existing economic and operating conditions.

Gas physically transferred into the responding company's transportation, storage, and/or distribution facilities.

to move forward and backward atternately

to re-enter a completed bore hole for the purpose of additional work, to remove impurities and/or add new substances to mud

The injection of gas into oil or gas formations to effect greater ultimate recovery.

the geographical extent and configuration of the porous rock which serves as a gas depository 


Reservoir, analysis-
Reservoir, geometry-
Reservoir, storage
migration-
Reservoir,
stratigraphy-
Residential
consumption:
Rig site -
Rig-

Sloughing-

Storage additions:

Storage facilities -

Storage reservoir, interval -

Storage withdrawals:

Storage, area-

Storage, protective

area -

Storage, reservoir

integrity-

Storage, reservoir-

Supplemental gaseous

fuel supplies:

\section{Supplemental natural gas (SNG):}

Swabbing -

Therm:

Tight hole-

Tubing rams-

\section{Tubing string- \\ Ultimate storage capacity \\ Unaccounted for:}

the study or determination of the nature of the reservoir

the physical shape of the porous rock which serves as a gas depository

any gas which escapes from the porous rock depository by an avenue that is not controlled

a geological interpretation which treats the formation composition, sequence, and correlation

Gas used in private dwellings, including apartments for heating, cooking, water heating, and other household uses.

a prepared location upon which the rig and associated equipment are assembled

all the drilling and pumping equipment, including the derrick, used in drilling a well

the act of the side wall of the bore hole moving into or failing into the well bore from the existing wall

The volume of gas injected or otherwise added to underground natural gas or liquefied natural gas storage during the applicable reporting period.

the physical entities involved in the storage of gas such as lines, compressors, wells, and the gas storage formation

the thickness in feet of the gas storage rock

Total volume of gas withdrawn from underground storage during the applicable reporting period.

that area within the perimeter of the field which contains the gas

that area surrounding the outer limits of the reservoir which is deemed necessary to protect the reservoir from encroachment and from other operations that may affect the integrity of the reservoir

the ability of the storage formation to contain the gas in place

the porous formation in which the gas is stored

Synthetic natural gas, propane-air, coke oven gas, refinery gas, biomass gas, air injected for Btu stabilization, and manufactured gas commingled and distributed with natural gas.

A manufactured product chemically similar in most respects to natural gas, that results from the conversion or reforming of petroleum hydrocarbons and may easily be substituted for or interchanged with pipeline quality natural gas.

the act of lifting fluids in the casing of a well to the surface by means of a steel and rubber device which operates on a cable

One-hundred thousand British thermal units.

a well for which no information is released

devices of a configuration which will allow them to close around the outside of the tubing in such a manner as to prevent any flow of gas or oil on the outside to pass between the tubing and casing

a string of small diameter pipe, usually the last string run in a well

The maximum designed reservoir capacity, or if aquifer, the total developed capacity.

Represents differences between the sum of components of natural 


\section{Underground gas storage reservoir capacity: \\ Underground storage injection: \\ Underground storage \\ withdrawals:}

Underground storage:

Unit value, consumption:

Unit value, wellhead:

Valve

Valve, check-

Vented gas:

Well bead-

Well head control equipment-

Wellhead price:

Wells, collection -

Wells, observation-

Work (top storage) gas:

Working gas

Wrap- gas supply and the sum of components of natural gas disposition. These differences may be due to quantities unaccounted for or to the effects of data-reporting problems. Reporting problems include differences due to the net result of conversion of flow data metered at varying temperature and pressure bases and converted to a standard temperature and pressure base; the effect of variations in company accounting and billing practices; differences between billing cycle and calendar period time frames; and imbalances resulting from the merger of data reporting systems that vary in scope, format, definitions, and type of respondents.

Interstate company reservoir capacities are those certified by FERC. Independent producer and intrastate company reservoir capacities are reported as developed capacity.

Gas from extraneous sources put into underground storage reservoirs.

Gas removed from underground storage reservoirs.

The storage of natural gas in underground reservoirs at a difference location from it was produced.

Total price per specified unit, including all taxes, at the point of consumption.

The wellhead sales prices including charges for natural gas plant liquids subsequently removed from the gas, gathering and compression charges, and State production, severance, and/or similar charges.

control valve

a valve which permits flow in one direction but automatically closes when flow is attempted in the opposite direction

Gas released into the air on the base site or at processing plants.

an assemblage, of equipment attached to the casing at ground level that is used to control the flow of the well

that part of the well head assemblage that is used to control the pressure and flow

Wellhead sales price, including charges for natural gas plant liquids subsequently removed from the gas, gathering and compression charges, and State production, severance, and similar charges.

A well completed in an upper zone above the main storage zone to collect any gas that might escape from the storage zone

A well completed in the storage area listed to monitor the integrity of the storage zone or outer zones

The volume of gas in an underground storage reservoir above the designed level of the base. It may or may not be completely withdrawn during any particular withdrawal season. Conditions permitting, the total working capacity could be used more than once during any season.

The volume of gas in the reservoir above the designed level of base gas. It may or may not be completely withdrawn during any particular output season. Conditions permitting, the total working capacity could be used more than once during any season.

a single coil of rope around a cathead 
Zone, buffer-

Zone, collection-

Zone, creep (plastic

flow)-

Zone, unaccounted for circulation -

Zone, unconsolidated

Zone, upper gas -

Zone- an area lying between the outer limit.-, of the effective gas storage zone and the periphery of the protected area

a rock strata located above the storage zone which any escaping gas migrates

a rock strata which moves

a rock strata which, due to crevices or extremely vulgar porosity, will absorb the drilling fluid rapidly

a rock strata which is made tip of a physically loose, caving material a rock strata above the main storage zone that contains gas

a term used to distinguish sections of interlayered sand, shale, chert, and other rocks 


\section{APPENDIX}

Table 16-14: Additions to and Withdrawals from Gas Storage by State, 1992 (MCF)

\begin{tabular}{|c|c|c|c|c|c|c|c|}
\hline \multirow[b]{2}{*}{ State } & \multicolumn{3}{|c|}{ Underground Storage } & \multicolumn{3}{|c|}{ LNG Storage } & \multirow{2}{*}{$\begin{array}{l}\text { Net Change } \\
\text { in Storage }\end{array}$} \\
\hline & Injections & Withdrawals & Net & Additions & Withdrawals & Net & \\
\hline Alabama. & & 0 & 0 & 501 & 262 & 239 & 239 \\
\hline Arkansas. & 2,461 & 2,975 & -514 & 50 & 51 & -1 & -615 \\
\hline California & 148,039 & 176,158 & $-28,120$ & 13 & 51 & -38 & $-28,158$ \\
\hline Colorado & 23,061 & 27,921 & $-4,860$ & 0 & 0 & 0 & $-4,860$ \\
\hline Connecticut & 0 & 0 & 0 & 359 & 714 & -355 & 356 \\
\hline Delaware & 0 & 0 & 0 & 61 & 66 & -5 & -5 \\
\hline Georgia & 0 & 0 & 0 & 1,573 & 1,557 & 16 & 16 \\
\hline Idaho & 0 & 0 & 0 & 1,338 & 1,385 & -47 & -47 \\
\hline Illinois & 214,404 & 223,012 & $-8,608$ & 570 & 348 & 222 & $\mathbf{8 , 3 8 7}$ \\
\hline Indiana & 25,770 & 26,611 & -840 & 849 & 1,188 & -339 & $-1,179$ \\
\hline lowa & 65,818 & 70,077 & $-4,259$ & 4,659 & 4,247 & 412 & $-3,846$ \\
\hline Kansas & 84,249 & 102,735 & $-18,486$ & 0 & 0 & 0 & $-18,486$ \\
\hline Kentucky & 49,367 & 42,795 & 6,573 & 0 & 0 & 0 & 6,573 \\
\hline Louisiana & 193,051 & 207,010 & $-13,958$ & 12,545 & 12,097 & 448 & $-13,511$ \\
\hline Maine & 0 & 0 & 0 & 26 & 22 & 4 & 4 \\
\hline Maryland & 19,502 & 19,169 & 333 & 804 & 715 & 89 & 422 \\
\hline Massachusetts & 0 & 0 & 0 & 5,147 & 6,990 & $-1,844$ & $-1,844$ \\
\hline Michigan & 390,466 & 392,716 & $-2,251$ & 0 & o & o & $-2,251$ \\
\hline Minnesota & 1,372 & 1,329 & 43 & 3.594 & 3,380 & 213 & 256 \\
\hline Mississippi. & 55,105 & 53,373 & 1,732 & 0 & 0 & 0 & 1,732 \\
\hline Missouri & 3,080 & 3,094 & -15 & 0 & 0 & 0 & -15 \\
\hline Montana & 11,708 & 24,310 & $-12,602$ & 0 & 0 & 0 & $-12,602$ \\
\hline Nebraska & 10,254 & 9,848 & 407 & 283 & 173 & 111 & 517 \\
\hline Nevada & 0 & 0 & 0 & 83 & 155 & -71 & -71 \\
\hline New Jersey & 0 & 0 & 0 & 2,422 & 2,471 & -49 & -49 \\
\hline New Mexico & 18.963 & 21,421 & $-2,458$ & 0 & 2,599 & $-2,599$ & $-5,057$ \\
\hline New York & 62,265 & 60,693 & 1,572 & 732 & 363 & 370 & 1,942 \\
\hline North Carolina & 0 & 0 & 0 & 1,030 & 1,122 & -92 & -92 \\
\hline Ohio & 160,009 & 175,682 & $-15,672$ & 0 & $\mathbf{0}$ & 0 & $-15,672$ \\
\hline Oklahoma & 97,468 & 107,526 & $-10,058$ & 0 & 0 & 0 & $-10,058$ \\
\hline Oregon & 6,114 & 6,985 & -872 & 376 & 409 & -33 & -904 \\
\hline Pennsylvania & 383,762 & $\mathbf{3 7 7 , 8 8 9}$ & 5,873 & 2,869 & 2,797 & 72 & 5,945 \\
\hline Rhode island & 0 & 0 & 0 & 796 & 1,216 & -420 & -420 \\
\hline South Carolina & 0 & 0 & 0 & 339 & 323 & 16 & 16 \\
\hline South Dakota & 0 & 0 & 0 & 24 & 13 & 11 & 11 \\
\hline Tennessee & 0 & 0 & 0 & 2,759 & 3,065 & -306 & -306 \\
\hline Texas & 340,602 & 384,042 & $-43,441$ & o & 0 & 0 & $-43,441$ \\
\hline Utah & 31,222 & 26,740 & 4,482 & 0 & 0 & 0 & 4,482 \\
\hline Virginia & 0 & 0 & 0 & 173 & 168 & 6 & 6 \\
\hline Washington & 13,294 & 18,960 & $-5,667$ & 0 & 471 & -471 & $-6,137$ \\
\hline West Virginia & 138,647 & 146,827 & $-8,180$ & 0 & o & 0 & $-8,180$ \\
\hline Wisconsin & & 0 & 0 & 57 & 117 & -59 & -59 \\
\hline Wyoming & 6,340 & 13,876 & $-8,536$ & 0 & 0 & 0 & $-8,536$ \\
\hline Total & $2,555,393$ & $2,723,774$ & $-168,381$ & $\mathbf{4 4 , 0 3 3}$ & 48,534 & $-4,501$ & $-172,882$ \\
\hline
\end{tabular}

Note: Totals may not equal sum of $d$ components use to independent rounding

Source: Energy Information Administration Form ElA-176, "Annual Report of Natural and Supplemental Gas Supply and Disposition:' 
Table 16-15: Underground Natural Gas Storage Capacity by State, December 31, 1992 (Capacity in BCF)

\begin{tabular}{|c|c|c|c|c|c|c|c|c|c|}
\hline \multirow[b]{2}{*}{ State } & \multicolumn{2}{|c|}{ Interstate Companies } & \multicolumn{2}{|c|}{ Intrastate Companies } & \multirow{2}{*}{$\begin{array}{l}\text { Independent } \\
\text { Companies } \\
\text { Number of } \\
\text { Active } \\
\text { Fields }\end{array}$} & \multirow[b]{2}{*}{$\begin{array}{l}\text { Capacit } \\
\text { y (BCF) }\end{array}$} & \multirow{2}{*}{\multicolumn{2}{|c|}{$\begin{array}{l}\text { Total } \\
\text { Capacit } \\
\text { y (BCF) }\end{array}$}} & \multirow[b]{2}{*}{$\begin{array}{c}\text { Percent } \\
\text { of U:S. } \\
\text { Capacit } \\
y\end{array}$} \\
\hline & $\begin{array}{l}\text { Number } \\
\text { of Active } \\
\text { Fields }\end{array}$ & $\begin{array}{l}\text { Capacit } \\
\text { y }(B C F)\end{array}$ & $\begin{array}{c}\text { Number } \\
\text { of Active } \\
\text { Fields }\end{array}$ & $\begin{array}{c}\text { Capacity } \\
\text { (BCF) }\end{array}$ & & & & & \\
\hline Arkansas & $\overline{0}$ & 0 & 4 & 31 & 0 & 0 & $\overline{4}$ & 31 & 0.39 \\
\hline Califomia & 0 & 0 & 10 & 472 & 0 & 0 & 10 & 472 & 5.95 \\
\hline Colorado & 4 & 62 & 5 & 44 & 0 & 0 & 9 & 106 & 1.33 \\
\hline Illinois & 7 & 286 & 22 & 663 & 0 & 0 & 29 & 950 & 11.97 \\
\hline Indiana & 5 & 11 & 20 & 95 & 0 & 0 & 25 & 106 & 1.34 \\
\hline lowa & 9 & 280 & 0 & 0 & 0 & 0 & 9 & 280 & 3.53 \\
\hline Kansas & 19 & 286 & 1 & 4 & 0 & 0 & 20 & 291 & 3.66 \\
\hline Kentucky & 6 & 167 & 17 & 43 & 0 & 0 & 23 & 210 & 2.65 \\
\hline Louisiana & 8 & 530 & 1 & 9 & 0 & 0 & 9 & 539 & 6.80 \\
\hline Maryland & 1 & 62 & 0 & 0 & 0 & 0 & 1 & 62 & .79 \\
\hline Michigan & 29 & 728 & 17 & 266 & 0 & 0 & 46 & 994 & 12.54 \\
\hline Minnesota & 0 & 0 & 1 & 7 & 0 & 0 & 1 & 7 & .09 \\
\hline Mississippi & 3 & 107 & 2 & 8 & 0 & 0 & 5 & 115 & 1.45 \\
\hline Missouri & 0 & 0 & 1 & 31 & 0 & 0 & 1 & 31 & .39 \\
\hline Montana & 1 & 287 & 4 & 88 & 0 & 0 & 5 & 375 & 4.73 \\
\hline Nebraska & 2 & 93 & 0 & 0 & 0 & 0 & 2 & 93 & 1.18 \\
\hline New Mexico & 1 & 69 & 2 & 26 & 0 & 0 & 3 & 95 & 1.19 \\
\hline New York & 22 & 160 & 1 & a & 0 & 0 & 23 & 168 & 2.12 \\
\hline Ohio & 15 & 437 & 7 & 155 & 0 & 0 & 22 & 591 & 7.46 \\
\hline Oklahoma & 5 & 207 & 2 & 27 & 5 & 127 & 12 & 360 & 4.53 \\
\hline Oregon & 0 & 0 & 2 & 11 & 0 & 0 & 2 & 11 & .14 \\
\hline Pennsylvania & 35 & 609 & $\overline{8}$ & 37 & 7 & 23 & 50 & 669 & 8.44 \\
\hline Texas & 13 & 365 & 12 & 229 & 1 & 2 & 26 & 595 & 7.50 \\
\hline Utah & 3 & 112 & 0 & 0 & 1 & 3 & 4 & 115 & 1.45 \\
\hline Washington & 1 & 34 & 0 & 0 & 0 & 0 & 1 & 34 & .43 \\
\hline West Virginia & 27 & 476 & 0 & 0 & 12 & 49 & 39 & 525 & 6.62 \\
\hline Wyoming & 3 & 76 & 4 & 30 & 0 & 0 & 7 & 106 & 1.33 \\
\hline Total & 219 & 5,445 & 143 & 2,282 & 26 & 204 & 388 & 7,932 & 100.00 \\
\hline
\end{tabular}

Source: Energy information Administration (EIA), Form EIA-191, "Underground Gas Storage Report." 
Table 16-16: Status of underground gas storage at the end of the 1991-92 withdrawal season

Jurisdictional Gas In Place

5,285

Total Gas in Place

Base Gas

Working Gas

( data from FERC's Semi-Annual Report on Jurisdictional Underground Natural Gas Storage Fields in the United States end of 1991-92 withdrawal season)

Table 16-17: Status of underground gas storage at the end of the 1991-92 withdrawal season by Geographical Area.

\begin{tabular}{|c|c|c|c|c|c|}
\hline $\begin{array}{c}\text { Geographical } \\
\text { Area }\end{array}$ & $\begin{array}{l}\text { Number of } \\
\text { Storage } \\
\text { Companies }\end{array}$ & $\begin{array}{c}\text { Operating } \\
\text { Capacity(Mmef) }\end{array}$ & $\begin{array}{l}\text { G. I. P. } 11 / 1 / 91 \\
\text { (Mmcf) }\end{array}$ & $\begin{array}{l}\text { G. 1. P. } 4 / 30 / 92 \\
\text { (Mmcf) }\end{array}$ & $\begin{array}{l}\text { Net Gas Withdrawn } \\
\text { 91/92 Season (Mncf) }\end{array}$ \\
\hline Eastern & 11 & $1,959,695$ & $1,880,611$ & $1,346,599$ & 571,487 \\
\hline Midwestern & 14 & $2,178,967$ & $1,927,450$ & $1,521,954$ & 416,565 \\
\hline Southern & 4 & 412,515 & 358,290 & 271,325 & 91,774 \\
\hline $\begin{array}{l}\text { Western } \\
\text { Independent }\end{array}$ & 5 & 594,218 & 504,013 & 446,406 & 63,269 \\
\hline $\begin{array}{l}\text { Producers } \\
\text { TOTAL }\end{array}$ & $\begin{array}{l}3 \\
37\end{array}$ & $\begin{array}{r}139,870 \\
5,285,265\end{array}$ & $\begin{array}{r}134,547 \\
4,804,911\end{array}$ & $\begin{array}{r}126,856 \\
3,713,140\end{array}$ & $\begin{array}{r}9,689 \\
1,152,784\end{array}$ \\
\hline
\end{tabular}

(data from FERC's Semi-Annual Report on Jurisdictional Underground Natural Gas Storage Fields in the United States, end of 1991-92 withdrawal season)

Table 16-18: Types of storage fields in the geographical regions of the US

\begin{tabular}{ccccc} 
AREA & $\begin{array}{c}\text { DEPLETED } \\
\text { RESERVOIR }\end{array}$ & AQUIFER & CAVERN & TOTAL \\
\hline N.Eastern & 117 & 0 & 0 & 117 \\
Midwestern & 55 & 16 & 0 & 71 \\
Southern & 8 & 0 & 2 & 10 \\
Western & 12 & 4 & 0 & 16 \\
\hline Total & 192 & 20 & 2 & $\mathbf{2 1 4}$
\end{tabular}

(after FERC's Semi-Annual Report on Jurisdictional Underground Natural Gas Storage Fields in the United States, end of 1991-92 withdrawal season)

Table 16-19: Total US Storage Field Reservoirs by Type and Drive

\begin{tabular}{|c|c|c|c|c|c|c|}
\hline \multicolumn{3}{|c|}{ DEPLETED RESERVOIR } & \multirow[t]{2}{*}{ AQUIFER } & \multirow[t]{2}{*}{ CAVERN } & \multirow{2}{*}{$\begin{array}{c}\text { TOTAL } \\
\text { RESERVOIRS }\end{array}$} & \multirow{2}{*}{$\begin{array}{l}\text { NUMBER OF } \\
\text { OPERATORS }\end{array}$} \\
\hline$A L L$ & VOL & WD & & & & \\
\hline 337 & 282 & 55 & 42 & 11 & 390 & 101 \\
\hline
\end{tabular}


Table 16-20: Average Properties for Various Storage Reservoir Types

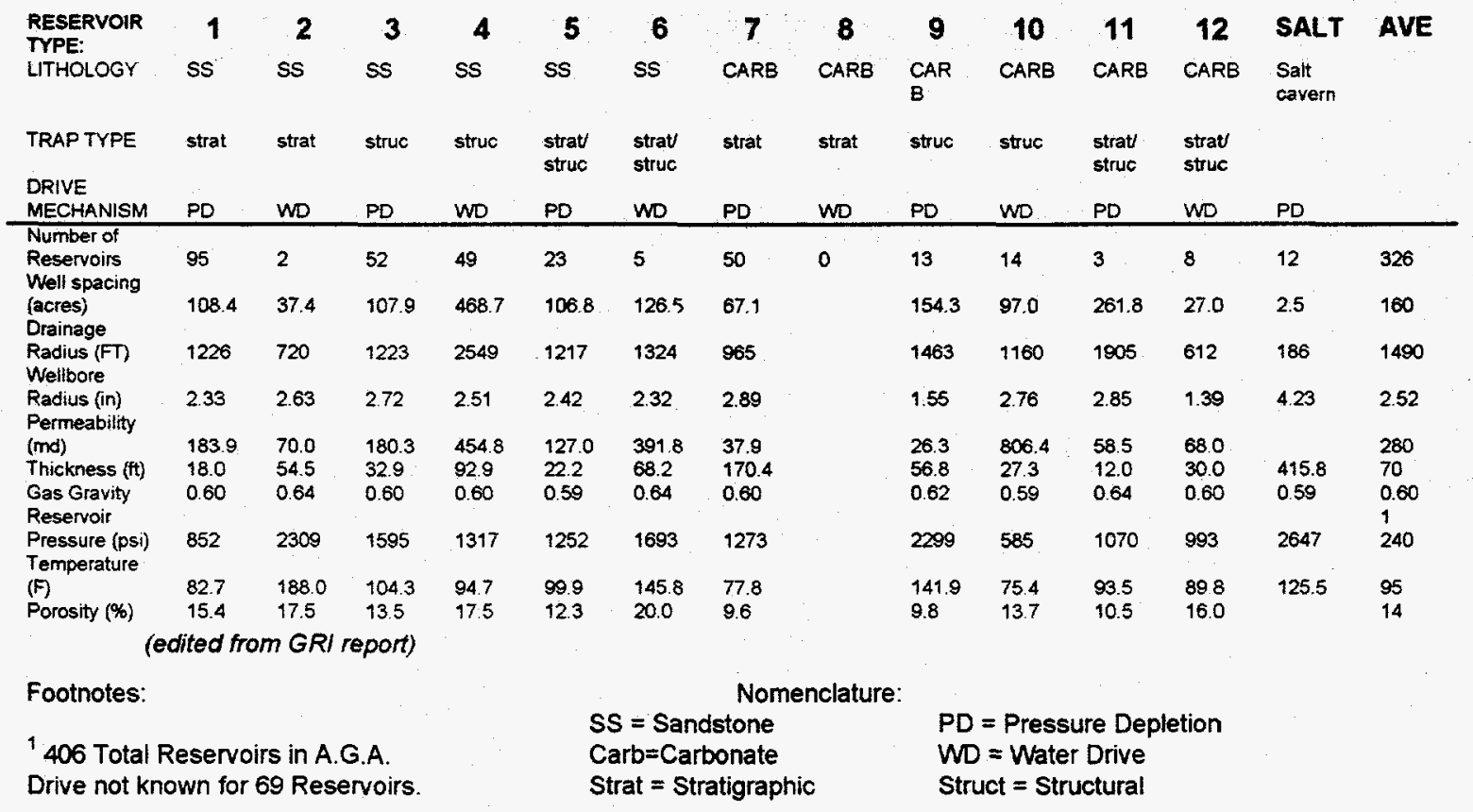

\section{2.) FERC Form-2}

\section{Unaccounted for Gas Reporting}

Gas losses from storage reservoirs can be reported in several ways by virtue of the reporting method. FERC Form 2 gas losses are reported as transportation losses' $98 \%$ of the time, vs. other forms of gas loss, such as reservoir. These volumes are shown on Table No. 16-21: . Table No. 16-22: shows the current and noncurrent average gas prices for the years indicated. Current refers to the average cost of gas injected into storage and noncurrent refers to the average price of base gas. Table No. 16-23: shows the relative percentages of reported losses. Storage losses are shown as a percentage of gas withdrawn from storage. The other percentages are as a percent of total sales and other deliveries (line 55). While these losses are small, the dollar losses are very large. 
Table 16-21: Unaccounted for Gas Form 2 1990-1993

\begin{tabular}{|c|c|c|c|c|c|c|c|c|c|}
\hline $\begin{array}{l}\text { FERC Form } 2 \text { - Gas } \\
\text { Account - Natural } \\
\text { Gas } \\
\text { pages } 520-521\end{array}$ & line no. 18 & 55 & 57 & 58 & 59 & SCF & 61 & SCF & 63 \\
\hline \multirow{3}{*}{ pages $520-521$} & GAS WITHDRAWN & & SCF & & & DISTRI- & & TOTAL & SCF \\
\hline & FROM & SCF & PROD & SCF & SCF & BUTION & MCF & UNACCOUNTED & TOT SALES, \\
\hline & UNDERGROUND & TOTAL SALES \& & SYSTEM & STORAGE & TRANSMISSION & SYSTEM & OTHER & FOR & OTHER DEL \& \\
\hline $\begin{array}{l}\text { YR. } \begin{array}{c}\text { EXACT } \\
\text { LEGAL NAME }\end{array}\end{array}$ & STORAGE & OTHER DELIVERIES & LOSSES & LOSSES & SYSTEM LOSSES & LOSSES & LOSSES & NATURAL GAS & UNACC FOR \\
\hline 1990 & $639,047,065$ & $40,958,565,361$ & 0 & $2,643,043$ & $51,261,481$ & $5,358,600$ & $20,099,519$ & $79,362,643$ & $40,997,189,070$ \\
\hline 1991 & $923,023,648$ & $39,090,669,487$ & 0 & $(5,394,904)$ & $125,327,191$ & $5,774,167$ & $23,619,529$ & $149,325,983$ & $39,239,995,470$ \\
\hline 1992 & $1,029,439,323$ & $36,621,157,970$ & 0 & 995,525 & $108,856,539$ & $2,403,167$ & $16,025,252$ & $128,669,886$ & $36,749,827,856$ \\
\hline 1993 & $1,032,115,337$ & $36,995,516,396$ & 0 & 125,298 & $120,317,124$ & $(2,111)$ & $31,730,977$ & $152,171,288$ & $37,147,687,684$ \\
\hline
\end{tabular}

Table 16-22: FERC Form 2 Unaccounted for Gas

FERC Form 2 - Gas Stored (page 220, column a-f, lines 1-7)

GAS BALANCEAT

\begin{tabular}{|c|c|c|c|c|c|c|c|c|c|}
\hline \multirow[b]{2}{*}{ YR } & \multicolumn{2}{|r|}{ GAS } & \multicolumn{2}{|l|}{ BALANCE AT } & \multicolumn{5}{|c|}{ BALANCE } \\
\hline & $\begin{array}{c}\text { EXACT LEGAL } \\
\text { NAME }\end{array}$ & $\begin{array}{l}\text { STORED } \\
\text { CODE }\end{array}$ & $\begin{array}{c}\text { BEGINNING OF } \\
\text { YEAR }\end{array}$ & $\begin{array}{l}\text { GAS DELIVERED } \\
\text { TO STORAGE }\end{array}$ & $\begin{array}{l}\text { GAS WTHDRAWN } \\
\text { FROM STORAGE }\end{array}$ & $\begin{array}{l}\text { OTHER DEBITS } \\
\text { OR CREDITS (NET) }\end{array}$ & $\begin{array}{l}\text { AT END OF } \\
\text { YEAR }\end{array}$ & $\begin{array}{l}\text { GAS VOLUME } \\
\text { MCF }\end{array}$ & $\begin{array}{c}\text { AMOUNT PER } \\
\text { MCF }\end{array}$ \\
\hline \multirow[t]{3}{*}{1990} & & Curr16401 & $\$ 871,049,644$ & $\$ 1,671,414,923$ & $\$ 1,155,222,735$ & $\$ 216,481,289$ & $\$ 1,603,723,121$ & $861,868,236$ & $\$ 1.86$ \\
\hline & & Noncurr & $\$ 730,877,284$ & $\$ 651,735,673$ & $(\$ 16,597,001)$ & $(\$ 203,934,749)$ & $\$ 1,195,275,209$ & $1,553,681,461$ & $\$ 0.77$ \\
\hline & & Total & $\$ 1,564,150,391$ & $\$ 2,347,842,430$ & $\$ 1,067,725,409$ & $(\$ 4,743,874)$ & $\$ 2,839,523,538$ & $2,408,686,839$ & $\$ 1.18$ \\
\hline \multirow[t]{3}{*}{1991} & & Curr16401 & $\$ 1,674,842,861$ & $\$ 1,282,191,676$ & $\$ 1,455,660,200$ & $(\$ 97,436,603)$ & $\$ 1,403,937,734$ & $739,449,873$ & $\$ 1.90$ \\
\hline & & Noncurr & $\$ 1,261,693,642$ & $\$ 178,152,452$ & $\$ 219,775,354$ & $\$ 91,318,363$ & $\$ 1,311,389,103$ & $1,607,482,990$ & $\$ 0.82$ \\
\hline & & Total & $\$ 2,947,402,095$ & $\$ 1,383,357,750$ & $\$ 1,596,068,365$ & $(\$ 14,031,807)$ & $\$ 2,720,659,673$ & $2,353,288,428$ & $\$ 1.16$ \\
\hline \multirow[t]{3}{*}{1992} & & Curr16401 & $\$ 1,075,800,447$ & $\$ 1,065,975,303$ & $\$ 1,125,384,782$ & $(\$ 65,839,076)$ & $\$ 950,551,892$ & $587,422,222$ & $\$ 1.62$ \\
\hline & & Noncurr & $\$ 1,282,306,590$ & $\$ 464,346,468$ & $\$ 303,654,173$ & $\$ 111,012,827$ & $\$ 1,250,821,230$ & $1,718,166,474$ & $\$ 0.90$ \\
\hline & & Total & $\$ 2,602,901,604$ & $\$ 1,619,388,984$ & $\$ 1,500,210,746$ & $\$ 861,886$ & $\$ 2,419,751,246$ & $2,390,250,340$ & $\$ 1.14$ \\
\hline \multirow[t]{2}{*}{1993} & & Curr16401 & $\$ 886,407,013$ & $\$ 608,574,624$ & $\$ 819,703,481$ & $(\$ 487,849,467)$ & $\$ 187,428,689$ & $120,981,017$ & $\$ 1.55$ \\
\hline & & Noncurr & $\$ 1,285,210,324$ & $\$ 457,929,885$ & $\$ 644,799,134$ & $\$ 371,581,820$ & $\$ 1,469,922,895$ & $2,033,706,583$ & $\$ 0.72$ \\
\hline
\end{tabular}


Table 16-23: Form-2 Losses \%

\begin{tabular}{cccc}
$\begin{array}{c}\text { STORAGE } \\
\text { LOSSES }\end{array}$ & $\begin{array}{c}\text { TRANSMISSION } \\
\text { SYSTEM LOSSES }\end{array}$ & $\begin{array}{c}\text { TOTAL } \\
\text { UNACCOUNTED }\end{array}$ \\
\hline 1990 & $0.41 \%$ & $0.13 \%$ & $0.19 \%$ \\
1991 & $-0.58 \%$ & $0.32 \%$ & $0.38 \%$ \\
1992 & $0.10 \%$ & $0.30 \%$ & $0.35 \%$ \\
1993 & $\underline{0.01 \%}$ & $\underline{0.33 \%}$ & $\underline{0.41 \%}$ \\
avg & $-0.016 \%$ & $0.27 \%$ & $0.33 \%$ \\
\hline
\end{tabular}

Table 16-24: EIA December Data Example A

\begin{tabular}{|c|c|c|c|c|c|c|c|c|c|c|c|c|c|}
\hline FERC & file & $\begin{array}{l}\text { 3. } 4 . \\
\text { CO\# COMPANY }\end{array}$ & $\begin{array}{l}5 . \\
\text { FIELD } \\
\text { CODE: }\end{array}$ & $\begin{array}{c}6 . \\
\text { FIELD NAME: }\end{array}$ & ST & RESERVOIR & REPORT RT & BASE & WORK & $\begin{array}{c}13 . \\
\text { MSCF } \\
\text { EOY GIP } \\
\text { TOTAL }\end{array}$ & INJ & $\begin{array}{l}16 . \\
\text { WITH }\end{array}$ & $\begin{array}{c}16 . \\
\text { Total } \\
\text { CALCULATED } \\
\text { DIFFERENCE }\end{array}$ \\
\hline & & & & & & & Dec-91 D & $3,262,757$ & $2,757,684$ & $6,020,441$ & $4,271,995$ & $3,939,475$ & \\
\hline & & & & & & & Dec-92. D & $3,262,757$ & $2,267,760$ & $5,530,517$ & $3,716,867$ & $4,220,547$ & $(13,756)$ \\
\hline & & & & & & & Dec-93 D & $3,484,670$ & $2,293,390$ & $5,778,060$ & $5,204,797$ & $5,075,073$ & $(117,819)$ \\
\hline & & & & & & & Dec-94 D & $3,484,670$ & $2,359,441$ & $5,844,111$ & $3,126,100$ & $3,218,310$ & $(158,261)$ \\
\hline
\end{tabular}

